SCAFFOLDING MIDDLE SCHOOL STUDENTS' CONTENT KNOWLEDGE AND ILL-STRUCTURED PROBLEM SOLVING IN A PROBLEM-BASED HYPERMEDIA LEARNING ENVIRONMENT

\author{
A Dissertation \\ by \\ SANIYE TUGBA BULU \\ Submitted to the Office of Graduate Studies of \\ Texas A\&M University \\ in partial fulfillment of the requirements for the degree of \\ DOCTOR OF PHILOSOPHY
}

May 2008

Major Subject: Educational Psychology 


\title{
SCAFFOLDING MIDDLE SCHOOL STUDENTS' CONTENT KNOWLEDGE AND ILL-STRUCTURED PROBLEM SOLVING IN A PROBLEM-BASED HYPERMEDIA LEARNING ENVIRONMENT
}

\author{
A Dissertation \\ by \\ SANIYE TUGBA BULU \\ Submitted to the Office of Graduate Studies of \\ Texas A\&M University \\ in partial fulfillment of the requirements for the degree of \\ DOCTOR OF PHILOSOPHY
}

\begin{abstract}
Approved by:
Chair of Committee, Susan J. Pedersen

Committee Members, Lauren D. Cifuentes

Kim E. Dooley

Stephanie L. Knight

Head of Department, Michael Benz
\end{abstract}

May 2008

Major Subject: Educational Psychology 


\begin{abstract}
Scaffolding Middle School Students' Content Knowledge and Ill-Structured Problem

Solving in a Problem-Based Hypermedia Learning Environment. (May 2008)

Saniye Tugba Bulu, B.A., Middle East Technical University; M.S., Middle East

Technical University

Chair of Advisory Committee: Dr. Susan J. Pedersen
\end{abstract}

This study focused on two areas under the overarching theme of the effects of domain-general and domain-specific scaffolds with different levels of support, continuous or faded. First, the study investigated the effects of scaffolds on learning of scientific content and problem-solving outcomes. Second, the study examined whether students' prior knowledge and metacognitive skills predict their success in problem solving across different scaffolding conditions.

A total of nineteen classes were randomly assigned to one of the four scaffolding conditions: domain-general continuous (DG-C), domain-general faded (DG-F), domainspecific continuous (DS-C), and domain-specific faded (DS-F). Each class had access to different worksheets depending on the scaffolding condition they had been assigned. All students engaged in four problem-solving activities for thirteen class periods. Students' scores on a multiple-choice pretest, posttest, inventory of metacognitive self-regulation, and four recommendation forms were analyzed. 
Results of the study revealed that students' content knowledge in all conditions significantly increased over the thirteen class periods. However, the continuous domainspecific condition outperformed the other conditions on the posttest. Although domaingeneral scaffolds were not as effective as domain-specific scaffolds on learning of scientific content and problem representation, they helped students develop solutions, make strong justifications, and monitor their learning. Unlike domain-specific scaffolds, domain-general scaffolds helped students transfer problem-solving skills even when they were faded. In terms of individual differences, results indicated that while students with lower prior knowledge and lower metacognitive skills benefited from the domaingeneral continuous condition, students with lower regulation of cognition benefited from the domain-general faded condition. Moreover, while students with lower prior knowledge, lower knowledge of cognition, and lower problem representation benefited from the domain-specific continuous condition, students with lower problem representation benefited from the domain-specific faded condition. In contrast, results of the study suggested that scaffolds did not substantially benefit the students with higher prior knowledge and higher metacognitive skills. Several suggestions are discussed for making further improvements in the design of scaffolds in order to facilitate illstructured problem solving in hypermedia learning environments. 


\section{DEDICATION}

This dissertation is dedicated to my parents,

my husband, and

my daughter Almila 


\section{ACKNOWLEDGMENTS}

I would like to express my sincere appreciation to my committee chair, Dr.

Pedersen, for her advice, encouragement, guidance, and support throughout my doctoral studies and this research. I would also like to thank my committee members, Dr.

Cifuentes, Dr. Dooley, and Dr. Knight, for their valuable input throughout the course of this research.

I would like to thank the teachers who agreed to implement Alien Rescue in their classrooms. This study would not have been possible without collaboration provided by teachers and students. I am also grateful to Jay Davis for making this collaboration possible and providing support during this study.

I would also like to thank all of my friends who have been supportive during this journey. I would like to express my deepest gratitude to my parents, Asim and Gunay Tokel, and to my sisters, Esra Mogulkoc and Saniye Tokel, for their encouragement and believing in me. Finally, I would like to express my love and thanks to my husband, Sanser Bulu, for his patience, ongoing support, encouragement, and love. Finally, thanks to my lovely daughter, Almila Bulu, who brings true meaning to my life. 


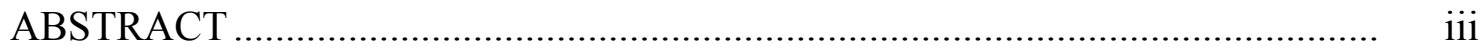

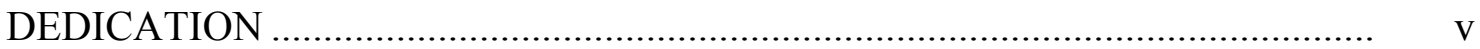

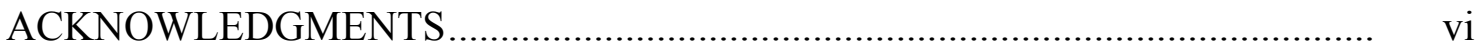

TABLE OF CONTENTS ....................................................................... vii

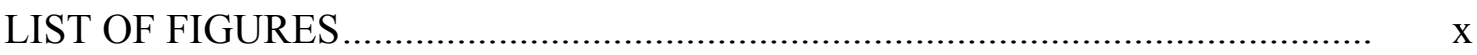

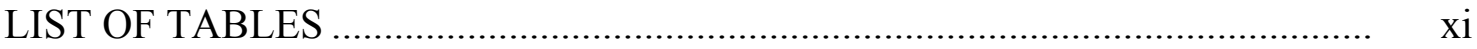

CHAPTER

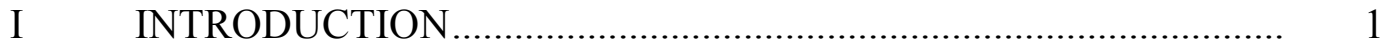

II LITERATURE REVIEW …………………............................ 3

Problem Solving .......................................................................... 3

Ill-Structured vs. Well-Structured Problems ........................... 3

Ill-Structured vs. Well-Structured Problem-Solving

Processes ..................................................................... 5

Requirements of Ill-Structured Problem Solving ................... 11

Challenges during Ill-Structured Problem Solving .............. 16

Scaffolding .......................................................................... 20

Features of Scaffolding .................................................... 22

Types of Scaffolding ..................................................... 23

Scaffolding Strategies to Support Ill-Structured Problem Solving. 25

Technology-Based Scaffolds............................................... 27

Prompt Scaffolds ............................................................ $\quad 30$

Peer Interaction and Teacher Support ................................. $\quad 35$

Effective Use of Scaffolds............................................................ 39

Types of Scaffolds............................................................ 40

Timing of Scaffolds............................................................. 40

Fading of Scaffolds ............................................................ 41

Limited Background Knowledge ......................................... 42

Limited Peer Scaffolding .................................................... 43

Distributed Scaffolding and Synergy .................................... 44 
III SCAFFOLDING MIDDLE SCHOOL STUDENTS' CONTENT KNOWLEDGE AND ILL-STRUCTURED PROBLEM-SOLVING PROCESS

Overview

Introduction

Ill-Structured Problem-Solving Processes

Requirements and Challenges of Solving Ill-Structured

Problems

Scaffolding

Purpose of the Study ................................................................. 61

Method

Participants .............................................................. 62

Materials ...................................................................... 62

Scaffolding Treatment Conditions ................................... 63

Research Design ......................................................... 67

Procedure................................................................... 67

Data Sources and Measurement ....................................... 69

Data Analysis ............................................................ 73

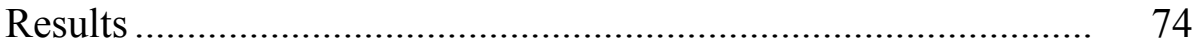

Learning of Scientific Content ........................................ 74

Problem-Solving Outcomes ............................................ 75

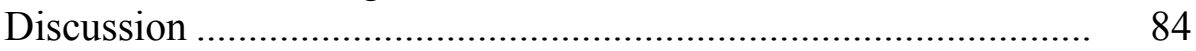

Effects of the Types of Scaffolds ...................................... 84

Effects of the Levels of Support in Scaffolds..................... 86

Conclusion......................................................................... 88

IV SCAFFOLDING ILL-STRUCTURED PROBLEM-SOLVING PERFORMANCE: THE ROLE OF STUDENTS' PRIOR KNOWLEDGE AND METACOGNITIVE SKILLS ....................... 90

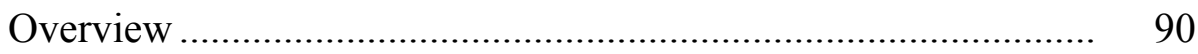

Introduction ...................................................................... 91

Cognitive Abilities to Solve Ill-Structured Problems ........... 91

Metacognitive Skills to Solve Ill-Structured Problems........ 92

Scaffolding in Ill-Structured Problem Solving..................... 95

Purpose of the Study ................................................................. 99

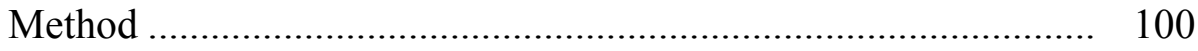

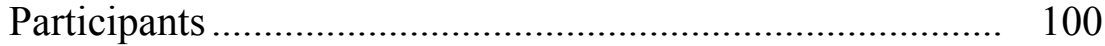

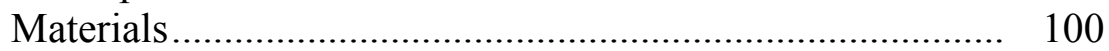

Scaffolding Treatment Conditions .................................... 101

Procedure................................................................... 103 
CHAPTER Page

Data Sources and Measurement ....................................... 105

Data Analysis .......................................................... 108

Results ......................................................................... 109

Comparison of Regression Slopes................................... 113

Discussion ......................................................................... 121

Effects of Prior Knowledge............................................. 121

Effects of Metacognitive Skills ...................................... 122

Conclusion.................................................................... 125

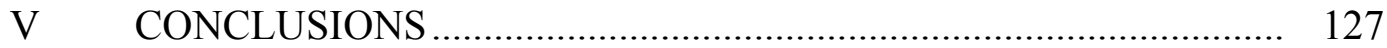

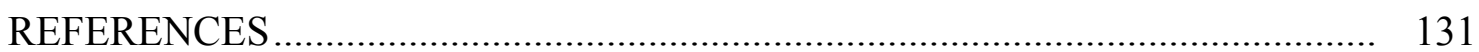

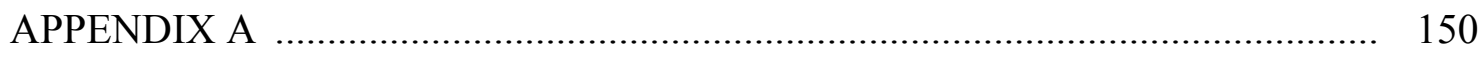

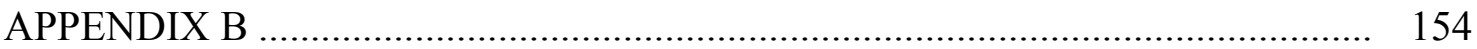

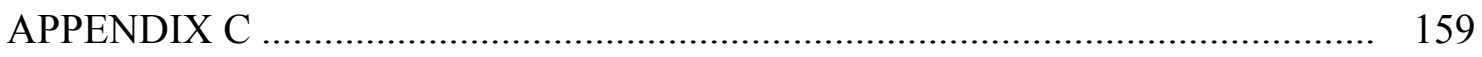

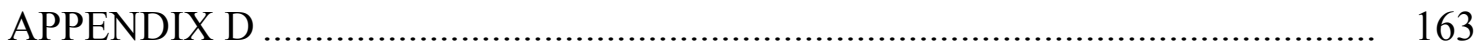

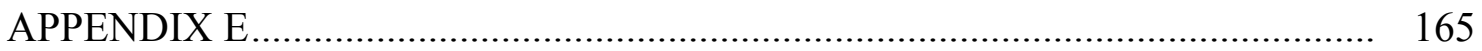

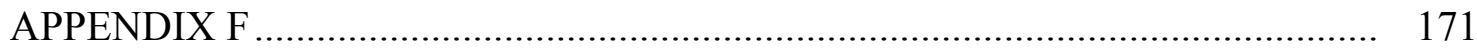

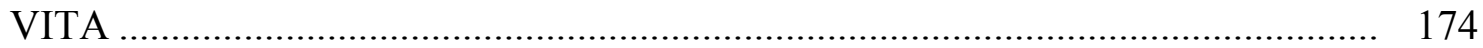




\section{LIST OF FIGURES}

Page

Figure 2.1 Summary of requirements of problem solving, novice characteristics, challenges, and scaffolding strategies ........................................ 26

Figure 3.1 Profile plots of four scaffolding conditions on problem representation.

Figure 3.2 Profile plots of four scaffolding conditions on making justifications

Figure 3.3 Profile plots of four scaffolding conditions on developing solutions

Figure 3.4 Profile plots of four scaffolding conditions on monitoring and evaluation.

Figure 4.1 Regression slopes of problem-solving scores on prior knowledge ... 116

Figure 4.2 Regression slopes of problem-solving scores on knowledge of cognition

Figure 4.3 Regression slopes of problem-solving scores on regulation of cognition

Figure 4.4 Regression slopes of problem-solving scores on problem representation

Figure 4.5 Regression slopes of problem-solving scores on objectivity 


\section{LIST OF TABLES}

Page

Table 3.1 The examples of domain-general and domain-specific prompts.......

Table 3.2 Questions, examples, and sentence starters for the domain-general and the domain-specific conditions

Table 3.3 Levels of support over time........

Table 3.4 Scoring problem-solving outcomes in students' recommendation forms

Table 3.5 Descriptive statistics for the learning of scientific content in four scaffolding conditions

Table 3.6 Descriptive statistics of the average scores for four problem-solving outcomes in four scaffolding conditions

Table 3.7 Descriptive statistics for four problem-solving outcomes over time.

Table 3.8 Analysis of between-subjects effects

79

Table 3.9 Analysis of univariate test results

Table 3.10 Analysis of within-subjects contrast

Table 4.1 Pearson's correlation among independent variables

Table 4.2 Summary of multiple-regression analysis.

Table 4.3 Significant predictors of success of problem solving across four scaffolding conditions

Table 4.4 Regression equations for the four scaffolding conditions 


\section{CHAPTER I}

\section{INTRODUCTION}

Problem solving is an essential cognitive activity and learning outcome in everyday and professional contexts (Jonassen, 1997; 2000). Professional communities demand advanced skills, requiring people to be able to learn, reason, think creatively, make decisions, and solve problems (National Research Council, 1996). Moreover, educational reforms emphasize the importance of higher order thinking skills and teaching students how to solve complex problems to function effectively as workers and citizens in today's life (American Association for the Advancement of Science, 1993; National Commission on Excellence in Education, 1983; National Commission on Mathematics and Science Teaching for the 21st Century, 2000). However, researchers indicate that students are faced with various challenges that are based on the difficulties of novice learners to meet the complex cognitive and metacognitive requirements of the problem-solving processes (Brown, 1987; Land, 2000).

Scaffolding has been extensively used for different cognitive and metacognitive purposes to help learners cope with these challenges. Despite justification for the use of scaffolds to support knowledge integration and problem solving, the effectiveness of scaffolding depends on certain factors. One of the major issues indicated by Azevedo and Jacobson (2008) is "what to scaffold" namely whether to support domain knowledge

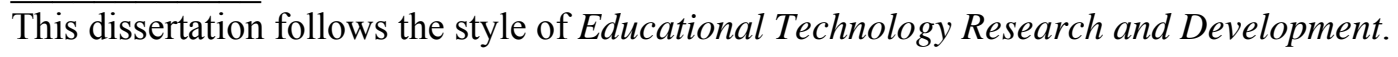


or metacognition, or both. A few studies explicitly explored the relative effects of what to scaffold. Another important issue of concern relates to the levels of support in scaffolds over time, namely "when and how to scaffold" (Azevedo \& Jacobson, 2008). Recently, most of the current studies have been criticized for missing the issue of fading support, and more research is suggested to facilitate understanding of the fading element of scaffolding (Davis \& Miyake, 2004; Puntambekar \& Hubscher, 2005). Individual characteristics of learners are another factor that influences scaffolding effectiveness. Researchers suggest that prior knowledge and metacognitive skills of learners might affect their use of scaffolds. However, there is tension between domain-generality and specificity of metacognitive skills, and therefore a difference in the effect of scaffolds for learners with different metacognitive skills. More research is needed to understand how middle school students with different characteristics can be supported in an illstructured problem-solving environment.

In summary, there are questions that need to be addressed relating to how to design effective scaffolding strategies. This study examined the effects of different types of scaffolds, specifically domain-general and domain-specific prompts, with different levels of support, continuous and faded, on learning and problem-solving outcomes in ill-structured problem solving in hypermedia learning environments. This study also examined which types of scaffolds better met the needs of learners with different characteristics. 


\section{CHAPTER II}

\section{LITERATURE REVIEW}

This chapter focuses on the scaffolding in ill-structured problem-solving processes. First, ill-structured and well-structured problem-solving processes are explained and compared. Then, requirements of ill-structured problem solving and the challenges based on the difficulties to meet complex cognitive and metacognitive requirements are addressed. This is followed by the definition of scaffolding, and an explanation is given for the types of scaffolding strategies to support the challenges of ill-structured problem solving. Finally, effective use of scaffolds and implications for future research are presented.

\section{Problem Solving}

Complex, ill-structured problem solving is of increasing importance in education (Bransford, Sherwood, \& Sturdevant, 1987). Educational reforms emphasize the importance of higher order thinking skills and teaching students how to solve problems to function effectively as workers and citizens in today's life (American Association for the Advancement of Science, 1993; National Commission on Excellence in Education, 1983; National Commission on Mathematics and Science Teaching for the 21st Century, 2000).

\section{Ill-Structured vs. Well-Structured Problems}

Jonassen (2000) defined problems as the difference between a goal state and a current state. The structure of problems can be defined on a continuum from simple, 
well-structured problems with convergent solutions to complex, ill-structured problems with multiple solutions.

Well-structured problems require the application of a limited number of concepts, rules, and principles being studied to a constrained problem situation (Jonassen, 1997). Greeno (1978) described these as problem of transformation, in which an initial situation is present, the goal is known, and it consists of a set of operations. Therefore, the goal in this type of problem is "to find the sequence of operations that transform the initial situation into a goal”' (Greeno, 1978, p. 241). Moreover, wellstructured problems have single, prescribed, and optimal solution paths (Sinnott, 1989), and are generally encountered in schools. Math and science problems in the textbooks are typical examples of well-structured problems; their solution is based on the constrained knowledge being studied in the classroom and textbook preceding the problem (Jonassen, 1997).

Ill-structured problems, on the other hand, require using reason, logic, math, and analytical abilities (Sinnott, 1989). They are characterized as complex and open-ended problems in which the initial stage is vague, goals are unclear, and the components and operators are not well-specified (Chi \& Glaser, 1985). Unlike well-structured problems, information needed to solve ill-structured problems is not entirely contained in the problem statement. In addition, they have multiple solutions, solution paths, or no solution at all (Kitchener, 1983). Ill-structured problems are generally faced in real life. Design problems, political issues, and sociological concerns can be examples of this type of problem. Solutions to these types of problems may require a combination of different 
content domains, including science, math, political science, sociology, and psychology (Jonassen, 1997).

Transferability of well-structured problem-solving skills that are taught in schools to the ill-structured problems in the real world is very limited (Jonassen, 1997). Therefore, it is important to distinguish ill-structured problems from well-structured ones to understand how essential components of each should be emphasized and supported in education.

\section{Ill-Structured vs. Well-Structured Problem-Solving Processes}

Traditionally, problem solving has been defined as cognitive operations in the initial state to achieving a goal under some rules that specify allowable operations (constraints) (Chi \& Glaser, 1985). Problem-solving processes have been explained by information-processing models, including general problem solver (GPS) (Newell \& Simon, 1972), the IDEAL model (Bransford \& Stein, 1993), and Gick's model (Gick, 1986).

GPS (Newell \& Simon, 1972) illustrates problem-solving thinking processes such as recognizing and understanding the problem, constructing a problem space (mental representation of the problem), and searching for a solution. Another problemsolving model, the IDEAL problem solver (Bransford \& Stein, 1993), includes identifying problems, defining problems, exploring alternative approaches, acting on a plan, and looking at the effects.

Information-processing models generally focus on two important processes: representation and search (Gick, 1986). Based on the various problem-solving models, 
Gick's model simplified problem solving into three processes: (a) problem representation, (b) searching for a solution, and (c) implementing a solution. Overall, the early models of problem solving are more suitable with well-structured problems that include interpretation and understanding of the problem, constructing the problem space, schema activation for solution searching and using different strategies, and implementing a solution.

Early studies proposed that ill-structured and well-structured problem-solving processes were not different from each other (Simon, 1973; 1978). However, researchers argued that solving ill-structured problems required skills used for well-structured problems as well as additional components and skills in metacognition, argumentation, and epistemic beliefs (Brabeck \& Wood, 1990; Dunkle, Schraw, \& Bendixen, 1995; Hong, Jonassen, \& McGee, 2003). Therefore, models that explain well-structured problem solving may not take into account the processes involved during everyday logical problem solving (Sinnott, 1989).

Several researchers have conducted studies about the processes of ill-structured problem solving by using a thinking-aloud approach while adults were trying to solve everyday problems (Sinnott, 1989; Voss \& Post, 1988). Sinnott's (1989) model includes five main points: 1) processes to construct problem spaces, 2) processes to choose and generate solutions, 3) monitors, 4) memories, and 5) non-cognitive elements. She argued that monitoring, memory, and non-cognitive elements, as well as the goal clarity/heuristic availability, play a central role during the processes of constructing problem space and the processes of choosing and generating solutions. 
Voss and Post (1988) described two structures of the problem-solving processes involved with ill-structured social science problems: problem solving and reasoning. They proposed that representation and solution processes are the most important processes in the problem solving structure. They found that two main problem-solving strategies are used during problem representation: decomposition (delineating the number of factors and breaking a problem into parts) and conversion (converting the problem into one that could be solved). In addition to the general strategies that initiate the representation and solution process, they argued that experts developed domainrelated reasoning structure in both phases.

Moreover, Jonassen's (1997) model for ill-structured problem solving includes various processes as follows:

- Articulation of problem space and contextual constraints

o Identifying and clarifying alternative opinions, positions, and perspectives of stakeholders.

o Generating possible problem solutions

o Assessing the viability of alternative solutions by constructing arguments and articulating personal beliefs

o Monitoring problem space and solution options

o Implementing and a monitoring solution

o Adapting the solution (p. 79-83)

Based on the work of Sinnott (1989), Voss and Post (1988), and Jonassen (1997), Hong (1998) summarized the processes of ill-structured problem solving into three steps: (a) 
representation of problems, (b) solution generation and selection, and (c) monitoring and evaluation. First, the problem representation involves constructing a problem space that includes defining problems, searching and selecting information, and developing justification for the selection. Second, the solution process includes generating and selecting the solution. Finally, the monitoring and evaluating process incorporates assessing the solution by developing justification.

Although well-structured and ill-structured problem-solving processes are parallel to each other, there are a number of important differences based on the nature of problem-solving processes and solving components. The following section compares well-structured and ill-structured problems by describing problem-solving processes including problem representation, solution process, and monitoring and evaluation. Problem Representation

Representation of the problem, the mental construction of the problem space, is the most significant part of problem solving (Bransford \& Stein, 1993; Jonassen, 2000). When learners are faced with a problem, they first begin with representation, which includes the solvers' interpretation and understanding of the problem. Incorrect representation makes it impossible to solve the problem since solvers do not know what to search for (Chi \& Glaser, 1985).

Since most of the ill-structured problems are pseudo problems, the first step in ill-structured problem solving is deciding whether there is a problem (Jonassen, 1997). Next, to understand the problem, the learner should identify what is known, what is unknown, what the goal is, and what causes the problem as well as its constraints. In 
well-structured problem solving, recognizing and classifying the problem types are important activities. However, conceptual knowledge is one of the most important aspects that differentiate the two. Ill-structured problem solving requires extensive knowledge from memory (Voss \& Post, 1988).

Unlike the well-structured problem-solving process, the ill-structured problemsolving process includes multiple representations and problem spaces. Learners frequently bridge between the multiple problem spaces through cognitive and noncognitive associations in order to decide the most relevant one (Sinnott, 1989). They choose the most appropriate problem space by identifying alternate views, perspectives, and opinions on that problem (Jonassen, 1997).

\section{Solution Process}

Since well-structured problems include well-specified present and goal states and a single solution, they do not require taking into account alternative arguments, seeking out new evidence, or evaluating the reliability of information (Kitchener, 1983). Generally, solvers need to employ strategies or rules of thumb (Gick, 1986). Among the variety of strategies, including random search, subgoaling, decomposition, and generatetest (Chi \& Glaser, 1985), means-ends-analysis is a powerful strategy that can be used during well-structured problem solving. Employed by both the GPS and the IDEAL models, the means-ends-analysis strategy includes breaking up the problem into subcomponents, determining distance between initial and goal/sub goal state, and solving the difference repeatedly until reaching a final solution. 
On the other hand, for ill-structured problems there are conflicting assumptions, evidence, and opinions that lead to multiple solutions (Kitchener, 1983). Learners should select the one among the multiple solutions that they think is suitable to the problem essence and reachable based on the problem and its constraints (Sinnott, 1989). Voss and Post (1988) argued that the solution process compromise not only finding a solution but also evaluating it. Therefore, as a part of the solution process, learners also need to justify their solution by indicating why it will work as well as considering the possible difficulties of the proposed solution and how these difficulties may be resolved.

Sinnott (1989) argued that the process of generating and choosing goals and solutions is not only affected by prior knowledge solutions. Rather, it is a creative exercise, which can be affected by both previous learning and unconscious processes and emotions. In this process, learners monitor their own processes, shifts, choices, styles, emotional reactions, and unrelated thoughts.

\section{Monitoring and Evaluation}

Following the problem representation and solution search in solving wellstructured problems, the final step is implementing the solution. Learners employ monitoring and evaluation activities during solution search and implementation. If the solution is successful, then the problem is solved. If the solution fails to work, then the learner goes back to an earlier stage and attempts to redefine the problem, generates a new hypothesis, and uses another method to solve it (Gick, 1986). On the other hand, in ill-structured problem solving, learners engage in monitoring and evaluating activities 
from the beginning when they start solving the problem with problem representation to solution search and justification.

Kitchener (1983) proposed a three-level model of cognitive processing for monitoring ill-structured problem solving. At the first level, cognition, knowledge is built on pre-monitored cognitive processes that an individual holds including computing, memorizing, reading, perceiving, etc. At the second level, metacognition describes the process used to monitor cognitive progress while the learner is engaged in level one, the cognitive task.

Kitchener (1983) proposed that for well-structured problems metacognitive processes might be sufficient. However, ill-defined problems do not have a definite single solution, and each solution may have some validity and contain some error. Therefore, learners should make epistemic assumptions. The third level, epistemic cognitive monitoring, leads a learner to monitor the epistemic nature of problems and the truth value of alternative solutions. It includes learners' knowledge on the limits of knowing, the certainty of knowing, and the criteria of knowing. By assessing the truth value of solutions, learners develop a strategy to represent a problem and select one solution.

\section{Requirements of Ill-Structured Problem Solving}

Ill-structured problem solving requires certain cognitive knowledge, including domain-specific and structural knowledge. Additionally, problem solving engages metacognitive and justification skills (Jonassen, 1997). 


\section{Cognition}

Domain-specific knowledge is essential to problem solving since problem representation is constructed based on it (Jonassen, 1997). Research on the performance of experts and novices showed that experts continuously used domain knowledge during problem solving (Chi, Feltovich, \& Glaser, 1981; Voss \& Post, 1988). Knowledge of the problem domain also influences the use of problem-solving heuristics (Chi \& Glaser, 1985). Voss and Post (1988) found that experts search internally from their own knowledge and use strategies that involve domain-related history. Additionally, studies showed that experts and novices do not use different heuristics. However, domainspecific knowledge assists experts in the selection of choosing the best solution path without considering other solutions (Chi \& Glaser, 1985).

Since ill-structured problem solving depends on the context, domain-specific knowledge must also be well-integrated, structured, and condensed in relation to the problem goals (Chi \& Glaser, 1985; Voss \& Post, 1988). Namely, ill-structured problems require structural knowledge, which has also been referred to as internal connectedness, integrative understanding, or conceptual knowledge (Jonassen, Beissner, \& Yacci, 1993). Jonassen et al. (1993) defined structural knowledge as a theoretical construct for describing the ways that humans construct and store knowledge. Namely, structural knowledge describes how declarative knowledge is interconnected and involves the integration of declarative knowledge into useful knowledge structures. It mediates the translation of declarative into procedural knowledge and facilitates the application of procedural knowledge. 
Other research suggests that experts' knowledge structures differ from novices in that experts have more complicated schemata (Chi, Glaser, \& Rees, 1982). While they have schemata of principles that may include schemata of objects, novices only have schemata of objects. Associated with the information in schemata, experts and novices start representation with different problem categories. For example, while experts initially categorized problems according to physics principles and applied them, novices categorized problems according to the similarities and identical keywords and focused on the literal characteristics of a problem (Chi et al., 1981).

In summary, both domain-specific and structural knowledge are important for solving ill-structured problems. They facilitate the solution process by helping learners choose the best solution path and guiding retrieval of appropriate procedures (Chi \& Glaser, 1985).

\section{Metacognition}

Metacognition is thinking about thinking and focuses on what people know and how they apply that knowledge. In other words, it is the consciousness about cognitive aspects of thinking (Jacobs \& Paris, 1987).

The concept of metacognition was introduced by Flavell (1976; 1979; \& 1981) and Brown (1975; 1978). Flavell (1976) defined metacognition as “one's knowledge concerning one's own cognitive processes or products or anything related to them" (p. 232). He further defined it as a "knowledge or cognition that takes as its object or regulates any aspect of any cognitive endeavor" (Flavell, 1981, p. 37). Brown (1987) also defined metacognition as an "understanding of knowledge, an understanding that 
can be reflected in either effective use or overt description of the knowledge in question" (p. 65). Further, Brown and Campione (1981) divided metacognition into two broad categories: knowledge about cognition and regulation of cognition.

Knowledge about cognition. The first category of metacognition, knowledge about cognition, concerns the self-awareness of learners regarding their own cognitive resources and the compatibility between them and a learning situation (Brown \& Campione, 1981). The learners' reflection of what is known about a problem domain is an important metacognitive strategy engaged during problem representation (Jonassen, 1997). Knowledge about cognition can be divided into three subcategories including (a) knowledge about cognitive tasks and resources (declarative), (b) knowledge about particular strategies that may be invoked to solve the task (procedural), and (c) knowledge of when and how the strategy should be applied (conditional) (Jacobs \& Paris, 1987; Kitchener, 1983). In order to employ strategies effectively, successful problem solvers need to have all these components of knowledge of cognition, as well as awareness of the success or failure of any of these components.

Regulation of cognition. The second category of metacognition, regulation of cognition, refers to self-control and self-regulatory mechanisms during problem solving. As stated previously, ill-structured problems have no clear solution and require consideration of multiple solutions and alternatives. Therefore, the uncertain nature of ill-structured problems requires learners to regulate their cognitive efforts to keep track of the solution process and their effectiveness (Jonassen, 1997; Kluwe \& Friedrichsen, 1985). 
Mechanisms to regulate thinking include monitoring, planning the next step, evaluating the effectiveness actions, and revising one's strategies for learning (Baker \& Brown, 1984; Brown \& Campione, 1981; Jacobs \& Paris, 1987).

First, monitoring is an important element of the ill-structured problem-solving process because it includes unclear goals and components. Monitoring is a complex process where learners reflect on not only what they know about a problem domain, but also what it means (Jonassen, 1997). Learners regularly monitor their cognitive efforts, shifts, choices, and emotional reactions during problem solving (Gick, 1986; Sinnott, 1989). Monitoring processes assist learners as they control their own processes, apply appropriate strategies, deal with their limitations, and stay on track (Kluwe \& Friedrichsen, 1985).

Second, planning is selective organization of actions to achieve a cognitive goal (Jacobs \& Paris, 1987). It reduces the uncertainty of ill-structured problems with regard to future action. Planning requires a considerable amount of decision making about the direction of one's approach including evaluating goals, selecting and evaluating strategies, and monitoring the execution of a plan (Kluwe \& Friedrichsen, 1985). Plans arise from feedback from the monitoring process, as well as the reflections of the solver on the completed actions (Hong, 1998).

Third, evaluation, as well as monitoring, is an ongoing process during illstructured problem solving. The solution process in ill-structured problem solving comprises both finding the solution and evaluating it (Voss \& Post, 1988). Learners need to evaluate the reliability of the information, evidence, and expert opinions. 
In addition to supporting planning, monitoring, and evaluation, regulation of cognition also supports learners as they develop justification skills. Since ill-structured problems have divergent solutions and do not have one single and best solution, learners need to justify the selected solution by constructing logical arguments (Jonassen, 1997, Voss \& Post, 1988). The process of justification requires solvers to provide arguments for why the proposed solution will work, to consider the possible difficulties of the solution, and how those difficulties may be resolved (Voss, 1988).

In summary, solving ill-structured problems requires not only content knowledge, but also regulation of cognition. Research on the performance of good-poor problem solvers (Dorner, Kreuzig, Reither, \& Staudel, 1983), good-poor learners (Thorndyke \& Stasz, 1980), and expert-novices (Simon \& Simon, 1978) showed the importance of metacognition. Results of these studies based on the thinking-aloud protocols showed that good problem solvers, good learners, and experts showed more systematic executive control strategies, including monitoring, checking, evaluating, and analyzing their own cognitive state and solution, by planning more carefully.

\section{Challenges during Ill-Structured Problem Solving}

Problem solving is a complex process that requires domain-specific knowledge, structural knowledge, metacognitive processes to plan, monitor, evaluate, and revise investigation plans, and justification skills. Challenges that learners face during illstructured problem solving are based on the difficulties of novice learners to meet the complex cognitive and metacognitive requirements of the problem-solving process. 
These challenges can be summarized as follows (Edelson, Gordin, \& Pea 1999;

Greening, 1998; Quintana et al., 2004; Reiser, 2004):

o Superficial mapping to prior knowledge

o Unfamiliar heuristic strategies

o Unreflective thinking

Superficial Mapping to Prior Knowledge

Representing a problem requires learners to make sense of their resources, identify what is known, what is unknown, what the goal is, and what causes the problem. Problem mapping onto internal representations and cognitive processes is central to problem representation (Jonassen, 2003).

As previously stated, research suggests that learners should have both domainspecific and structural knowledge to be successful in ill-structured problem solving. However, research showed that knowledge structures of novices are different from those of experts in that they have incomplete and poorly formed structures (Chi et al., 1982; Gick, 1986). Because of this limited domain and structural knowledge, novices focus on less elaborate understanding (Land, 2000). Learners' failure to focus on the details in the problem and their inability to see the meaningful patterns in an expert way may affect the sense making, problem representation, and solution search (Chi et al., 1981; Quintana et al., 2004). They may have difficulties mapping their intuitive thinking to scientific constructs, and they may misapply prior knowledge while searching their memories for similar problems (Land, 2000). 
These findings point to the prior knowledge paradox in complex learning environments. Schank and Cleave (1995) note the bootstrapping dilemma for these environments: "How can students learn by doing, when they do not know how to do what they have to do to learn?" (p.178). Therefore, learners need support to close the gap between their own ways of thinking and the ways presented by experts.

\section{Unfamiliar Heuristic Strategies}

Learners need to understand the task and use appropriate heuristic strategies for data gathering, analysis, and interpretation during problem solving (Edelson et al., 1999; Reiser, 2004). However, the use of heuristic strategies often depends on having relevant prior domain knowledge (Garner \& Alexander, 1989). Since these strategies are typically tacit for experienced problem solvers, instructors fail to make them explicit for learners (Reiser, 2004). Therefore, learners who lack the background knowledge and are new to those environments may be overwhelmed with the complexity of options, be distracted by unimportant tasks, have difficulties initiating the inquiry, and have trouble using the most relevant strategies (Quintana et al., 2004). For that reason, learners need support to see disciplinary ways of thinking and to acquire strategies for approaching problems.

\section{Unreflective Thinking}

Reflection plays a critical role in encouraging learners to be autonomous in complex learning environments. The reflection process can support both the content (sense making) and process or one's own thinking (metacognition) (Davis, 2003). 
Because of the uncertain nature of ill-structured problems, problem solvers need to regulate their cognition, including planning, monitoring, and evaluation (Baker \& Brown, 1984; Brown \& Campione, 1981; Jacobs \& Paris, 1987; Kluwe \& Friedrichsen, 1985). During the problem-solving process, they should identify the task, divide it into components, and plan each step toward the solution. They also need to monitor, evaluate the effectiveness of any action, and revise strategies for learning. The reflection process motivates learners to revisit, test, and reformulate the links and connections among their ideas, which results in meaningful products and better knowledge integration (Davis, 2003). However, difficulties in planning and monitoring investigations and learners' focus on reaching immediate outcomes without interpretation may present a challenge to learners (Brush \& Saye, 2001; Loh, 2003; Quintana et al., 2004; Reiser, 2004). Studies showed that even though learners are capable of reflecting, they often do not recognize that they should reflect and articulate their ideas (Davis \& Linn, 2000; Loh et al., 2001). Furthermore, even though learners are prompted to reflect, they have difficulties reflecting productively (Davis, 2003).

Another challenge in reflection and articulation results from the difficulties in argumentation and justification skills. The process of argumentation, including making and justifying claims with evidence (Toulmin, 1958), is needed in the dialectic nature of ill-structured problems. As previously stated, learners need to understand the epistemic nature of the ill-structured problems and the truth value of the alternative solutions (Kitchener, 1983). However, research shows that learners are not willing to participate in discussions and refute arguments of peers (Cho \& Jonassen, 2002). Learners also have 
problems weighing opinions, keeping track of alternatives, constructing logical arguments to persuade peers, and offering and receiving critiques (Cerbin, 1988;

Quintana et al., 2004; Reiser, 2004; Webb \& Palincsar, 1996). Use of metacognitive strategies often depends on having relevant prior domain- knowledge (Garner \& Alexander, 1989). Difficulties in regulation in the absence of domain knowledge point to the metacognitive knowledge paradox, which presents a challenge to learners (Land, 2000). How can learners use metacognitive strategies, which are often based on domain knowledge, in the absence of domain-knowledge? Therefore, during the problem-solving process learners need support that promotes productive reflection in order to cope with the lack of metacognitive and justification skills.

\section{Scaffolding}

Scaffolding can help learners cope with the challenges of ill-structured problem solving. Vygotsky's idea of the Zone of Proximal Development (ZPD) provided the foundation for the concept of scaffolding. The ZPD was mentioned in the 1962 English translation (Thought and Language) of Thinking and Speech (1934) (Wertsch, 1985). However, implications of Vygotsky's ZPD did not become apparent until Mind in Society was published in 1978.

Vygotsky (1978) defined the ZPD as a "distance between the actual developmental level as determined by independent problem solving and the level of potential development as determined through problem solving under adult guidance or in collaboration with more capable peers" (p. 86). He believed that learning is stimulated when children interact and cooperate with people and peers in the learning environment. 
Namely, individuals have learning potential that can be reached with assistance or scaffolds provided by more capable experts in their zone of proximal development. The notion of scaffolding was used and developed by Wood, Bruner, and Ross (1976) to describe a process where a tutor enables a child or novice to solve a problem, carry out a task, or achieve a goal that he or she would not be able to achieve on his or her own. Wood et al. (1976) defined the term scaffolding as an "adult controlling those elements of the task that are initially beyond the learner's capacity, this permitting him to concentrate upon and complete only those elements that are within his range of competence.” (p. 90). Cazden (1979) further extended scaffolding beyond a description of parent-children interactions to an analysis of teacher-student interactions in the classroom.

An important aspect of scaffolding is the support provided by an expert or tutor until a learner can perform independently by his or her own (Puntambekar \& Hubscher, 2005). Bruner (1985) argued that tutors play a critical role for "scaffolding" the learning task to make learners internalize external knowledge and convert the support into their conscious control. Wood et al. (1976) defined six types of functions for a tutor:

o Recruitment: The first task of the tutor is to get the learner interested in the task and to adhere to the learning objectives.

o Reduction of degrees of freedom: This involves simplifying the task to the level where the learner recognizes the task requirements that he has achieved. 
o Direction maintenance: An effective tutor should keep the learner motivated to pursue a particular objective and maintain directions by making it worthwhile for the learner to risk taking the next step.

o Marking critical features: Part of the role of the tutor is to accentuate the features of a task by a variety of different means. This provides the discrepancy between what the learner has done and what the learner would recognize as a correct solution.

o Frustration control: The role of the tutor is to reduce frustration and to make problem solving less stressful without creating too much dependency on the tutor.

o Demonstration: The tutor's role is modeling or imitating solutions to a task, which involves idealization of the act to be performed, and presentation of complete solutions that are already partially executed by the tutee himself.

\section{Features of Scaffolding}

Four important features of scaffolding were defined: intersubjectivity, ongoing diagnosis, range of support, and fading (Puntambekar \& Hubscher, 2005; Stone, 1998). First, it is assumed that the goal of an activity is understood by the learners, even though it is beyond their individual capabilities (Stone, 1998). Intersubjectivity, or shared understanding of the goal of an activity, is attained when a tutor and tutee collaboratively redefine the task so that there is shared ownership of the task (Puntambekar \& Hubscher, 2005). 
Second, ongoing diagnosis of the learners' levels of understanding and skill is accompanied by the careful calibration of a tutor's support (Puntambekar \& Hubscher, 2005; Stone, 1998). According to Wood et al. (1976), an effective tutor must have both the knowledge of the task, as well as how it may be completed, and the knowledge of the performance characteristics of his/her tutee. In this way, a tutor can generate feedback or devise appropriate solutions for the tutee.

Third, ongoing diagnosis leads the adult to provide a range of gradual support. Support should include nonverbal assistance in the form of modeling, pointing, and extensive dialogue in reciprocal teaching (Stone, 1998).

Finally, fading the support provided by the tutor puts learners in control and allows them to take the responsibility for their own learning. Once learners internalize the external knowledge to their independent development, there is a transfer of responsibility from the teacher to the learner (Puntambekar \& Hubscher, 2005; Stone, 1998; Wood et al., 1976; Vygotsky, 1978). At that time, scaffolding can be removed.

\section{Types of Scaffolding}

Early studies describing scaffolding were observational studies of a parent interacting with children. Around the mid-1980s, scaffolding studies began to focus on the dynamics of teacher-student interactions in the classroom. Saye and Brush (2002) called this type of teacher and peer initiated scaffolding "soft scaffold," which served as dynamic and situation-specific aids. This type of scaffolding requires teachers' ongoing diagnoses of the understandings of learners and the provision of timely support based on responses. 
In this day and age, with the increasing use of technology supported environments, scaffolding is no longer restricted to individual interactions and has expanded to include a number of different tools and resources. These tools can be embedded into multimedia and hypermedia software. Saye and Brush (2002) called this kind of scaffolding "hard scaffold". They defined it as "static supports that can be anticipated and planned in advance based upon typical student difficulties with a task" (p. 82). Saye and Brush (2002) distinguished between "soft" and "hard" scaffolds based on their delivery system, such as teacher or peer and technology. However, it is possible that teachers and peer can also deliver hard scaffolds, namely static supports, and technological tools such as intelligent tutoring systems can deliver soft scaffolds, namely dynamic supports.

Hannafin, Land, and Oliver (1999) also defined four types of scaffolds that have potential to support learners in technology-based learning environments: conceptual, metacognitive, procedural, and strategic.

Conceptual scaffolds guide learners concerning what to consider when solving a problem. These may include hints to guide them to available resources or suggestions of tool manipulation when learners solve complex and fuzzy problems.

Metacognitive scaffolds guide learners on how to think during learning. It supports self-management and self-regulation, including planning, evaluation, and monitoring. It could also be used to remind learners to reflect on the goal and prompt them to use resources. 
Procedural scaffolds guide learners on how to utilize available resources and tools. This type of scaffolding provides support when learners are disoriented and suffering from cognitive overload. Flags, bookmarks, and assistants (like in the software) can be examples of this type of scaffolding.

Strategic scaffolds guide learners toward a variety of alternative approaches and techniques to solve the problem. They support identifying and selecting needed information, evaluating resources, and relating new knowledge to previous knowledge. Types of strategic scaffolding include helping learners to begin to solve the problem by asking questions, alerting the learner to available resources with hints on which tools and resources might contain the needed information, and providing responsive sensitive guidance at key decision points.

\section{Scaffolding Strategies to Support Ill-Structured Problem Solving}

Researchers have been investigating the role of different instructional scaffolds to meet the challenges of ill-structured problem solving. Scaffolds have been provided in different formats, including technology-based scaffolds, prompt scaffolds, peer interaction, and teacher support. This section explains how each format helps learners cope with the cognitive and metacognitive challenges during ill-structured problem solving. Fig. 2.1 provides a summary of requirements of problem solving, novice characteristics, challenges, and scaffolding strategies. 


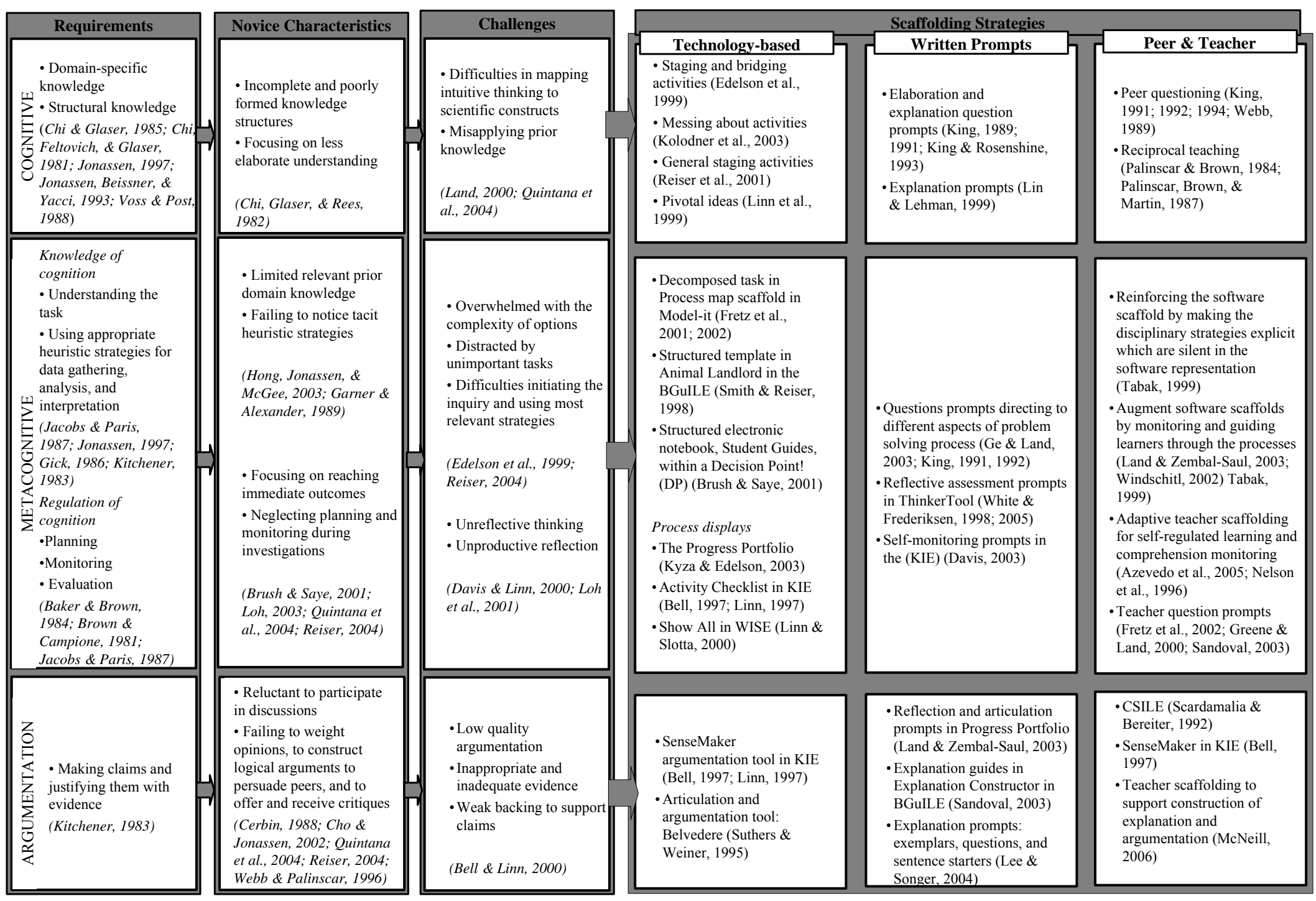

Fig. 2.1 Summary of requirements of problem solving, novice characteristics, challenges, and scaffolding strategies 


\section{Technology-Based Scaffolds}

There has been a body of research on using technology to scaffold learners in illstructured problem solving. Varieties of scaffolding types have been embedded in a large diversity of hypermedia and software to meet the challenges of ill-structured problem solving.

First, technology-based tools have been used to prepare learners conceptually and to solve the bootstrapping problem by prompting and guiding new connections to existing models and personal experiences. An example of facilitating the conceptual model of learners is provided by a variety of software that embeds familiar and orienting activities. For example, within the Greenhouse Effect Visualizer and the WorldWatcher, Edelson et al. (1999) incorporated "staging activities," which are sequences of structured investigations. They also used "bridging activities" to enable learners to draw visualizations that articulated their initial conceptions. Kolodner et al. (2003) also used a similar kind of activity called "messing about" in Learning by Design, in which learners design and build an initial model based on their prior knowledge. Another software, The Biology Guided Interactive Learning Environment (BGuILE) (Reiser et al., 2001), used "general staging activities" to enable learners to reveal what they believed and understood about the topic. In order to motivate reorganization of thoughts, Linn, Shear, Bell, and Slotta (1999) also used "pivotal ideas," which had students articulate their prior conceptions about a phenomenon and highlight inconsistencies. In summary, all those activities helped learners to bridge the gap between their own and scientists' practices by 
introducing investigation techniques and preparing them for investigation by providing background knowledge and motivation.

Second, throughout the literature, technology-based tool interfaces have been organized to display disciplinary strategies for helping learners to understand a task, decompose open-ended problems, and acquire strategies (Edelson et al., 1999; Quintana et al., 2004; Reiser, 2004). For example, the process map scaffold in Model-it software (Fretz, Wu, Zhang, Krajcik, \& Soloway, 2001; 2002) constrains space of activities by decomposing the task into three functional modes, including plan, build, and test. By decomposing the task, learners have a limited set of choices. In each of the three modes, different tools are presented to learners. This type of scaffold has been helpful for novice learners in creating dynamic models of complex systems. In another example, Animal Landlord in the BGuILE (Smith \& Reiser, 1998) used a structured template including actions, observations, and interpretations. By using video as data for animal actions, students are required to observe their analysis of animal behavior, annotate instructions to their data, and make comparisons and interpretations. Narrowing down options and requiring learners to select from limited options encouraged them to grapple with decisions they might otherwise overlook.

In another example, Brush and Saye (2001) structured an electronic notebook, Student Guides, within Decision Point! (DP). They provided categorized questions that a historian might use to organize and synthesize evidence about an event. Students were required to think about and record their analysis based on the predefined categories that experts would use. However, they found that students often ignored the guiding 
structures in the DP environment. After some prompting, they used the categorizing questions, but they unreflectively filled in the spaces rather than using the guides to help them find connections among events.

Third, technology-based tools have been used to support learners' reflective skills when they plan, monitor, and evaluate during ill-structured problem solving. Tools have been mainly used to help learners see their own thinking and learning processes, namely "making tacit learning processes explicit and overt" (Lin, Hmelo, Kinzer, \& Secules, 1999, p. 47). Lin et al. (1999) called this type of tool "process displays". Process displays encourage students' reflection in three ways. First, they record the activities of investigation, and enable learners to organize and manage these records. Second, they facilitate learners to monitor the process, review, and reflect on what they have done. Third, they let learners communicate their own learning process with others.

In the literature, various programs and templates have been designed to use technology for recording, tracking, and displaying learning processes. While some of these tools are content-specific, others are content-neutral and can be adapted to different domains. The Progress Portfolio is an example of a content-neutral program (Kyza \& Edelson, 2003). As students conduct investigations in other environments (e.g. Newtonian physics), they use Progress Portfolio tools to create a page about their investigations by capturing information, storing it, and annotating information about the pages. The data camera tool, text fields, and sticky notes help learners record, monitor, and present their inquiry progress and reflect on their ideas. 
Other examples of using technology to display learning processes includes the SICUN (Lajoie \& Azevedo, 2000), Activity Checklist and SenseMaker argumentation tool in KIE (Bell, 1997; Linn, 1997), Belvedere argumentation tool (Suthers \& Weiner, 1995), and Show All in WISE (Linn \& Slotta, 2000). These tools also keep track of the completed activities by recording and organizing, and they then graphically present it to let learners check their actions and reflect on them. In addition to displaying processes that learners have engaged in, technology-based tools can also embed prompts to guide students in tracking and understanding their process. Prompts are explained in detail in the next part.

\section{Prompt Scaffolds}

Throughout the literature, prompts have been extensively used for different cognitive and metacognitive purposes in ill-structured problem-solving processes. Prompts have been either incorporated into software programs to track and understand learners' own processes, or been provided by peers and teachers. Prompts guide learners as they organize, interpret, and externalize mental activities that are usually covert. Prompts are especially important for learners who are likely to jump into solutions when faced with a problem-solving task (Lin et al., 1999). Research on prompts includes investigations of questions, reminders, or hints.

First, prompts have been used to guide novice learners with little knowledge to make connections to their prior knowledge. King and Rosenshine's (1993) study is an example of using prompts to facilitate knowledge construction. In their study, fifth grade students were presented with strategy prompt cards. They found that question prompts 
promoted learning by eliciting responses such as explanations, inferences, and justifications (King \& Rosenshine, 1993). In a similar study, pairs of fourth and fifth grade students were provided prompts that were intended to access prior knowledge and experience (King, 1994). Analyzing both comprehension tests and knowledge maps, King (1994) found that students who received prompts engaged in complex knowledge construction.

In another example of using prompts to support knowledge integration, Davis's (2003) and Linn's (1997) study provided self-monitoring prompts in a guidance system that is a part of the Knowledge Integration Environment (KIE). These prompts were intended to encourage eighth graders to plan and reflect on the activities and identify the strengths and weaknesses of their work. Their findings showed that students expanded their repertoire of ideas, identified weaknesses in their knowledge, differentiated among ideas, and made connections to their current knowledge. Furthermore, they found that engaging in productive reflection promoted integration of knowledge.

Second, prompts have been used to help learners understand the task, make their thinking explicit, and facilitate their reflection during problem solving (Palincsar \& Brown, 1984; Scardamalia \& Bereiter, 1985). For example, Ge and Land (2003) provided question prompts to help students focus on the different aspects of the problemsolving processes, including problem presentation, solution search, making justifications, and evaluation. Similarly, in the King studies (1991; 1992) questions were categorized into three levels, including planning, monitoring, and evaluating, to help fifth graders articulate the steps and reflect on their process. Both of these studies 
indicated that question prompts facilitated the problem-solving processes and outcomes by teaching students how to be strategic problem solvers.

In another example, Lin and Lehman (1999) provided explanation and justification prompts in a computer simulation of a biology laboratory activity designed for college students. Qualitative analysis of near-transfer problem-solving tasks showed that question prompts directed students' attention to understand when, why, and how to employ strategies, which helped them plan and monitor their problem solving.

White and Frederiksen (1998; 2005) designed a Thinker Tools Inquiry Curriculum to scaffold students' inquiry process, metacognitive knowledge, and skills. They provided reflective prompts in the Reflective Assessment tool to encourage students to evaluate their work at the end of each inquiry cycle, including question, predict, experiment, model, and apply. Their results showed that reflective prompts decreased the gap between low and high achieving students by helping low achieving students acquire greater understanding of the inquiry performances.

Third, prompts have been used to support scientific explanation and argumentation (Bell \& Davis, 2000). Land and Zembal-Saul (2003), for example, provided reflective prompts in Progress Portfolio to support reflection and explanation. Their findings indicated that these prompts supported learners to become precise in their explanations, offer justifications, and connect evidence with claims.

In another example, prompts have been provided in Explanation Constructor software in the BGuILE environment in the form of explanation guides (Sandoval, 1998; 2003). They provided students with hints about what to include in their explanations. 
Moreover, prompts also provided guidance to students about what a good scientific explanation looks like. The studies using Explanation Constructor found that providing students with prompts helped them to construct useful explanations (Sandoval, 2003; Zembal-Saul et al., 2002).

In another study, Lee and Songer (2004) provided prompts to fifth and six graders in the forms of exemplars, questions, and sentence starters to promote explanations during biodiversity curriculum. By analyzing pretest and posttest measures, written explanations, and post interview transcripts, they found that students' knowledge about diversity became stronger, as well as their explanation ability to match given evidence to a claim.

In summary, the literature has illustrated that prompts have the potential to facilitate knowledge acquisition, metacognitive thinking and problem solving, and scientific explanation. In addition, some studies compared the effects of different prompt scaffolds. For example, Davis and Linn (2000) compared self-monitoring prompts, intended to encourage planning and reflection, to activity prompts, intended to facilitate completion of specific aspects of the task. By analyzing the responses to each prompt, they found that activity prompts were helping students finish activities and elicit scientific ideas. However, self-monitoring prompts were more successful in prompting knowledge integration.

In another study, Zydney (2005) investigated the effectiveness of two types of prompts, focusing and reflective questions, in the multimedia learning environment Pollution Solution, on $8^{\text {th }}$ grade students' problem-solving abilities. First, she provided 
focusing questions under certain headings, including problem, hypothesis, plan, and resources, in a research plan template to help students organize their research. Second, she gave reflective questions in a status report to help students with assessing and integrating their learning. She found that focusing question prompts were more effective in helping students to understand problems, formulate hypotheses, and ask specific questions than the reflective question prompts.

In addition, Davis (2003) investigated two types of reflection prompts, including generic and directed, which evolved from the self-monitoring prompts described previously. While generic prompts are designed to encourage students to think aloud without providing instruction on what to think about, directed prompts are designed for providing hints to give directions for productive reflection. Generic prompts helped students expand their repertoire through eliciting more ideas and forced them to give reflective answers that gave more opportunities to integrate knowledge. Therefore, compared to a directed prompt condition, a generic prompt condition allowed learners to develop understanding that was more coherent by giving them control over their reflection.

In another study, Lin and Lehman (1999) provided three types of prompts to scaffold college students in reflecting on their own problem-solving processes during a computer simulation of a biology laboratory activity. These prompts were reasonjustification prompts, rule-based prompts, and emotion-focused prompts. First, reasonjustification prompts were used to ask students to give reasons for their actions, planning, and monitoring. These types of prompts were used to help students develop an 
understanding of their strategies. Second, rule-based prompts were used to ask students to explain rules and procedures to help them with developing and understanding the nature of the problem-solving tasks. Finally, emotion-focused prompts were used to let students reflect on their feelings to enhance their understanding of their emotional state. Their results showed that students in the reason-justification group performed significantly better than the other groups on the far-transfer problem-solving posttest.

\section{Peer Interaction and Teacher Support}

Since software tools cannot always diagnose individuals' needs and provide sufficient scaffolding to all learners, adaptive forms of scaffolding, including peers and teachers, are crucial in the ill-structured learning environment (Land, 2000; Lin et al., 1999; Greene \& Land, 2000; Quintana et al., 2004; Reiser 2004).

\section{Peer Interaction}

Peer interaction, especially questioning, has been found to be an effective strategy for fostering cognitive and metacognitive thinking. From a Piagetian perspective, Tudge (2000) proposed that peers can provide effective scaffolds to promote and develop thinking, even more effective than adults in some conditions.

First, by eliciting explanations, peer interaction can help learners reflect on their experiences, close gaps in their understanding, and make connections to their prior knowledge. A series of studies on peer questioning conducted by King (1991; 1992; 1994) showed that seeking information, giving explanations, and receiving feedback from peers helped learners with activating prior knowledge, eliciting their own perspectives, and enhancing their learning. Moreover, Webb's (1989) research on peer 
interaction and learning in small groups showed that when students provided more and higher-level explanations, they learned more. Greene and Land (2000) also found that peer interaction was effective when group members offered suggestions, were open to negotiate ideas, and shared previous experiences.

Another series of studies (Palincsar \& Brown, 1984; Palincsar, Brown, \& Martin, 1987) investigated the effect of reciprocal teaching, which involved dialogue between the student and their teachers or peers. In research investigations on reciprocal teaching in the context of peer tutoring (Brown \& Palincsar, 1987), $7^{\text {th }}$ grade learners in reading classes were trained as tutors to engage in four main strategies, including predicting, question generating, self-reviewing, and clarifying. During reciprocal teaching structured by these four strategies, students took turns with the role of leading the discussion in their group. The results showed that both tutors and students internalized the strategies and applied them to their work. Through the verbal and social interaction students' comprehension had been increased, which was comparable to students who worked in the context of adult teachers-students reciprocal teaching.

Second, peer interaction has been found to be an effective strategy for helping learners to see multiple perspectives and enhance reflection (Lin et al., 1999). Several computer tools are used to support peer interaction and discourse in ill-structured problem-solving environments.

For example, the Computer Supported Learning Environment (CSILE) (Scardamalia \& Bereiter, 1992) provides a database where students can create text and graphical notes. Using CSILE, students can search existing notes and provide comments 
to each other. Another tool, SenseMaker in KIE (Bell, 1997), enables learners to construct arguments by organizing and clustering evidence collected from the Internet. Organization and structure of the tool fosters meaningful collaboration among peers. The Collaboration and Negotiation Tool for Case-Based Learning (CoNet-C) developed by Choi, Land, and Turgeon (2005) also provides pages where students can access their discussion activities, review the questions, and exchange questions and answers with peers.

Application of these social discourse-based tools to education showed that peer interaction served a critical role in facilitating reflection and construction of knowledge. By comparing and contrasting different perspectives from their peers, students can discriminate between different perspectives and reflect on their understanding. Questions from peers pushed the learners to consider alternative perspectives, search new information to enhance their understanding, and identify gaps.

\section{Teacher Support}

Teachers play an important role in arranging all the elements of a learning environment, including psychological, pedagogical, technological, cultural, and pragmatic (Hannafin et al., 1999; Saye \& Brush, 2002). It is clear in the literature that the role of the teacher is crucial to support problem solving, specifically to orchestrate all the activities, integrate tools (Puntambekar \& Hubscher, 2005), and provide metascaffolding, as learners need scaffolds for the scaffolds (Pea, 2004). Teachers can scaffold the use of a tool by modeling conceptually, addressing content knowledge gaps, and providing reminders throughout the investigation (Fretz et al., 2001). Teachers can 
also prompt reflection through questions, identify the limitations and strengths of students' thinking, rebuild the questions, provide examples, and offer hints. Dynamic interaction with the teacher has been found to be helpful in expanding, formalizing, refining, and reasoning the ideas of students (Fretz et al., 2002; Greene \& Land, 2000; Sandoval, 2003).

A variety of strategies that teachers employ to support technological tools in classrooms can be characterized into two categories: reinforcing and augmenting software scaffolds (Land \& Zembal-Saul, 2003; Tabak, 1999; 2004). Therefore, teachers and technology perform complementary roles. First, teachers reinforce the software scaffold by making explicit the disciplinary strategies that are silent in the software representation. Successful scaffolding depends not only on competence in the use of the tools, but also appropriate use of the tools (Tabak, 2004). However, software scaffolds alone may not have been sufficient to promote the appropriate or expert use of these tools. Therefore, teachers can explicate the rationale that underlies the tools by modeling the use of the software. Teachers can also make their thinking processes explicit through dialogue, writing, drawings, and other representations (Windschitl, 2002). Additionally, they can direct student attention and prompt students to use these features. Modeling (which is rooted in language) objects of the software scaffolds would be more helpful for the students (Tabak, 1999).

Second, teachers augment software scaffolds by monitoring and guiding learners through the processes that are not supported by the software. They can employ a variety of assessment strategies to understand how ideas are evolving and give feedback on the 
processes (Land \& Zembal-Saul, 2003; Windschitl, 2002), and establish scientific norms for successful engagement in scientific discourse (Tabak, 1999).

Previous research showed that teachers can both scaffold comprehension and comprehension monitoring during problem solving. For example, Azevedo, Cromley, Winters, Moos, and Greene (2005) found that adaptive scaffolding, which includes a human tutor who used various aspects of self-regulated learning processes dynamically and adaptively, was more effective in improving significant declarative knowledge and deeper conceptual understanding than the fixed scaffolding, which includes domainspecific questions. Findings also indicated that learners in the adaptive scaffolding condition regulated their learning by planning and activating prior knowledge, monitoring their cognitive activities and understanding, using effective strategies, and engaging in adaptive help-seeking behavior. In their research examining the effect of teacher scaffolding and comprehension monitoring, Nelson, Watson, Ching, and Barrow (1996) also found that learning outcomes increased with the help of the teacher scaffolding and monitoring.

\section{Effective Use of Scaffolds}

Current research on scaffolding in ill-structured problem solving in hypermedia learning environments has shown different effects of scaffolds. While some studies showed the positive effects of scaffolds, others showed that scaffolds sometimes are not useful. Based on the literature, scaffolding effectiveness in ill-structured problem solving depends on certain factors, including types of scaffolds, timing of scaffolds, fading of scaffolds, limited background knowledge, limited peer scaffolding, and distribution of 
scaffolding and synergy (Land \& Zembal-Saul, 2003; Lin \& Lehman, 1999; Tabak, 1999).

\section{Types of Scaffolds}

As Perkins and Salomon (1989) suggested, both general and specialized knowledge are needed for effective problem solving and cognitive skills. Students need to have general problem solving and metacognitive skills to be successful problem solvers. They also need to have prior knowledge to use metacognitive strategies effectively, since they are often depending on them (Garner \& Alexander, 1989). Therefore, they can be represented on a continuum from general to specific knowledge (Perkins \& Salomon, 1989).

However, in the literature, most of the researchers have focused on either domain-general or domain-specific prompts, and only a few studies compared them. Since it might be difficult to focus on all aspects all of the time during classroom instruction, understanding the relative effects of domain-general and domain-specific prompts is important (Azevedo \& Jacobson, 2008; McNeill \& Krajcik, 2006). Future studies are needed to examine the effects of specific types of scaffolds in order to identify the tools that work best in a complex classroom environment (Puntambekar \& Hubscher, 2005).

\section{Timing of Scaffolds}

Throughout the literature, scaffolds were provided at certain times. For example, White and Frederiksen (1998) used prompts after each activity for reflective selfassessment. Moreover, Davis (2003) used Thinking Ahead directed prompts before the 
activity and Checking Our Understanding directed prompts after the activity. She found that students reflected more poorly to the directed prompts after the activity than they did to the directed prompts before the activity.

Kyza and Edelson (2003) found that students responded differently to the prompts provided by the technology and teachers depending on the timing. While students were willing to do an activity that they previously ignored when prompted by software, they chose to ignore the teacher prompting when the timing seemed wrong. Therefore, future studies need to examine the effects of scaffolding according to timing factors.

\section{Fading of Scaffolds}

Fading scaffolds as students became capable of an activity is the central concept of the original notion of scaffolding (Puntambekar \& Hubscher, 2005). However, recent studies did not adopt this notion and used a continuous form of scaffolding. In the literature, there are different suggestions about how to fade scaffolds effectively. One way fading can be accomplished is by distributing scaffolds (Pea, 2004). By distributing scaffolds rather than removing them systematically, they become part of the community (Puntambekar \& Kolodner, 2005).

Fading can also be accomplished by a systematic gradual reduction of support (Lee \& Songer, 2004). A few studies compared the effect of fading versus continuous scaffolds by gradually withdrawing them over time.

Lee and Songer (2004), for example, compared two scaffolding treatments: continuous and fading prompts, which provide domain-specific support. They found that 
both the continuous and faded domain-specific groups showed a gain in knowledge about biodiversity. However, their results indicated that the continuous domain-specific support group outperformed the faded domain-specific support group in writing scientific explanations. This result is different from another study conducted by McNeill, Lizotte, Krajcik, and Marx (2006). They used a combination of domain-general and domain-specific prompts, and then faded the domain-specific prompts over time. Therefore, the continuous group received both domain-general and domain-specific prompts throughout the unit; the faded group did not receive the domain-specific prompts later in the unit. Their results showed that fading the prompts resulted in greater learning of scientific explanation (claim, evidence, and reasoning) than continuous support.

One reason for this inconsistency might be the type of prompts, domain-general versus domain-specific. There are still many questions to be researched about the fading of scaffolds (Davis \& Miyake, 2004). Therefore, more research is needed to understand more the issue of fading, including identifying proper ways of fading and establishing the effects of fading on students' learning.

\section{Limited Background Knowledge}

One reason for the failure of using scaffolds was learners' limited background knowledge. Research showed that novice learners may fail to take advantage of the scaffolds, see them as a restricting factor in their progress, simply ignore them, or answer superficially (Brush \& Saye, 2001; Ge \& Land, 2003; Greene \& Land, 2000). 
Therefore, in order to help learners get the benefits of the scaffolds and not ignore them, they can be guided by the inclusion of review and feedback from peers and teachers.

Moreover, if tools do not encourage learners to self-evaluate, become aware of their knowledge limitation, and admit knowledge deficiencies, they will not use this guidance to evaluate their ideas (Land \& Zembal-Saul, 2003). As a result, they might experience more problems with making progress. Therefore, scaffolding that is more explicit is needed to help learners engage in evaluation of their understanding, which can be done by either prompting learners to evaluate expert-like perspectives or to selfassess their knowledge when dynamic feedback is not immediately available.

\section{Limited Peer Scaffolding}

Previous studies showed that simply having peers work together was not always fully effective. Learners who do not have adequate prior knowledge fail to engage each other in a metacognitive function, including questioning, clarification, and justification (Fretz et al., 2001, 2002; Garner \& Alexander, 1989; Land \& Zembal-Saul, 2003). Although, Ge and Land's (2003) qualitative findings indicated positive effects of peer interactions in facilitating cognitive thinking and metacognitive skills, quantitative findings did not show a significant effect of peer interaction. Similarly, in Choi's study (2002), although online peer support helped learners to generate more questions, it did not affect the quality of the questions, further interactions, and learning outcomes. Previous studies on guided peer questioning shows that support students may not ask strategic questions during problem solving without the teacher simply telling students to ask and answer each other's questions (King, 1991). Therefore, the reason for the failure 
of these studies might be a lack of prior knowledge and limited training of students on how to use the guidance provided.

Consequently, to better interact with each other, the peer interaction process itself should be scaffolded by guidance and monitoring with various strategies, including question prompts and peer reviewing (Ge \& Land, 2003; Land \& Zembal-Saye, 2003; Wu, Farrell, \& Singley, 2002). More research is needed to examine how to aid students in being better learning partners, considering the different levels of prior knowledge and metacognitive skills (Greene \& Land, 2000).

\section{Distributed Scaffolding and Synergy}

There is growing agreement in recent literature on the system approach of scaffolding (Edelson et al., 1999; Lehrer \& Schauble, 2000; Puntembekar \& Kolodner, 2005; Tabak, 2004). This view supports the idea that, in order to make scaffolding more successful, it should be distributed across software tools, teacher, and peers. Tabak (2004) defined distributed scaffolding as a "multiple forms of support that are provided through different means to address the complex and diverse learning needs" (p. 305). She distinguished the different forms of scaffolding in the literature in three patterns, representing patterns of distributed scaffolding: differentiated scaffolds, redundant scaffolds, and synergistic scaffolds.

Differentiated scaffolds include combining multiple forms of support in which each need is addressed by its own scaffold. Researchers extensively used combinations of scaffolds for different needs. One example of a differentiated scaffolding pattern was presented in the Knowledge Integration Environment (Bell, 1997). While the 
argumentation tool, SenseMaker, was helping students to construct their arguments, classroom debate during SenseMaker presentations provided a means of comparing and discriminating between multiple perspectives. Similarly, the Learning by Design (LBD) project used design diaries to help students record their thinking throughout the inquiry and pin-up sessions to make students present and discuss their designs (Puntambekar \& Kolodner, 2005). In another example, the Explanation Constructor used procedural, directed, and dialogical scaffolds in the BGuILE environment (Reiser et al., 2001). While prompts in the ExplanationConstructor helped students articulate their explanations, whole-class discussion made students present their explanations and answer teachers' questions. In the class discussion, students were able to refine their explanations.

Since there are multiple ZPD in the classroom, different students might need different types and levels of support for the same need (Brown, Bransford, Ferrara, \& Campione, 1983; Palincsar, 1998). In a classroom setting, it is not possible for a teacher to provide support to each student within his or her ZPDs (Puntambekar \& Hubscher, 2005). Redundant scaffolds can solve this problem by including multiple supports that target the same need. For example, while software prompts can be provided to guide reflection on one point, teacher prompts can direct reflection at a second point. Therefore, learners who missed the opportunity at one point can have an additional opportunity for support.

Among the other types of distributed scaffolds, Tabak (2004) suggested that synergy among the provided multiple scaffolds is critically important to promote 
learning. By synergistic scaffolds, she refers to multiple supports including the teacher, software, and other agents interacting and targeting the same need. Unlike the redundant scaffolding pattern, these scaffolds are not directly aimed at the same need. Instead, they are intertwined and they complete each other to produce a robust network of support.

Designing synergy requires including scaffolds to facilitate the use of other tools and scaffolds. Teachers can make significant contributions to synergy. For example, although teachers are provided with the same scaffolds, they will adopt them in different ways and they may use different instructional strategies to support students' problem solving. Synergistic scaffolds have not received much attention, and there is need for research examining the role of the teachers and other agents in a complex learning system. Future research should examine in depth the teacher strategies that are used to support technological tools, and to what extend the teacher scaffolds are domain-general and domain-specific. Moreover, different roles of teachers and the relationship between the teaching strategies and student performances should be investigated (Tabak, 1999). Future research also needs to examine whether functions of both software and teacher scaffolding can be best achieved by the teacher alone or by software alone, and how their responsibilities should be distributed (Pea, 2004; Puntambekar \& Hubscher, 2005; Tabak, 2004). 


\title{
CHAPTER III
}

\section{SCAFFOLDING MIDDLE SCHOOL STUDENTS' CONTENT KNOWLEDGE AND ILL-STRUCTURED PROBLEM-SOLVING PROCESS}

\begin{abstract}
Overview
This study investigated the effects of domain-general and domain-specific scaffolds with different levels of support, continuous and faded, on learning of scientific content and problem-solving process. A total of nineteen classes were randomly assigned to one of the four scaffolding conditions: domain-general continuous (DG-C), domain-general faded (DG-F), domain-specific continuous (DS-C), and domain-specific faded (DS-F). Each class had access to different worksheets depending on the scaffolding condition they had been assigned. All students engaged in four problemsolving activities for thirteen class periods. Students' scores on a multiple-choice pretest, posttest, and four recommendation forms were analyzed in order to examine the effectiveness of scaffolds. Students' content knowledge in all conditions significantly increased from pretest to posttest. However, the continuous domain-specific condition outperformed the other conditions on the posttest. Although domain-general scaffolds were not as effective as domain-specific scaffolds on learning of scientific content and problem representation, they helped students develop solutions, make strong justifications, and monitor their learning. Unlike domain-specific scaffolds, domaingeneral scaffolds helped students transfer problem-solving skills when they were faded. Several suggestions are discussed for making further improvements in the design of
\end{abstract}


scaffolds in order to facilitate ill-structured problem solving in hypermedia learning environments.

\section{Introduction}

Problems vary in their nature and amount of structure. Problems can be represented on a continuum from well-structured problems (e.g., solving a puzzle or an equation, following a recipe) to ill-structured problems (e.g., political and social dilemmas, designing a roller coaster, recommending a solution to a given problem) (Jonassen, 2000). Complex, ill-structured problem solving is of increasing importance in education (Bransford et al., 1987), as ill-structured problems are more often encountered in real life. They are typically open-ended and the initial stage is vague; goals are unclear, and the components and the operators are not well-specified (Chi \& Glaser, 1985). They may have multiple solutions, solution paths, or no solution at all (Kitchener, 1983).

\section{Ill-Structured Problem-Solving Processes}

Based on various problem-solving models (Jonassen, 1997; Hong, 1998; Sinnott, 1989; Voss \& Post, 1988), Ge and Land (2003) developed a model that summarized illstructured problem solving into four processes: (a) problem representation, (b) developing solutions, (c) making justifications, and (d) monitoring and evaluation.

The first step of problem solving, representation of the problem and the mental construction of the problem space, is the most significant part of problem solving (Bransford \& Stein, 1993; Jonassen, 2000). When learners are faced with a problem, they first begin with representation, which includes the solvers' interpretation and 
understanding of the problem. Incorrect representation makes it impossible to solve the problem since solvers do not know what to search for (Chi \& Glaser, 1985). Since most of the ill-structured problems are pseudo problems, the first step in ill-structured problem solving is deciding whether there is a problem (Jonassen, 1997). Next, to understand the problem, solvers should identify what is known and what is unknown. Ill-structured problem solving requires extensive knowledge from memory (Voss \& Post, 1988). After representing the problem, solvers start generating solutions. However, for ill-structured problems there are conflicting assumptions, evidence, and opinions that lead to multiple solutions (Kitchener, 1983). Therefore, solvers should select one among the multiple solutions that they think is suitable to the problem essence and that is reachable based on the problem and its constraints (Sinnott, 1989).

After generating solutions, solvers need to justify them by indicating why they will work, as well as consider the possible difficulties of the proposed solution and how these difficulties may be resolved (Voss \& Post, 1988). Since ill-defined problems do not have a definite single solution and each solution may have some validity and contain some error, solvers should make epistemic assumptions. By assessing the truth-value of possible solutions, solvers develop a strategy to select one solution (Kitchener, 1983).

During solution search and justification, problem solvers continuously engage in monitoring and evaluating activities (Voss \& Post, 1988). These activities assist solvers to control their own processes, apply appropriate strategies, deal with their limitations, and stay on track (Kluwe \& Friedrichsen, 1985). 


\section{Requirements and Challenges of Solving Ill-Structured Problems}

In order to be successful in ill-structured problem solving, learners should have cognitive knowledge, including both domain-specific knowledge (Chi et al., 1981; Voss \& Post, 1988) and structural knowledge (Jonassen et al., 1993). While domain-specific knowledge refers to the knowledge of how much someone knows about a domain, structural knowledge refers to the internal connectedness of concepts within the domain (Jonassen et al., 1993). As Chi and Glaser (1985) noted, domain and structural knowledge facilitate the problem representation and solution process by helping learners to choose the best solution path and guide retrieval of appropriate procedures. However, knowledge structures of novices are different from those of experts in that novices have incomplete and poorly formed structures (Chi et al., 1982; Gick, 1986). Because of their knowledge structures, novice learners do not establish elaborated understanding of concepts and they do not see meaningful patterns like experts do (Chi et al., 1981; 1982; Gick, 1986). They often fail to map their intuitive thinking to scientific constructs and they may misapply prior knowledge while searching their memories for similar problems (Land, 2000).

Ill-structured problem solving also demands metacognitive skills, including planning, monitoring, and evaluating problem-solving processes. The uncertain nature of ill-structured problems requires learners to regulate their cognitive efforts to keep track of the solution process and their effectiveness (Jonassen, 1997; Kluwe \& Friedrichsen, 1985). Studies on the performance of good-poor problem solvers (Dorner et al., 1983), good-poor learners (Thorndyke \& Stasz, 1980), and expert-novices (Simon \& Simon, 
1978) showed the importance of metacognition in that it helps solvers to be more systematic and use executive control strategies, including monitoring, checking, evaluating, and analyzing their own cognitive state and solution by planning carefully. However, novice learners often have difficulties with using these skills and they tend to focus on reaching immediate outcomes without interpreting their actions (Brush \& Saye, 2001; Loh, 2003; Quintana et al., 2004; Reiser, 2004). Therefore, novice learners' lack of metacognitive skills causes them to be unaware of their thinking process and not to reflect on their learning (Davis \& Linn, 2000; Loh et al., 2001).

\section{Scaffolding}

Scaffolding has been used to facilitate learners to cope with the challenges of complex problem solving (Bransford, Brown, Cooking, 2000; Wood et al., 1976). Scaffolds can be defined as temporary supports provided by the teacher or another student to help students bridge the gap between their current abilities and the intended goal (Rosenshine \& Meister, 1992). Vygotsky’s idea of the Zone of Proximal Development (ZPD) provided the foundation for the concept of scaffolding. He proposed that individuals have learning potential that can be reached with the help of experts who are more capable in their zone of proximal development.

Throughout the literature, scaffolding has been provided in different formats, including technology-based scaffolds (Fretz et al., 2001; 2002; Kyza \& Edelson, 2003; Smith \& Reiser, 1998), prompt scaffolds (Davis, 2003; Ge \& Land, 2003; King \& Rosenshine, 1993; Lin \& Lehman, 1999), peer interaction (Greene \& Land, 2000; 
Scardamalia \& Bereiter, 1992; Webb, 1989), and teacher support (Azevedo et al., 2005; Fretz et al., 2001; Palincsar \& Brown, 1984; Tabak, 1999).

One of the most often used instructional scaffolds, prompt scaffolds, was the focus of this study. Throughout the literature prompts have been incorporated into either software programs or written curriculum materials, or provided by peers and teachers. Research on prompts included investigations of questions, hints, examples, reminders, and sentence starters. Prompts have been found to be effective in facilitating illstructured problem-solving processes, including problem representation, developing solutions, making justifications, and monitoring and evaluation (Ge \& Land, 2003). First, prompts can support learners to represent problems by directing their attention to important characteristics, helping them identify relevant information, eliciting explanation, and activating their prior knowledge (King, 1994). Second, prompts can help learners develop solutions by making connections to their existing knowledge, and directing their attention to identifying goals and solution constraints (Ge \& Land, 2003; King \& Rosenshine, 1993). Third, prompts can support learners to develop justification by helping them articulate their ideas (Lee \& Songer, 2004; Lin \& Lehman, 2000). Finally, prompts can support learners as they organize, monitor, and evaluate by making their thinking and learning process explicit (Lin et al., 1999).

Use of prompt scaffolds falls mainly into two categories: domain-general and domain-specific. Domain-general scaffolds support concepts and strategies that can be applied across domains, such as problem-solving skills (McNeill \& Krajcik, 2006). These types of scaffolds can help students understand the strategies that can be used for 
problem solving, such as the importance of finding relevant information to understand a problem, using evidence, and reasoning. Namely, they help students comprehend the general idea of the problem-solving process and support them in planning, monitoring, and evaluating, regardless of the content area. In contrast, domain-specific scaffolds support concepts and strategies that students develop in certain domains (McNeill \& Krajcik, 2006). These types of scaffolds provide hints to novice learners about what specific content knowledge to use during problem solving (Lee \& Songer, 2004).

The following review examines the research findings on the use of domaingeneral and domain-specific prompt scaffolds to cope with the cognitive and metacognitive challenges of problem solving. Table 3.1 shows the examples of domaingeneral and domain-specific prompts in the literature.

\section{Domain-General Prompts}

The literature has illustrated that domain-general prompts have the potential to facilitate knowledge acquisition (Davis, 2003; King, 1994; King \& Rosenshine, 1993), metacognitive thinking and problem solving in various domains (Ge \& Land, 2003; King, 1991; Lin \& Lehman, 1999; White \& Frederiksen, 1998; 2005), and scientific explanation (Land \& Zembal-Saul, 2003). 
Table 3.1 The examples of domain-general and domain-specific prompts

\begin{tabular}{|c|c|c|}
\hline $\begin{array}{l}\text { Attributes of } \\
\text { prompts }\end{array}$ & Studies & Example Prompts \\
\hline \multirow{3}{*}{$\begin{array}{l}\text { - Domain- } \\
\text { general } \\
\text { - Facilitated } \\
\text { knowledge } \\
\text { acquisition }\end{array}$} & $\begin{array}{l}\text { King and } \\
\text { Rosenshine } \\
(1993)\end{array}$ & $\begin{array}{l}\text { "Explain how..."; "Why is ... important"; "How do ... and ... differ"; } \\
\text { "What is a new example of..." }\end{array}$ \\
\hline & $\begin{array}{l}\text { Davis (2003) and } \\
\text { Linn (1997) }\end{array}$ & $\begin{array}{l}\text { "To do a good job on this project; we need to..."; "When we critique } \\
\text { evidence; we need to..."; "Pieces of evidence we didn't understand } \\
\text { very well included..." }\end{array}$ \\
\hline & $\begin{array}{l}\text { King studies } \\
(1991 ; 1992)\end{array}$ & $\begin{array}{l}\text { "What is the problem?"; "What information is given to us?"; "What } \\
\text { we should do next?"; "Are we on the right track?"; "What worked?"; } \\
\text { "What did not work?" }\end{array}$ \\
\hline \multirow{5}{*}{$\begin{array}{l}\text { - Domain- } \\
\text { general } \\
\text { - Facilitated } \\
\text { problem solving }\end{array}$} & $\begin{array}{l}\text { Ge and Land } \\
(2003)\end{array}$ & $\begin{array}{l}\text { "What are the parts of the problem?"; "What information do you need } \\
\text { for this system?"; "Do I have evidence to support my solution?"; "Are } \\
\text { there alternative solutions?" }\end{array}$ \\
\hline & $\begin{array}{l}\text { Lin and Lehman } \\
\text { (1999) }\end{array}$ & $\begin{array}{l}\text { "What is your plan for solving the problem?"; "How are you deciding } \\
\text { what to do next?"; "How did you decide that you have enough data to } \\
\text { make conclusions?" }\end{array}$ \\
\hline & $\begin{array}{l}\text { White and } \\
\text { Frederiksen } \\
(1998 ; 2005)\end{array}$ & $\begin{array}{l}\text { "Being systematic: Students are careful, organized, and logical in } \\
\text { planning and carrying out their work. When problems come up, they } \\
\text { are thoughtful in examining their progress and deciding whether to } \\
\text { alter their approach or strategy."; "Understanding the processes of } \\
\text { inquiry..."; "Using tools of science..."; "Reasoning carefully..." }\end{array}$ \\
\hline & Zydney (2005) & $\begin{array}{l}\text { "What issues is your client trying to solve"; "What are some ideas for } \\
\text { ways the client could solve the problem?"; "What do you need to learn } \\
\text { in order to solve the problem?"; and "What resources do you plan to } \\
\text { consult to fill in your gaps in knowledge?"; "What did you know } \\
\text { already about this problem?"; "How did investigation influence your } \\
\text { ideas about this problem?"; and "What do you need to learn more about } \\
\text { to solve this problem?" }\end{array}$ \\
\hline & $\begin{array}{l}\text { Brush and Saye } \\
(2001)\end{array}$ & $\begin{array}{l}\text { "How close are you to understand the issue so that you can answer the } \\
\text { central questions?"; "What strategies have worked best for you in } \\
\text { gathering information?"; "What strategies have been ineffective?" }\end{array}$ \\
\hline \multirow{2}{*}{$\begin{array}{l}\text { - Domain- } \\
\text { general } \\
\text { - Facilitated } \\
\text { scientific } \\
\text { explanation }\end{array}$} & $\begin{array}{l}\text { Land and } \\
\text { Zembal-Saul } \\
(2003)\end{array}$ & $\begin{array}{l}\text { "Describe your procedure"; "What were the results of the } \\
\text { experiment?"; "What claims can you make about light based on this } \\
\text { experiment?"; "Describe your explanation for what happens to light" } \\
\text { and "Explain how evidence supports your explanation" }\end{array}$ \\
\hline & $\begin{array}{l}\text { McNeill and } \\
\text { Krajcik (2006) }\end{array}$ & $\begin{array}{l}\text { "Provide scientific data to support your claim. You should only use } \\
\text { appropriate data and include enough data." } \\
\text { "Connect your claim and evidence. Tell why your data counts as } \\
\text { evidence using scientific principles." }\end{array}$ \\
\hline \multirow{3}{*}{$\begin{array}{l}\text { - Domain- } \\
\text { specific } \\
\text { - Facilitated } \\
\text { scientific } \\
\text { explanation }\end{array}$} & $\begin{array}{l}\text { Sandoval; 1998; } \\
2003\end{array}$ & $\begin{array}{l}\text { "The factor in the environment exerting a pressure is..."; "This puts } \\
\text { pressure on ... because..."; and "The trait selected by this pressure is } \\
\text {.." }\end{array}$ \\
\hline & $\begin{array}{l}\text { Lee and Songer } \\
(2004)\end{array}$ & $\begin{array}{l}\text { "Are ... and ... the same species?", "I think my invertebrate .... lives } \\
\text { in ... because ....", "How does the mouth shape help the invertebrate } \\
\text { catch food?"; "I think a beetle and an ant can be grouped together } \\
\text { because they have external skeletons and six legs. These data show that } \\
\text { both of them are insects" }\end{array}$ \\
\hline & McNeill & $\begin{array}{l}\text { "Tell why atoms rearranging is related to the mass staying the same or } \\
\text { changing." } \\
\text { "Tell how the type of products formed is related to why the mass } \\
\text { stayed the same or changed." }\end{array}$ \\
\hline
\end{tabular}


First, domain-general prompts have been used to guide novice learners with little knowledge to make connections to their prior knowledge. King and Rosenshine's (1993) study is an example of using prompts to facilitate knowledge construction. In their study, fifth grade students were presented with strategy prompt cards. They found that question prompts promoted learning by eliciting responses such as explanations, inferences, and justifications (King \& Rosenshine, 1993). In a similar study, pairs of fourth and fifth grade students were provided prompts that were intended to access prior knowledge and experience (King, 1994). Analyzing both comprehension tests and knowledge maps, King (1994) found that students who received prompts engaged in complex knowledge construction.

In another example of using prompts to support knowledge integration, Davis's (2003) and Linn's (1997) study provided self-monitoring prompts in a guidance system that is a part of the Knowledge Integration Environment (KIE). These prompts were intended to encourage eighth graders to plan and reflect on the activities and identify the strengths and weaknesses of their work. Their findings showed that students expanded their repertoire of ideas, identified weaknesses in their knowledge, differentiated among ideas, and made connections to their current knowledge. Furthermore, they found that engaging in productive reflection promoted integration of knowledge.

In addition to knowledge integration, domain-general prompts have also been used to facilitate problem-solving processes. For example, Ge and Land (2003) provided question prompts to help students focus on the different aspects of the problem-solving processes, including problem presentation, solution search, making justifications, and 
evaluation. Similarly, in the King studies $(1991 ; 1992)$ questions were categorized into three levels, including planning, monitoring, and evaluating, to help fifth graders articulate the steps and reflect on their process. Both of these studies indicated that question prompts facilitated the problem-solving processes and outcomes by teaching students how to be strategic problem solvers.

In another example, Lin and Lehman (1999) provided explanation and justification prompts in a computer simulation of a biology laboratory activity designed for college students. Qualitative analysis of near-transfer problem-solving tasks showed that question prompts directed students' attention to understand when, why, and how to employ strategies, which helped them plan and monitor their problem solving.

White and Frederiksen (1998; 2005) designed a Thinker Tools Inquiry Curriculum to scaffold students' inquiry process, metacognitive knowledge, and skills. They provided reflective prompts in the Reflective Assessment tool to encourage students to evaluate their work at the end of each inquiry cycle, including question, predict, experiment, model, and apply. Their results showed that reflective prompts decreased the gap between low and high achieving students by helping low achieving students acquire greater understanding of the inquiry performances.

In order to support reflection and articulation of scientific explanation, Land and Zembal-Saul (2003) provided reflective prompts in Progress Portfolio. Their findings indicated that these prompts supported learners to become precise in their explanations, offer justifications, and connect evidence with claims. 
Furthermore, some studies compared the effects of different types of domaingeneral prompts. For example, Davis and Linn (2000) compared self-monitoring prompts, intended to encourage planning and reflection, to activity prompts, intended to facilitate completion of specific aspects of the task. By analyzing the responses to each prompt, they found that activity prompts were helping students finish activities and elicit scientific ideas. However, self-monitoring prompts were more successful in prompting knowledge integration. Moreover, Zydney (2005) found that focusing question prompts were more effective than the reflective question prompts in helping students to understand problems, formulate hypotheses, and ask specific questions.

Despite the advantages of prompts, researchers who used combined scaffolding in their studies found that prompts were not always useful. Students sometimes failed to take advantage of prompts and saw them as a restricting factor in their progress (Ge \& Land, 2003; Greene \& Land, 2000). In one example, Brush and Saye (2001) provided prompts to support problem solving and knowledge integration of eleventh graders in a Decision Point (DP) hypermedia unit. They provided prompts to help students organize their work in an expert way and assist them with monitoring their progress and selfassessment. They found that guiding structures and prompts were not useful. Students did not have enough time to complete them and entered very superficial information. Other studies also showed that using different types of prompts at the same time was not effective. For example, Zydney (2005) developed a multimedia learning environment, Pollution Solution, for eighth graders. Students were provided with focusing question prompts to help them organize their research and reflective question prompts to help 
them with assessing and integrating their learning. Findings of the study indicated that the combination of the prompts was not as effective as individual prompts. Similar to the findings of Brush and Saye (2001), the lack of time to complete both types of domaingeneral prompts might have affected students' performance.

Domain-Specific Prompts

In general, although reflective domain-general prompts have been found to help learners start the knowledge integration process, they were found to be unsuccessful in fostering knowledge integration on their own (Bell \& Davis, 2000). Therefore, literature suggests that domain-specific prompts are required to help students develop warranted explanations that contribute to knowledge integration (Kyza \& Edelson, 2003).

Researchers examined the use of domain-specific prompts to support scientific explanation (Lee \& Songer, 2004; McNeill \& Krajcik, 2006; Sandoval, 2003) and reflection and argumentation (Bell \& Davis, 2000).

First, domain-specific prompts have been used to facilitate students' scientific explanations. For example, Explanation Constructor software in the BGuILE environment provided domain-specific prompts in the form of explanation guides (Sandoval, 1998; 2003). They provided students with hints about what to include in their explanations. Moreover, prompts also provided guidance to students about what a good scientific explanation looks like. The studies using Explanation Constructor found that providing students with prompts grounded within domain-specific knowledge helped them to construct useful explanations (Sandoval, 2003; Zembal-Saul et al., 2002). 
In another study, Lee and Songer (2004) provided prompts to fifth and six graders in the forms of exemplars, questions, and sentence starters to promote explanations during biodiversity curriculum. By analyzing pretest and posttest measures, written explanations, and post interview transcripts, they found that students' knowledge about diversity became stronger, as well as their explanation ability to match given evidence to a claim.

\section{Domain-General vs. Domain-Specific Prompts}

As Perkins and Salomon (1989) suggested, both general and specialized knowledge are needed for effective problem solving and cognitive skills. Students need to have general problem solving and metacognitive skills to be successful problem solvers. They also need to have prior knowledge to use metacognitive strategies effectively since these strategies often depend on prior knowledge (Garner \& Alexander, 1989). Therefore, there is a continuum from general to specific knowledge (Perkins \& Salomon, 1989).

However, in the literature most of the researchers have focused on either domaingeneral or domain-specific prompts, and only a few studies compared them. In one comparative study, McNeill and Krajcik (2006) examined the effects of domain-general and domain-specific prompts on learning and scientific explanation. Their results showed that students in both types of scaffolding conditions showed significant improvement in their explanations over the unit, as well as their claims and their ability to justify their claims with evidence and reasoning. Furthermore, they found that 
domain-specific prompts resulted in greater understanding of chemistry content and scientific explanations than domain-general prompts.

Since it might be difficult to focus on all aspects all of the time in classroom instruction, understanding the relative effects of domain-general and domain-specific prompts is important (Azevedo \& Jacobson, 2008; McNeill \& Krajcik, 2006). More research is needed to examine the relative effects of the two types of prompts, especially for ill-structured problems and middle school students.

Fading Mechanism of Scaffolds

Fading scaffolds by decreasing the levels of support is an important characteristic of scaffolding (Puntambekar \& Hubscher, 2005). Fading supports puts learners in control and allows them to take the responsibility for their own learning. Once learners internalize the external knowledge there is a transfer of responsibility and scaffolding can be removed (Stone, 1998; Wood et al., 1976; Vygotsky, 1978).

The literature presented above mainly used the continuous form of scaffolding. A few studies compared the effect of continuous versus faded levels of support by gradually withdrawing prompts over time. Lee and Songer (2004), for example, found that both the continuous and faded domain-specific groups showed a gain in knowledge about biodiversity. However, their results indicated that the continuous domain-specific support group outperformed the faded domain-specific support group in writing scientific explanations. In another study, McNeill et al. (2006) used a combination of domain-general and domain-specific prompts and then faded the domain-specific prompts over time. Therefore, the continuous group received both domain-general and 
domain-specific prompts throughout the unit; the faded group did not receive the domain-specific prompts later in the unit. Their findings indicated that students who received faded support had greater learning gains for scientific explanation.

Studies comparing the continuous and faded levels of support found contradictive results. One of the reasons for this inconsistency might be the use of different types of prompts in each study: domain-general, domain-specific, or the combination of both. There are still remaining questions about how fading levels of support is effective for different types of scaffolds.

Purpose of the Study

Although it has been presented in the literature that prompts have the potential to facilitate knowledge integration and problem solving in various domains, there is tension between domain-general versus domain-specific, and continuous versus faded scaffolding. Therefore, the purpose of this study was twofold. First, it aimed to examine the relative effects of domain-general or domain-specific scaffolding for supporting students during ill-structured problem solving. Second, it aimed to find if continuous or fading support within domain-general and domain-specific scaffolds better supports students during ill-structured problem solving. The study examined the following questions:

1. What are the effects of domain-general and domain-specific scaffolds with different levels of support (continuous and faded) on students' learning of scientific content? 
2. What are the effects of the domain-general and domain-specific scaffolds with different levels of support (continuous and faded) on students' problem-solving outcomes (problem representation, developing solutions, making justifications, and monitoring and evaluation) in the ill-structured problem-solving tasks in a hypermedia learning environment?

\section{Method}

\section{Participants}

Participants were drawn from 415 sixth grade students at three middle schools in the Southwestern United States. The participants reflected the ethnic makeup of the schools that were 50\% Hispanic, 35\% African American, 14\% White, and 1\% other. A total of 332 students (181 male, 151 female) returned consent forms and agreed to participate in the study. There were nineteenth classes: two of the teachers had six classes, one of the teachers had five classes, and one of the teachers had two classes.

\section{Materials}

The hypermedia program used in this study was Alien Rescue, a problem-based learning environment designed to engage middle school students in solving complex, illstructured problems (Liu, Williams, \& Pedersen, 2002). The primary learning objectives of Alien Rescue focus on our solar system and the tools and procedures that scientists use to study it.

The program begins with a presentation of a complicated problem in which students were asked to participate in problem solving, acting as scientists. The scenario includes a group of six species of aliens, whose planetary system has been destroyed, 
that have arrived in Earth's orbit. Students were asked to work at a newly operational international space station to rescue the alien species by finding them new homes in our solar system that can support their life forms. To accomplish this goal, students learned about the planets and large moons of our solar system.

\section{Scaffolding Treatment Conditions}

\section{Types of Scaffolds}

Based on the previous research on scaffolding problem solving, two types of scaffolds were designed in the study: domain-general and domain-specific. Domaingeneral scaffolds were designed to support the processes of ill-structured problem solving which were defined by Ge and Land (2003) as problem representation (PR), developing solutions (DS), making justifications (MJ), and monitoring and evaluation (ME). Domain-general scaffolds were designed to direct students to each step of the problem-solving process regardless of the content area (McNeill \& Krajcik, 2006). Additionally, domain-specific scaffolds were designed to support students' understanding in the domain. Domain-specific scaffolds were intended to reflect salient features in the content and to help students think what content knowledge to use during problem solving. All treatment materials were reviewed by a middle school science teacher. Examples of domain-general and domain-specific scaffolding treatment materials are provided in Appendix A and Appendix B.

Adapted from Lee and Songer (2004), three kinds of prompts for each scaffolding condition were designed in the form of questions (Q), examples (E), and sentence starters (SS). Examples of the prompts are presented in Table 3.2. 
First, prompts were provided in question format to highlight the problem-solving processes in the domain-general condition and the salient content knowledge related to the problem in the domain-specific condition. Domain-general question prompts were intended to support students in understanding the problem, developing solutions, providing evidence, and evaluating solutions. In contrast, domain-specific question prompts provided content and task specific hints to consider during the problem-solving processes, such as facts about the alien species and characteristics of worlds.

Second, prompts were given in the form of examples. In the domain-general condition, an example of the general problem-solving process was provided in order to present how a problem solver might approach and engage in the ill-structured problemsolving processes. In the domain-specific condition, an example of solving the problem of one alien species, the Eolani, was provided.

Third, prompts were provided in the form of sentence starters. These were similar to the question prompts in that they guided students through the problem-solving processes and provided hints specific to the problem. Unlike the question prompts, sentence starters provided less support and were more reflective. 
Table 3.2 Questions, examples, and sentence starters for the domain-general and the domain-specific conditions

\begin{tabular}{|c|c|c|c|}
\hline Conditions & Questions & Example problem solving & Sentence starters \\
\hline $\begin{array}{l}\text { Domain- } \\
\text { general } \\
\text { conditions }\end{array}$ & $\begin{array}{l}\text { - What information do you need to find in } \\
\text { order to solve this problem? } \\
\text { - How do you plan to solve this problem? } \\
\text { - What is the possible solution to the problem } \\
\text { of the Akona? } \\
\text { - What is your evidence to support your } \\
\text { solution? } \\
\text { - Is your evidence appropriate for the } \\
\text { problem? } \\
\text { - Is your evidence enough to convince } \\
\text { someone of your solution? } \\
\text { - How does your evidence support your } \\
\text { solution? } \\
\text { - What are the benefits and drawbacks of your } \\
\text { solution? } \\
\text { - What other possible solutions can you } \\
\text { suggest? } \\
\text { - Are you using your plan? }\end{array}$ & $\begin{array}{l}\text { - Example problem: "Ashley is asked to } \\
\text { propose a solution on what can be done to } \\
\text { decrease the air pollution in her community" } \\
\text { - Before she can recommend any solutions, } \\
\text { she needs to understand the problem. For } \\
\text { example, she investigated... } \\
\text { - After understanding the problem, Ashley } \\
\text { needs to develop solutions. There may be } \\
\text { multiple solutions. She needs to decide and } \\
\text { select one of them. For example, she found } \\
\text { that... } \\
\text { - Simply listing solutions is not enough. } \\
\text { Ashley should provide relevant evidence to } \\
\text { the problem to support her solution. } \\
\text { - Finally, Ashley should evaluate her solution } \\
\text { and make quality judgments. } \\
\text { - Other possible solution would be... }\end{array}$ & $\begin{array}{l}\text { - To solve this problem, I need to find } \\
\text { - My plan is } \\
\text { - My response to the problem is } \\
\text { - Evidence to support my solution is } \\
\text { - My proposed solution would work } \\
\text { because } \\
\text { - My decision to select the solution is } \\
\text { - Other possible solutions to the problem } \\
\text { are }\end{array}$ \\
\hline $\begin{array}{l}\text { Domain- } \\
\text { specific } \\
\text { conditions }\end{array}$ & $\begin{array}{l}\text { - What does Akona need to survive? Think } \\
\text { about the facts including body, food, habitat, } \\
\text { dwellings, communication, and technology. } \\
\text { - On which world can the Akona survive? } \\
\text { - What are the characteristics of the selected } \\
\text { world that the Akona can live on? Think } \\
\text { about the characteristics including gravity } \\
\text { level, atmospheric and surface features, } \\
\text { seismic activity, magnetic field, } \\
\text { temperature, and chemical composition. } \\
\text { - How are the characteristics of the selected } \\
\text { world useful in finding a new world for the } \\
\text { Akona? } \\
\text { - What are the benefits and drawbacks of the } \\
\text { selected world? } \\
\text { - What are the other worlds that you think the } \\
\text { Akona can survive? }\end{array}$ & $\begin{array}{l}\text { - Relevant needs of the Eolani are... } \\
\text { - The Eolani can live on Ganymede. } \\
\text { - Information about Ganymede ... } \\
\text { - Ganymede can be suitable world for the } \\
\text { Eolani because... } \\
\text { - Drawbacks of Ganymede are... } \\
\text { - The Eolani can also live on Mars because ... }\end{array}$ & $\begin{array}{l}\text { - Needs of the Akona are } \\
\text { - I think the Akona can live on } \\
\text { - Characteristics of the selected world are } \\
\text { - Additional information about my selected } \\
\text { world is } \\
\text { - Characteristics of my selected world will be } \\
\text { useful because } \\
\text { - My decision to select the world as potential } \\
\text { home is } \\
\text { - Alternative worlds where the Akona can } \\
\text { survive are }\end{array}$ \\
\hline
\end{tabular}




\section{Levels of Support in Scaffolds}

Previous studies faded scaffolds by a systematic gradual reduction of support. For example, in the study of Palincsar and Brown (1984), the teacher initially modeled and demonstrated the effective comprehension activities to support seventh-grade poor readers. Then, students took turn to use these strategies. Students had difficulties at the beginning, but guidance and prompts provided by the teacher helped them become more capable of assuming their role and applying the strategies. In another example, Lee and Songer (2004) provided modeled explanations, content prompts, and sentence starters. They withdrawed the modeled explanations first, the direct content prompts second, and sentence starters at last. Having been provided with the example explanations, students became familiar with how to use direct content prompts in their own explanations.

Based on the literature, order of fading three types of prompts has been decided to create continuous and fading support conditions (Lee \& Songer, 2004; Palincsar \& Brown, 1984). As shown in Table 3.3, in the continuous support condition all of the three prompts were provided during all of the four problem-solving activities. However, in the fading support condition prompts were faded gradually over four problem-solving activities: examples were withdrawn after the first activity, both examples and questions were withdrawn after the second activity, and all of the examples, questions and sentence starters were withdrawn after the third problem-solving activity. No scaffolding was provided for the last problem-solving activity. 
Table 3.3 Levels of support over time

\begin{tabular}{lcl}
\hline & Continuous support & \multicolumn{1}{c}{ Faded support } \\
\hline Problem-solving activity 1: The Akona & Q+E+SS & Q+E+SS (Full support) \\
Problem-solving activity 2: The Jakala-Tay & Q+E+SS & Q+SS (Medium support) \\
Problem-solving activity 3: The Kaylid & Q+E+SS & SS (Minimum support) \\
Problem-solving activity 4: The Wroft & Q+E+SS & No scaffold (No support) \\
\hline Note. Q = Questions; E = Examples; SS = Sentence Starters & &
\end{tabular}

\section{Research Design}

A mixed-model design was used to examine the effectiveness of different types of scaffolds with different levels of support. Between-subjects factors included four scaffolding conditions: domain-general continuous (DG-C), domain-general faded (DGF), domain-specific continuous (DS-C), and domain-specific faded (DS-F). Withinsubjects factors involved repeated measures over time. For the effects of scaffolding conditions on learning of scientific content, multivariate analysis of variance (MANOVA) was used. Quantitative data for the learning of content measure was collected before and after the study by using a multiple-choice pretest and posttest. For the effects of scaffolding conditions on problem-solving outcomes, 4 (Condition) $\mathrm{x} 4$ (Time) mixed-model MANCOVA was used. Four problem-solving outcomes (PR, DS, $\mathrm{MJ}$, and ME) were measured at each of the four problem-solving activities over time.

\section{Procedure}

This study was conducted daily during 45-minute period science classes. Students engaged in the program Alien Rescue for thirteen class periods. They also engaged in introduction and data collection for two class periods. 
Before the study, the researcher contacted the teachers and explained the purposes of research, procedure, scaffolding conditions, and the hypermedia-learning environment, Alien Rescue. Two weeks prior to engaging in Alien Rescue students were informed about the study and consent forms were handed out. Ten days prior to assigning the conditions students took a multiple-choice pretest. Next, the classes of each teacher were randomly assigned to one of the four scaffolding conditions in such a way that each teacher taught all four conditions: DG-C $(n=84)$, DG-F $(n=69)$, DS-C $(n=103)$, and DS-F $(n=76)$. However, only one teacher, who had two classes, taught the domain-general continuous and the domain-specific continuous conditions. Each class received different worksheets throughout four problem-solving activities, depending on the condition they had been assigned. Participant teachers were instructed to avoid providing different information than what was in the worksheets. The researcher participated as an observer in the classroom in order to check if teachers were using the worksheets properly. Teachers confirmed not to give additional support and observation of the classroom indicated that they used the worksheets appropriately.

On the first day of the study, students watched the opening scenario and became familiar with the learning environment. On the second day, they were informed that they needed to engage in problem-solving activities for each of the four species in order: the Akona, the Jakala-Tay, the Kaylid, and the Wroft. Next, teachers passed out the worksheets for the first problem-solving activity, the Akona. Students spent two days working on the first activity by using the software Alien Rescue and the worksheets. Students were reminded throughout the activity that they should use the worksheets as a 
guide by reading the example, answering the questions, and completing the sentence starters. At the end of the two-day problem-solving activity, students gave the worksheets to the teacher. On the next day, students were provided with forms to write their recommendations for the problem solution for the first alien, the Akona. Next day, students started working on the second problem-solving activity. Teachers followed the same procedure for the rest of the activities as the first one. Overall, students spent two days working on the problem of each species, and one day writing their recommendations for the problem solution. At the end of the study, students took a multiple-choice posttest identical to the pretest.

\section{Data Sources and Measurement}

\section{Multiple-Choice Pretest and Posttest}

A pretest and posttest with 20 multiple-choice items served as a measure of students' learning of scientific content. The items were chosen from the Holt Science and Technology Assessment Item Listing (1998), released TASS and TAKS items, and the factual knowledge test in the Teacher's Manual of Alien Rescue (Pedersen, 2000). The multiple-choice test items covered three key content learning goals in the hypermedia problem-based learning environment: components of the solar system, characteristics of worlds that define them, and instruments that scientists use. Multiple-

choice responses for each test were scored, with a maximum possible score of 20 . Since identical pretest and posttests were given one-month apart, the possibility of pretest effect was weak. Moreover, since all students received the same pretest, any possible effect should have been distributed evenly across the conditions that should not effect 
the variance between groups. Reliability analysis showed that Cronbach's alpha was 0.743. The multiple-choice test is included in Appendix C.

\section{Recommendation Forms}

Students completed four recommendation forms (see Appendix D), one for each species, and these were used in order to assess their problem-solving outcomes. A rubric system developed by Ge and Land (2003) had been modified and used to score students' recommendation forms. The rubric was based on research of ill-structured problem solving (Chi \& Glaser, 1985; Jonassen, 1997; Kitchener, 1983; Sinnott, 1989; Voss, 1988; Voss \& Post, 1988) and developed rubrics (Blum \& Arter, 1996; Hong, 1998). In the rubric system Ge and Land (2003) identified four constructs as important indicators for measuring ill-structured problem-solving outcomes: (a) problem representation, (b) developing solutions, (c) making justifications for generating and selecting solution, and (d) monitoring and evaluating the solutions. These constructs, which correspond to the dependent variables of this study, could be found in the recommendation forms where students were required to write their solution, provide rationale by explaining benefits and drawbacks for choosing one world over the other worlds. By using the rubric students' recommendation forms for each of the four problem-solving activities were scored for problem representation, developing solutions, making justifications, and monitoring and evaluation. The scoring rubric is provided in Appendix E. Table 3.4 presents the examples of scoring problem-solving outcomes in students' recommendation forms. 
Table 3.4 Scoring problem-solving outcomes in students' recommendation forms

\begin{tabular}{|c|c|c|c|c|}
\hline & Construct & Range of scores/Descriptions & Examples & Score \\
\hline Rep & senting the problem/ & 0-7 points with one point assigned for each need of the species. & "Akona does not like water." & 1 \\
\hline $\begin{array}{l}\text { Iden } \\
\text { info }\end{array}$ & $\begin{array}{l}\text { ifying relevant } \\
\text { nation }\end{array}$ & & $\begin{array}{l}\text { "If Jakala-Tay breaths hydrogen, they die. They also need sulfur } \\
\text { in the atmosphere." }\end{array}$ & 2 \\
\hline & & & $\begin{array}{l}\text { "I discovered that the Akona can't live in a planet that has } \\
\text { earthquakes. They have to live in a cold place. They also cannot } \\
\text { be near any water, because if they are they can die" }\end{array}$ & 3 \\
\hline & & 2: Best world is recommended. & "I should send the Akona to Charon." & 2 \\
\hline$\stackrel{\tilde{0}}{\Omega}$ & Selecting solution & 1: Acceptable world is recommended. & "My decision was to send the Akona to Pluto." & 1 \\
\hline 苛 & & $\begin{array}{l}\text { ones is recommended. } \\
\end{array}$ & "I will send Akona to Venus." & 0 \\
\hline$\stackrel{\infty}{\Xi}$ & & $0-5$ points with one point assigned for each supporting data about & "Io has nitrogen and sulfur, and it does not have hydrogen." & 3 \\
\hline$\tilde{0}$ & Providing & & "Triton is cold and it has no water." & 2 \\
\hline$\sum_{0}^{\infty}$ & $\begin{array}{l}\text { Supporting data for } \\
\text { the solution }\end{array}$ & & "Charon has no atmosphere." & 1 \\
\hline & & & "Mars has right atmosphere." & 0 \\
\hline$\tilde{0}$ & Constructing & $\begin{array}{l}\text { 4: Argument is well constructed. } \\
\text { 2: Argument is poorly constructed. } \\
0 \text { : No argument is constructed. }\end{array}$ & $\begin{array}{l}\text { "Average temperature on Charon is } 37 \mathrm{~K} \text { that is good for the } \\
\text { Akona because they love the cold. It does not have water; this is } \\
\text { good because they are allergic to it. It also has carbon and } \\
\text { nitrogen, and Akona needs these minerals." }\end{array}$ & 4 \\
\hline 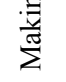 & & $\begin{array}{l}\text { 3: Evidence to support the argument is strong and relevant. } \\
\text { 2: Evidence to support the argument is relevant. }\end{array}$ & $\begin{array}{l}\text { "The temperature in Pluto is } 37 \mathrm{~K} \text {. Seismic activity level in Charon } \\
\text { is level } 1 \text {. Atmospheric pressure in Pluto is .01" }\end{array}$ & 3 \\
\hline & Providing evidence & 1: Evidence to support the argument is weak or irrelevant. & "The temperature in Pluto is cold. Atmospheric pressure is low." & 2 \\
\hline & & 0 : No any evidence is provided & "Charon has the right minerals for Akona." & 1 \\
\hline.$\tilde{\Xi}$ & & $\begin{array}{l}\text { 3: The recommended world is evaluated, and drawbacks are } \\
\text { discussed, supported with reasoning. }\end{array}$ & $\begin{array}{l}\text { "One of the main drawbacks of Pluto is there is little earthquake } \\
\text { activity, and Akona does not live on earthquakes" }\end{array}$ & 3 \\
\hline 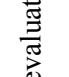 & $\begin{array}{l}\text { Evaluation of } \\
\text { solution(s) }\end{array}$ & $\begin{array}{l}\text { 2: The recommended world is evaluated, and drawbacks are } \\
\text { mentioned, but no reasons are provided. }\end{array}$ & "Drawback of the Mars is that it has seismic activity at level 3." & 2 \\
\hline 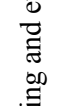 & & $\begin{array}{l}\text { 1: Evaluation of the world is stated, but no reasoning is provided, } \\
\text { and no potential drawbacks are mentioned. } \\
0 \text { : The world is not evaluated. }\end{array}$ & "Benefit of sending Akona to Mars is that it has right minerals." & 1 \\
\hline : & Assessing & $\begin{array}{l}\text { 4: Alternative world(s) are stated and discussed, supported with } \\
\text { reasoning. }\end{array}$ & $\begin{array}{l}\text { "Another place I would send Akona is Titan because there is no } \\
\text { earthquake and it is cold." }\end{array}$ & 4 \\
\hline$\stackrel{0}{\Sigma}$ & $\begin{array}{l}\text { alternative } \\
\text { solutions }\end{array}$ & $\begin{array}{l}\text { 2: Alternative world(s) are stated but no reasons are provided. } \\
0 \text { : Alternative world(s) are not mentioned at all. }\end{array}$ & "Other planets get to much Sun." & 2 \\
\hline
\end{tabular}


The first construct in the rubric, representing the problem, was intended to measure the identification of relevant information about each alien species. Students were scored one point for each need they stated. The second construct, developing solutions, was evaluated by two attributes, including selecting a solution and providing supporting data. Students received two points if they recommended the best world, one point if they recommended an acceptable world, and zero points for any other choices. Moreover, students received one point for each supporting detail that they stated, to a maximum of five points. The third construct, making justifications, was subdivided into two attributes: constructing an argument and providing evidence. Students received scores based on the quality of their arguments for the proposed solution and the quality of evidence about the selected world. The last construct, monitoring and evaluation, included two attributes, including evaluation of solutions and assessing alternative solutions. Students received scores based on the statements they made about the effectiveness or benefits of the selected world, and the potential pros and cons, and how they supported these claims with relevant evidence. Moreover, students were scored for assessing alternative solutions.

Recommendation forms were graded by two raters, including the researcher. The raters were blind to student names and the scaffolding conditions associated with each recommendation form. Before grading, the researcher explained each construct in the rubric to the independent rater. Then, the researcher and the rater reached a consensus on the rubric by scoring twenty of the recommendation forms together. Then, both raters scored the remaining recommendation forms independently using the rubric. Next, two 
raters discussed any discrepancies of the assigned values until they reach a consensus. For the first two constructs, there were not many differences between the scores of the two raters; this was because scoring was simply counting the number of needs of the aliens that were stated, scoring the world that they chose, and counting the supporting details about the world that they chose. Constructing argument was the hardest one to score since it was more subjective than the others.

\section{Data Analysis}

In order to address the first research question about the effects of the types of scaffolds with different levels of support on students' learning of scientific content, multivariate analysis of variance (MANOVA) was conducted. Students' pretest and posttest scores were treated as dependent variables. Two hundred and sixty seven students who completed both the pretest and the posttest were included in the analysis.

In order to address the second research question about the effects of types of scaffolds with different levels of support on students' problem-solving outcomes over time, a repeated measure multivariate analysis of variance (also known as doubly multivariate repeated measures) was conducted. Doubly multivariate analyses are appropriate when the same subjects are measured on several variables at each point in time (Stevens, 2002). In this study, students were measured on four dependent variables including problem representation, developing solutions, making justifications, and monitoring and evaluation for each of the four problem-solving activities in time. Students' pretest scores were used as the covariate. Two hundred and eight students completed all of the four problem-solving activities and were included in the analysis. 
Initial statistical analyses were conducted to examine the statistical assumptions of MANOVA. The results of the Box's M Test showed that the covariance matrices of the dependent measures were similar across scaffolding conditions at the .05 alpha level. Levene's test results also indicated that homogeneity of variance of dependent variables assumption was met at the .05 alpha level. Initial analysis also showed that pretest scores were appropriate covariance because there was a significant correlation between the dependent variables and the covariate. Moreover, interaction between the covariate and the scaffolding conditions was not significant, so assumption of homogeneity of the regression hyperplanes was also met. Wilks's Lambda $F(\alpha=.05)$ was used in interpreting multivariate test results.

\section{Results}

\section{Learning of Scientific Content}

Table 3.5 summarizes the descriptive statistics for the learning of scientific content in four scaffolding conditions. The MANOVA results revealed that there were no statistically significant differences on the pretest scores, $F(3,263)=.28, p>.84$, partial $\eta^{2}=.00$, observed power .10 . However, students' posttest scores were statistically significant, $F(3,263)=12.95, p<.00$, partial $\eta^{2}=.13$, observed power 1.00. This result suggests that differences in the mean across time depended on the scaffolding conditions. Planned comparison contrast results showed that both domainspecific conditions led to a greater improvement in students' learning of scientific content, from pretest to posttest, than both domain-general conditions. Moreover, results indicated that there was no statistically significant difference between the continuous and 
faded domain-general conditions. However, students in the continuous domain-specific condition outperformed those in the faded domain-specific condition.

Table 3.5 Descriptive statistics for the learning of scientific content in four scaffolding conditions

\begin{tabular}{lccccccccc}
\hline & \multicolumn{3}{c}{ Continuous } & \multicolumn{3}{c}{ Faded } & & \multicolumn{3}{c}{ Total } \\
& $M$ & $S D$ & $n$ & $M$ & $S D$ & $n$ & $M$ & $S D$ & $n$ \\
\hline Pretest & & & & & & & & & \\
Domain-general & 5.68 & 2.42 & 70 & 5.35 & 2.42 & 57 & 5.53 & 2.42 & 127 \\
Domain-specific & 5.65 & 2.76 & 74 & 5.42 & 2.44 & 66 & 5.54 & 2.60 & 140 \\
$\quad$ Total & 5.66 & 2.59 & 144 & 5.39 & 2.42 & 123 & 5.53 & 2.51 & 267 \\
Posttest & & & & & & & & & \\
Domain-general & 8.97 & 2.99 & 70 & 8.56 & 3.73 & 57 & 8.78 & 3.33 & 127 \\
Domain-specific & 11.95 & 3.72 & 74 & 9.24 & 3.84 & 66 & 10.67 & 3.99 & 140 \\
Total & 10.50 & 3.68 & 144 & 8.92 & 3.78 & 123 & 9.77 & 3.80 & 267 \\
\hline
\end{tabular}

\section{Problem-Solving Outcomes}

A doubly multivariate analysis was conducted to examine the effects of the types of scaffolds with different levels of support on students' problem-solving outcomes.

Table 3.6 summarizes the descriptive statistics of the average scores for four problemsolving outcomes of four scaffolding conditions. Table 3.7 also showed the descriptive statistics for four problem-solving outcomes over time. 
Table 3.6 Descriptive statistics of the average scores for four problem-solving outcomes in four scaffolding conditions

\begin{tabular}{lccccccccc}
\hline & \multicolumn{3}{c}{ Continuous } & \multicolumn{3}{c}{ Faded } & & \multicolumn{3}{c}{ Total } \\
& $M$ & $S D$ & $n$ & $M$ & $S D$ & $n$ & $M$ & $S D$ & $n$ \\
\hline Problem representation & & & & & & & & & \\
Domain-general & 2.38 & 0.68 & 52 & 2.32 & 0.63 & 51 & 2.35 & 0.65 & 103 \\
Domain-specific & 2.96 & 0.72 & 53 & 2.82 & 0.77 & 52 & 2.89 & 0.74 & 105 \\
Total & 2.67 & 0.75 & 105 & 2.58 & 0.74 & 103 & 2.63 & 0.75 & 208 \\
\hline Developing solutions & & & & & & & & & \\
Domain-general & 2.68 & 0.83 & 52 & 2.50 & 0.68 & 51 & 2.59 & 0.76 & 103 \\
Domain-specific & 2.85 & 0.99 & 53 & 2.15 & 0.95 & 52 & 2.50 & 1.03 & 105 \\
Total & 2.76 & 0.92 & 105 & 2.33 & 0.84 & 103 & 2.55 & 0.90 & 208 \\
\hline Making justifications & & & & & & & & & \\
Domain-general & 4.40 & 0.84 & 52 & 4.07 & 0.75 & 51 & 4.24 & 0.81 & 103 \\
Domain-specific & 4.37 & 1.01 & 53 & 3.72 & 0.89 & 52 & 4.05 & 1.00 & 105 \\
Total & 4.38 & 0.93 & 105 & 3.90 & 0.84 & 103 & 4.14 & 0.92 & 208 \\
\hline Monitoring and evaluation & & & & & & & & & \\
Domain-general & 2.49 & 0.86 & 52 & 2.58 & 0.90 & 51 & 2.53 & 0.87 & 103 \\
Domain-specific & 1.12 & 0.73 & 53 & 0.99 & 0.64 & 52 & 1.05 & 0.69 & 105 \\
Total & 1.80 & 1.05 & 105 & 1.78 & 1.12 & 103 & 1.79 & 1.08 & 208 \\
\hline
\end{tabular}


Table 3.7 Descriptive statistics for four problem-solving outcomes over time

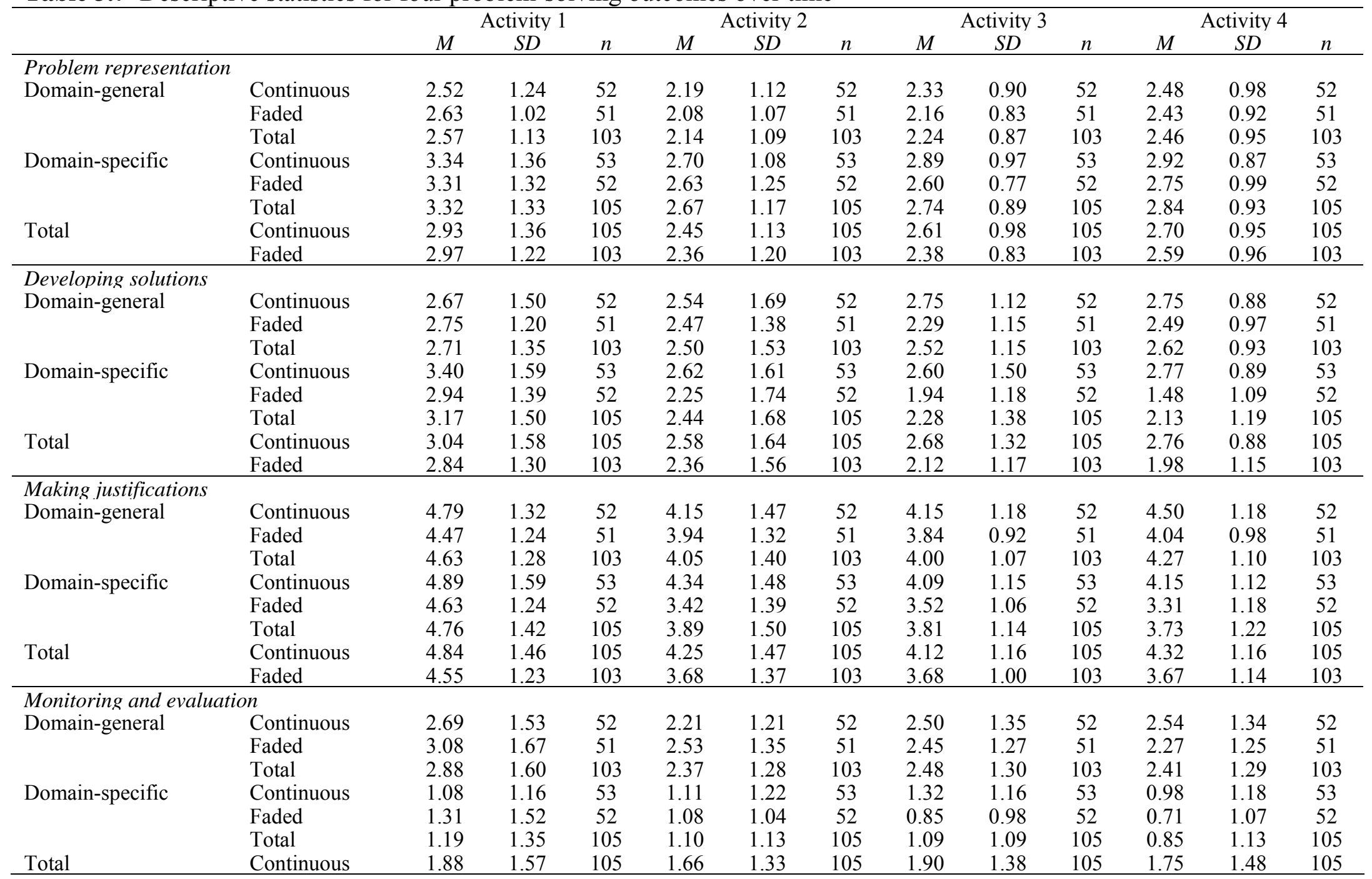




\section{Between-Subjects Analysis}

The results of the multivariate analysis revealed a significant main effect for condition, $F(12,529)=22.59, p<.00$, partial $\eta^{2}=.31$, observed power 1.00 . This result indicates that the scaffolding conditions differ on the set of the four dependent variables. Furthermore, a univariate analysis of between-subjects effects (See Table 3.8) showed statistically significant effects for all problem-solving outcomes, problem representation, developing solutions, making justifications, and monitoring and evaluation. Follow-up pairwise comparisons were conducted to see the differences between scaffolding conditions. The results indicated that students in both domain-specific conditions outperformed those in both domain-general conditions in problem representation. However, students in both domain-general conditions outperformed those in both domain-specific conditions in monitoring and evaluation. The partial eta square statistics indicated that while $14 \%$ of the variability was accounted for problem representation, $49 \%$ of the variability was accounted for monitoring and evaluation. Moreover, while the results did not indicate statistically significant differences between the continuous and faded domain-general conditions, it showed that students in the continuous domainspecific condition significantly outperformed those in the faded domain-specific condition in both developing solutions and making justifications. The partial eta square statistics indicated that $7 \%$ and $8 \%$ of the variability were accounted for developing solutions and making justifications, respectively. 
Table 3.8 Analysis of between-subjects effects

\begin{tabular}{lcccc}
\hline Source & $d f$ & $F$ & Partial $\eta^{2}$ & $p$ \\
\hline PR & 3 & $11.05^{* * *}$ & .14 & .00 \\
DS & 3 & $5.05 * *$ & .07 & .00 \\
MJ & 3 & $5.78^{* * *}$ & .08 & .00 \\
ME & 3 & $65.60 * * *$ & .49 & .00 \\
\hline Note. PR = Problem representation; DS = Developing solutions; MJ = Making justifications; ME = Monitoring and evaluation. \\
$* * p<.01 .{ }^{* * *} p .001$.
\end{tabular}

Within-Subjects Analysis

Although results of the multivariate analysis did not reveal statistically significant multivariate main effects of time, $F(12,192)=1.09, p>.38$, partial $\eta^{2}=.06$, interaction effects of condition $\mathrm{x}$ time were significant, $F(36,568)=2.14, p<.00$, partial $\eta^{2}=.18$. Analysis of univariate test results (Table 3.9) showed that interaction effects of condition $\mathrm{x}$ time were not statistically significant for problem representation and monitoring and evaluation. However, statistically significant interaction effects of condition $\mathrm{x}$ time were found for developing solutions and making justifications.

Table 3.9 Analysis of univariate test results

\begin{tabular}{lcccc}
\hline Source & $d f$ & $F$ & Partial $\eta^{2}$ & $p$ \\
\hline PR & 9 & 0.91 & .01 & .51 \\
DS & 9 & $3.93 * * *$ & .06 & .00 \\
MJ & 9 & $2.29 *$ & .02 & .03 \\
ME & 9 & 1.89 & .03 & .05 \\
\hline Note. PR = Problem representation; DS = Developing solutions; MJ = Making justifications; ME = Monitoring and evaluation. \\
${ }^{*} p<.05 . * * *<.001$.
\end{tabular}


The results indicated that developing solution and making justification scores of students were changing in different ways over time. Table 3.10 presents the results of the withinsubjects contrast for developing solutions and making justifications. Fig. 3.1, 3.2, 3.3, and 3.4 present the profile plots of four scaffolding conditions on four problem-solving outcomes.

For developing solutions scores, results of the within-subjects contrasts showed that there was not a particularly significant trend in both domain-general conditions over time. However, results indicated a significant linear and quadratic trend in the continuous domain-specific condition. The linear trend indicated that developing solutions scores of students decreased over time, but the quadratic trend indicated that the decrease leveled off at the last problem-solving activity. However, a significant linear trend in the faded domain-specific condition indicated that scores decreased linearly over time.

For students' making justification scores, results of the within-subjects contrasts showed a significant quadratic trend for both domain-general conditions. However, results indicated a significant linear trend and a small but significant quadratic trend in the continuous domain-specific condition. However, in the faded domain-specific conditions, significant linear, quadratic, and cubic trends were found over time. As seen in the profile plots, although justification scores of students in both domain-general conditions decreased at the second problem-solving activity, the quadratic trend indicated that there was an increase later. However, the linear trend in both domainspecific conditions indicated that the scores of students decreased over time. While the 
quadratic trend in the continuous domain-specific conditions indicated that the decrease leveled off, the quadratic trend in the faded domain-specific conditions indicated that scores continued to decrease.

Table 3.10 Analysis of within-subjects contrast

\begin{tabular}{|c|c|c|c|c|c|}
\hline \multicolumn{2}{|c|}{ Measure } & $d f$ & $F$ & Partial $\eta^{2}$ & $p$ \\
\hline \multicolumn{6}{|c|}{ Domain-general continuous } \\
\hline \multirow[t]{3}{*}{ DS } & Linear & 1 & 0.36 & 0.01 & 0.55 \\
\hline & Quadratic & 1 & 0.16 & 0.00 & 0.69 \\
\hline & Cubic & 1 & 0.55 & 0.01 & 0.46 \\
\hline \multirow[t]{3}{*}{ MJ } & Linear & 1 & 1.48 & 0.03 & 0.23 \\
\hline & Quadratic & 1 & $9.14 * *$ & 0.15 & 0.00 \\
\hline & Cubic & 1 & 0.19 & 0.00 & 0.67 \\
\hline \multicolumn{6}{|c|}{ Domain-general faded } \\
\hline \multirow[t]{3}{*}{ DS } & Linear & 1 & 2.08 & 0.04 & 0.16 \\
\hline & Quadratic & 1 & 2.15 & 0.04 & 0.15 \\
\hline & Cubic & 1 & 0.14 & 0.00 & 0.71 \\
\hline \multirow[t]{3}{*}{ MJ } & Linear & 1 & 5.12 & 0.09 & 0.03 \\
\hline & Quadratic & 1 & $7.89 * *$ & 0.14 & 0.01 \\
\hline & Cubic & 1 & 0.05 & 0.00 & 0.83 \\
\hline \multicolumn{6}{|c|}{ Domain-specific continuous } \\
\hline \multirow[t]{3}{*}{ DS } & Linear & 1 & $6.20 * *$ & 0.11 & 0.02 \\
\hline & Quadratic & 1 & $10.36^{* *}$ & 0.17 & 0.00 \\
\hline & Cubic & 1 & 0.56 & 0.01 & 0.46 \\
\hline \multirow[t]{3}{*}{ MJ } & Linear & 1 & $16.33 * * *$ & 0.24 & 0.00 \\
\hline & Quadratic & 1 & $4.43 *$ & 0.08 & 0.04 \\
\hline & Cubic & 1 & 0.00 & 0.00 & 1.00 \\
\hline \multicolumn{6}{|c|}{ Domain- specific faded } \\
\hline \multirow[t]{3}{*}{$\mathrm{DS}$} & Linear & 1 & $43.54 * * *$ & 0.46 & 0.00 \\
\hline & Quadratic & 1 & 0.52 & 0.01 & 0.47 \\
\hline & Cubic & 1 & 0.57 & 0.01 & 0.45 \\
\hline \multirow[t]{3}{*}{ MJ } & Linear & 1 & $33.20 * * *$ & 0.39 & 0.00 \\
\hline & Quadratic & 1 & $13.67 * * *$ & 0.21 & 0.00 \\
\hline & Cubic & 1 & $0.97 * *$ & 0.16 & 0.00 \\
\hline
\end{tabular}

Note. DS $=$ Developing solutions; $\mathrm{MJ}=$ Making justifications.

${ }^{*} p<.05 .{ }^{* *} p<.01 .{ }^{* * *} p<.001$. 


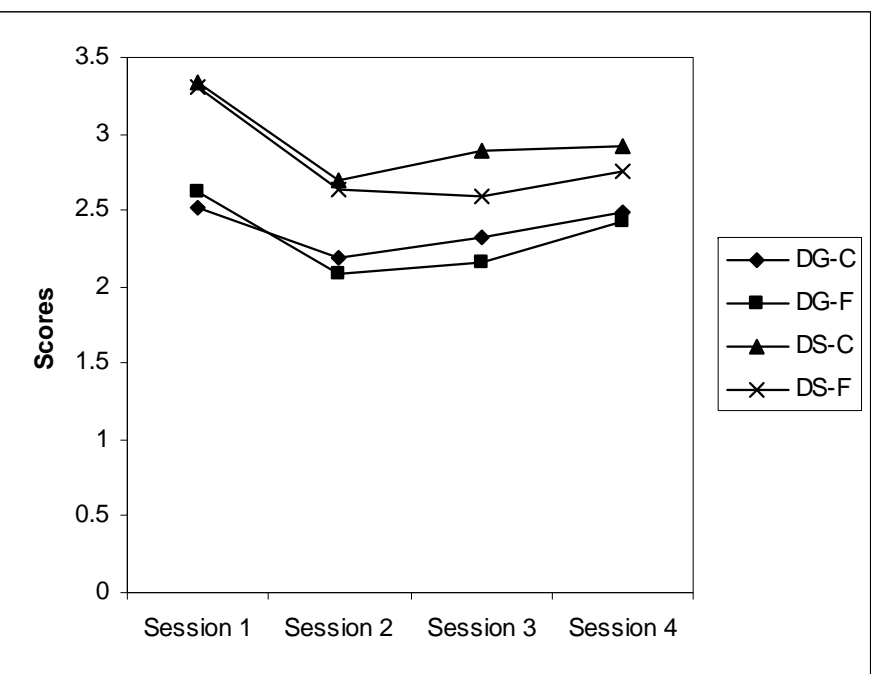

Fig. 3.1 Profile plots of four scaffolding conditions on problem representation

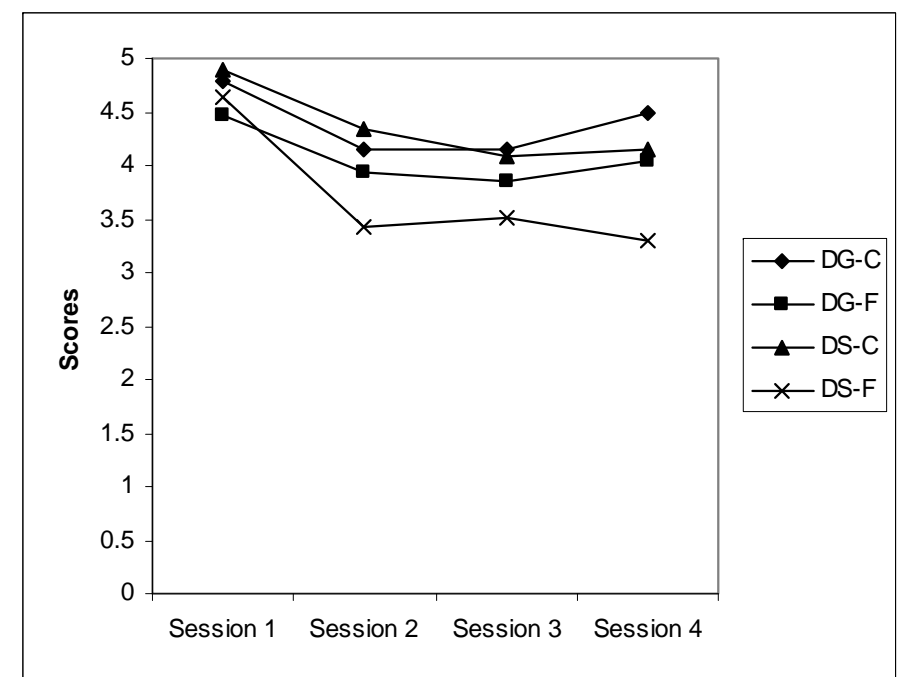

Fig. 3.2 Profile plots of four scaffolding conditions on making justifications 


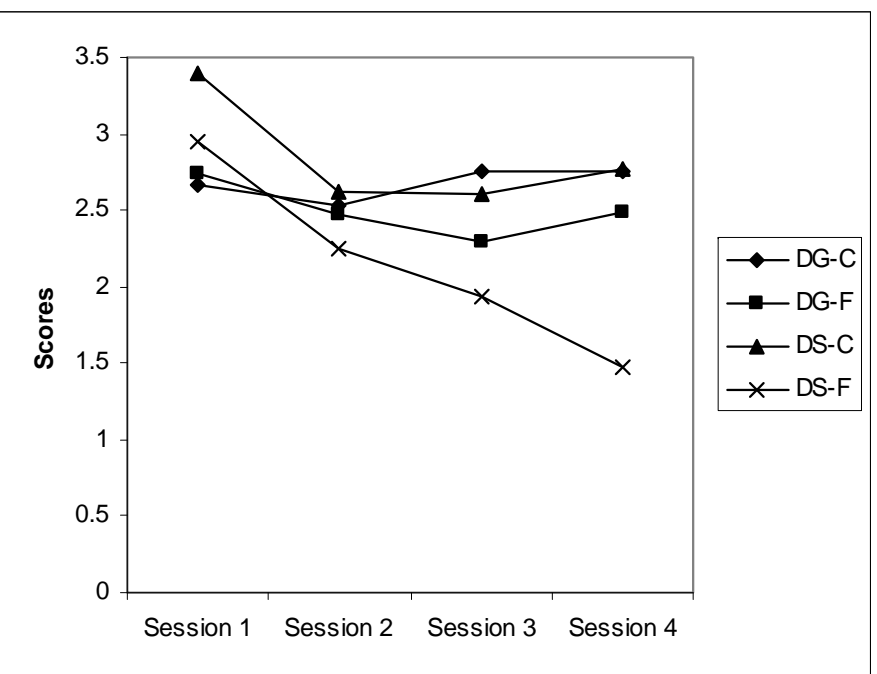

Fig. 3.3 Profile plots of four scaffolding conditions on developing solutions

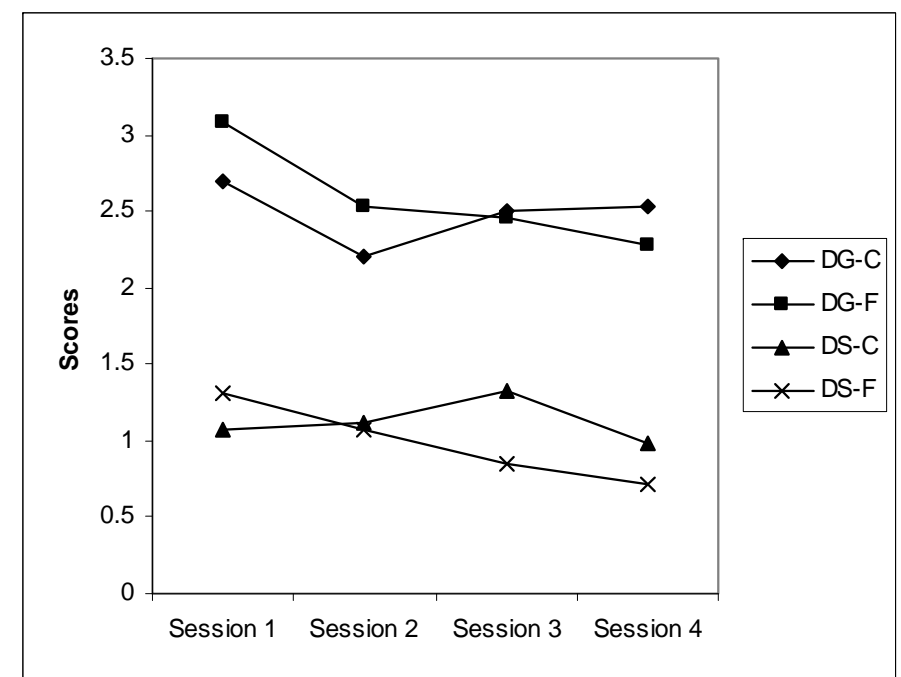

Fig. 3.4 Profile plots of four scaffolding conditions on monitoring and evaluation 
Discussion

Effects of the Types of Scaffolds

Overall findings of this study illustrated that students' content knowledge significantly increased across all conditions. Despite the overall learning gain, the results suggested that domain-specific scaffolds could better assist students in learning and integrating knowledge compared to domain-general scaffolds. This result was supported by the research of McNeill and Krajcik (2006), which indicated that domain-specific scaffolds resulted in greater understanding of content than domain-general scaffolds. This finding was also supported by other studies of Bell and Davis (2000) and Kyza and Edelson (2003), which indicated that domain-general scaffolds can start the knowledge integration process, yet they are unsuccessful in fostering knowledge integration on their own.

With regard to overall problem-solving outcomes, the results of this study illustrated that while domain-general scaffolds facilitated monitoring and evaluation more than domain-specific scaffolds, domain-specific scaffolds facilitated problem representation more than domain-general scaffolds. However, in spite of the differences of representation and monitoring scores, the results showed that students in the domaingeneral conditions developed solutions and made justifications as well as the ones in the continuous domain-specific condition.

Even though domain-general conditions did represent fewer needs of the aliens than domain-specific conditions, students were able to find evidence and make reasonable justifications to their solutions. One reason explaining why the domain- 
general scaffolds helped students develop solutions and make justifications could be that they supported students' self-checking, monitoring, and evaluation skills over time. These scaffolds directed students' attention mostly to problem solving. Even tough students in both domain-general and domain-specific conditions were asked to include evaluation of their solution and assessing alternative ones into their recommendation forms, high effect size for monitoring and evaluation indicated that students in the domain-general conditions engaged in monitoring and evaluating solutions throughout the process. These results were supported by the research of Ge and Land (2003) and White and Frederiksen (1998, 2005), which indicated that domain-general scaffolds can support explanation and justification skills by supporting planning, monitoring, and evaluating the problem space. As King $(1991,1992)$ studies indicated, these scaffolds facilitated the metacognitive knowledge and skills of students and helped them to be strategic problem solvers. Moreover, as in line with the literature, findings suggested that domain-general scaffolds helped students to be precise in their explanation and develop stronger arguments by connecting evidence with claims (Land \& Zembal-Saul, 2003; Lin \& Lehman, 1999).

Results indicated that domain-specific prompts also directed students' attention to problem solving as well as content, which helped them in developing solutions and justifying them. However, although domain-specific conditions represented more needs of the aliens, students in that condition could not find stronger evidence and make stronger arguments than the domain-general conditions. In their study, McNeill and Krajcik (2006) found that domain-specific scaffolds resulted in greater learning of 
scientific explanation than domain-general scaffolds, but only for teachers who provided general metacognitive support in addition to the domain-specific condition. Therefore, as in line with the literature, findings suggested that metacognitive support is important to scaffold ill-structured problem solving. Even when tough domain-specific scaffolds support knowledge integration and learning, metacognitive support is important to facilitate explanation, justification, and monitoring during ill-structured problem solving. Findings also suggested that metacognitive support could sometimes compensate for domain-specific support (Chi et al., 1982; Garner \& Alexander, 1989; Gick, 1986; Hong, 1998).

\section{Effects of the Levels of Support in Scaffolds}

Although different levels of support in domain-general scaffolds did not make significant differences in the learning of scientific content, the continuous domainspecific scaffolds assisted students better than the faded domain-specific scaffolds. This finding contradicted Lee and Songer's (2004) study, in which they did not find any significant differences between the continuous and the faded domain-specific conditions. However, their results showed that students in a continuous condition had more learning gain scores than those students in a faded condition.

In terms of the change of problem-solving outcomes over time, the results of the study did not indicate significant differences between the continuous and faded supports within the domain-general scaffolds. Both conditions' scores changed in the same way over time. Namely, even though domain-general scaffolds were faded over time, they were as effective as the continuous ones in facilitating the four problem-solving 
outcomes. This finding suggested that students who were provided with the faded scaffolds could be able to transfer their problem-solving skills over time.

Moreover, the results of the study did not show significant differences between the continuous and faded supports within the domain-specific scaffolds for problem representation and monitoring and evaluation. However, students who were provided with continuous domain-specific scaffolds significantly outperformed those who were provided with faded domain-specific scaffolds in developing solutions and making justifications. Although students' scores in the continuous condition decreased at first, it leveled off. However, students' scores in the faded condition decreased linearly over time. Therefore, findings of the study suggested that while the domain-general scaffolds were effective even when they were faded; the faded domain-specific scaffolds were not as effective as the continuous ones.

The result was consistent with the findings of Lee and Songer (2004), that the continuous domain-specific conditions supported greater learning of scientific explanation and justification than the faded domain-specific conditions. In contrast, McNeill et al. (2006) suggested that faded scaffolds support students better in learning of the explanation than continuous scaffolds. However, their fading mechanism was different from Lee and Songer's (2004) and the current study. McNeill et al. (2006) first provided domain-general and domain-specific scaffolds, and then faded the domainspecific ones.

These results supported the idea that the term scaffold may not be suitable for domain-specific scaffolds (McNeill, 2006). While the scaffold was defined as a 
temporary support, a cognitive tool was defined as a support that should continue in the learning process (McNeill, 2006; Salomon, Perkins, \& Globerson, 1991). Levels of support within domain-general scaffolds facilitated the problem-solving process in the same way over time. However, continuous and faded levels of support within domainspecific scaffolds played different roles in each problem-solving activity. It seemed likely that students depended on the domain-specific scaffolds continuously, which resulted in having difficulties applying their knowledge to develop solutions and make justifications when the scaffold was no longer there. Even though students in faded conditions outperformed in problem representation; they could not apply them and form strong arguments and evidence independently without the domain-specific scaffolds. Therefore, removing the scaffolds might have made them more frustrated.

\section{Conclusion}

Findings of this study can inform the design of scaffolds in order to facilitate complex problem solving in hypermedia learning environments. Instructional designers and teachers should be careful when choosing different types of supports in complex problem-solving environments. Metacognitive support is important, therefore, scaffolds should help students comprehend general problem-solving processes and support them in planning, monitoring, and evaluating. However, this study is limited to the nature of the problem-solving task. Although results suggested the importance of more general support, domain-specific scaffolds would better support problem-solving processes in well-structured problem solving. Therefore, further studies can examine how different types of scaffolds can support different types of problems, well- or ill-structured. The 
findings of the study also suggested that levels of supports within domain-general and domain-specific are not equally effective in supporting problem-solving outcomes. When designing continuous and faded supports, designers should consider the types of scaffolds that students might still need based on their learner characteristics and the nature of the task.

Future research has potential to advance our understanding of the fading mechanism by investigating more on what to fade, when to fade, and to what extent to fade. Literature has already indicated the effectiveness of domain-general and domainspecific scaffolds. Therefore, instead of having a control group, this study compared four treatments by manipulating the types of scaffolds and the levels of support within each type. However, modified replication of the study could be conducted with a control group. Individual characteristics of learners are important factor that influences scaffolding effectiveness. More research is needed to understand how middle school students with different level of prior knowledge and metacognitive skills can be supported in an ill-structured problem-solving environment. The classroom environment is a complex system where different factors can affect students' learning and performance. Consequently, further research is also recommended to examine the role of interaction between teachers and peers. 


\section{CHAPTER IV}

\section{SCAFFOLDING ILL-STRUCTURED PROBLEM-SOLVING PERFORMANCE: THE ROLE OF STUDENTS’ PRIOR KNOWLEDGE}

\section{AND METACOGNITIVE SKILLS}

\section{Overview}

This study investigated whether students' prior knowledge and metacognitive skills predict their success in problem solving across different scaffolding conditions. A total of nineteen classes were randomly assigned to one of the four scaffolding conditions: domain-general continuous (DG-C), domain-general faded (DG-F), domainspecific continuous (DS-C), and domain-specific faded (DS-F). Each class had access to different worksheets depending on the scaffolding condition they had been assigned. All students engaged in four problem-solving activities for thirteen class periods. Students' scores on a multiple-choice pretest, inventory of metacognitive self-regulation, and recommendation forms were analyzed. Results indicated that while students with lower prior knowledge and lower metacognitive skills benefited from the domain-general continuous condition, students with lower regulation of cognition benefited from the domain-general faded condition. Moreover, while students with lower prior knowledge, lower knowledge of cognition, and lower problem representation benefited from the domain-specific continuous condition, students with lower problem representation benefited from the domain-specific faded condition. On the other hand, results of the 
study suggested that scaffolds did not substantially benefit the students with higher prior knowledge and higher metacognitive skills.

\section{Introduction}

Research in various domains demonstrates that problem-solving performance is

enhanced by certain individual characteristics of learners (Smith \& Good, 1984). Among those characteristics, cognitive abilities and metacognitive skills that affect the problem solving are important. Expert-novice literature shows that novice learners are faced with challenges to meeting the cognitive and metacognitive requirements of problem solving (Chi et al., 1981). Therefore, scaffolding is necessary to facilitate problem-solving performance of novice learners. Despite overall effectiveness, research has shown that individual characteristics of learners affect their use of different characteristics of scaffolds. This study examined the role of learners' prior knowledge and metacognitive skills on their problem-solving performance across the use of scaffolds with different characteristics.

\section{Cognitive Abilities to Solve Ill-Structured Problems}

Domain-specific knowledge is a strong predictor of problem-solving performance and it affects the problem representation and its solution processes (Jonassen, 1997). As research on the performance of experts and novices showed experts continuously search and use domain knowledge during problem solving (Chi et al., 1981; Voss \& Post, 1988).

Domain-specific knowledge must also be well-integrated, structured, and condensed in relation to the problem goals (Chi \& Glaser, 1985; Voss \& Post, 1988). 
Therefore, ill-structured problems also require structural knowledge, which has also been referred to internal connectedness, integrative understanding, or conceptual knowledge (Jonassen et al., 1993). Jonassen et al. (1993) defined structural knowledge as a theoretical construct for describing the ways that humans construct and store knowledge. Structural knowledge describes how declarative knowledge is interconnected and involves the integration of declarative knowledge into useful knowledge structures. It mediates the translation of declarative into procedural knowledge and facilitates the application of procedural knowledge.

Both domain-specific and structural knowledge facilitate the solution process by helping learners choose the best solution path and guiding the retrieval of appropriate procedures (Chi \& Glaser, 1985). Either lack of knowledge or lack of access to knowledge because of the simple, incomplete, or inadequate structural knowledge might be a reason for failure in solving a problem (Chi et al., 1981).

\section{Metacognitive Skills to Solve Ill-Structured Problems}

If problem solvers do not have adequate domain-specific knowledge, they need to use domain-independent general strategies to find a solution (Chi et al., 1982; Gick, 1986; Hong, 1998). Since an ill-structured problem requires large amounts of information in various domains, learners sometimes may not have enough knowledge to solve the problem. Therefore, ill-structured problem solving also demands metacognitive skills (Hong, 1998; Jonassen, 1997).

The concept of metacognition was introduced by Flavell (1976; 1979; \& 1981) and Brown (1975; 1978). Flavell (1976) defined metacognition as “one's knowledge 
concerning one's own cognitive processes or products or anything related to them" (p. 232). He further defined it as a "knowledge or cognition that takes as its object or regulates any aspect of any cognitive endeavor" (Flavell, 1981, p. 37). Brown (1987) also defined metacognition as an "understanding of knowledge, an understanding that can be reflected in either effective use or overt description of the knowledge in question" (p. 65). Further, Brown and Campione (1981) divided metacognition into two broad categories: knowledge about cognition and regulation of cognition.

Knowledge about cognition concerns the self-awareness of learners regarding their own cognitive resources and the compatibility between them and a learning situation (Brown \& Campione, 1981). The learners' reflection of what is known about a problem domain is an important metacognitive strategy engaged during problem representation (Jonassen, 1997). Knowledge about cognition can be divided into three subcategories including (a) knowledge about cognitive tasks and resources (declarative), (b) knowledge about particular strategies that may be invoked to solve the task (procedural), and (c) knowledge of when and how the strategy should be applied (conditional) (Jacobs \& Paris, 1987; Kitchener, 1983). In order to employ strategies effectively, successful problem solvers need to have all these components of knowledge of cognition.

Regulation of cognition refers to self-control and self-regulatory mechanisms during problem solving. Since ill-structured problems have no clear solution and require consideration of multiple solutions and alternatives, learners need to regulate their 
cognitive efforts to keep track of the solution processes (Kluwe \& Friedrichsen, 1985; Jonassen, 1997).

Mechanisms to regulate thinking include monitoring, planning the next step, evaluating the effectiveness actions, and revising one's strategies for learning (Baker \& Brown, 1984; Brown \& Campione, 1981; Jacobs \& Paris, 1987). First, monitoring is an important element of the ill-structured problem-solving process because it includes unclear goals and components. Monitoring is a complex process where learners reflect on not only what they know about a problem domain, but also what it means (Jonassen, 1997). Learners regularly monitor their cognitive efforts, shifts, choices, and emotional reactions during problem solving (Gick, 1986; Sinnott, 1989). Monitoring processes assist learners as they control their own processes, apply appropriate strategies, deal with their limitations, and stay on track (Kluwe \& Friedrichsen, 1985).

Second, planning is selective organization of actions to achieve a cognitive goal (Jacobs \& Paris, 1987). It reduces the uncertainty of ill-structured problems with regard to future action. Planning requires a considerable amount of decision making about the direction of one's approach including evaluating goals, selecting and evaluating strategies, and monitoring the execution of a plan (Kluwe \& Friedrichsen, 1985). Plans arise from feedback from the monitoring process, as well as the reflections of the solver on the completed actions (Hong, 1998).

Third, evaluation, as well as monitoring, is an ongoing process during illstructured problem solving. The solution process in ill-structured problem solving 
comprises both finding the solution and evaluating it (Voss \& Post, 1988). Learners need to evaluate the reliability of the information, evidence, and expert opinions.

\section{Scaffolding in Ill-Structured Problem Solving}

Problem solving is a complex process that requires domain-specific knowledge, structural knowledge, metacognitive processes to plan, monitor, evaluate, and revise investigation plans, and justification skills. These requirements affect novice learners'

problem-solving performances. Different types of scaffolding strategies, domain-general and domain-specific, have been used to help students cope with the difficulties during problem solving.

Domain-general scaffolds support concepts and strategies that can be applied across domains, such as problem-solving skills (McNeill \& Krajcik, 2006). These types of scaffolds have been provided to help students comprehend the general idea of the problem-solving process and support them in planning, monitoring, and evaluating, regardless of the content area. Earlier studies showed that domain-general scaffolds have the potential to facilitate knowledge acquisition (Davis, 2003; King, 1994; King \& Rosenshine, 1993), metacognitive thinking and the problem-solving processes in various domains (Ge \& Land, 2003; King, 1991; Lin \& Lehman, 1999; White \& Frederiksen, 1998; 2005), and scientific explanation (Land \& Zembal-Saul, 2003). Unlike domaingeneral scaffolds, domain-specific scaffolds support concepts and strategies that students develop in certain domains (McNeill \& Krajcik, 2006). These types of scaffolds have been used to provide hints to novice learners about what specific content knowledge to use during problem solving (Lee \& Songer, 2004). The literature showed that domain- 
specific scaffolds have the potential to facilitate scientific explanation (Lee \& Songer, 2004; McNeill \& Krajcik, 2006; Sandoval, 2003) and reflection and argumentation (Bell \& Davis, 2000).

Despite the advantages of scaffolds, they were not always found useful, learners sometimes failed to take advantage of scaffolds and saw them as a restricting factor in their progress (Brush \& Saye, 2001; Ge \& Land, 2003; Greene \& Land, 2000; Zydney, 2005). Individual characteristics of learners are one of the important factors that influence the effective use of scaffolds. As Palincsar and Brown (1984) noted that scaffolds are useful within the "Zone of Proximal Development (ZPD)" defined as "the distance between the actual developmental level as determined by independent problem solving and the level of potential development as determined through problem solving under adult guidance or in collaboration with more capable peers" (Vygotsky, 1978, p. 86).

Successful scaffolds should facilitate learners' problem-solving performances by providing support based on their individual characteristics. Among these characteristics, prior knowledge and metacognitive skills are essential. The next section discusses the research findings on the use of scaffolds for learners with different levels of prior knowledge and metacognitive skills. The Role of Students' Prior Knowledge

Studies show that learners' prior knowledge affects their use of scaffolds. For example, Land and Zembal-Saul (2003) found that students with low prior knowledge did not effectively use the domain-general prompts, and they showed little progress. On 
the other hand, students with high prior knowledge took advantage of the domaingeneral scaffolds, as their knowledge served as a starting point.

These findings point to the prior knowledge paradox in complex learning environments. Schank and Cleave (1995) note the bootstrapping dilemma for these environments: "How can students learn by doing, when they do not know how to do what they have to do to learn?" (p.178). Research suggests that knowledge structures of novices are different from those of experts in that they have incomplete and poorly formed structures (Chi et al., 1982; Gick, 1986). Because of their knowledge structures, novice learners do not establish elaborated understanding of concepts and they do not see meaningful patterns like experts do (Chi et al., 1981; 1982; Gick, 1986). They often fail to map their intuitive thinking to scientific constructs, and they may misapply the prior knowledge while searching their memories for similar problems (Land, 2000). Therefore, learners need support to close the gap between their own ways of thinking and the methods presented by experts. To this end, researchers provided domain-specific scaffolds in order to facilitate students' domain knowledge. However, studies showed that while low prior knowledge learners did not make the most of the domain-specific scaffolds, high knowledge learners benefited from them (Lee \& Songer, 2004). This finding was interesting because domain-specific prompts have the potential to compensate for students' limited prior knowledge (Tabak, 1999).

Researchers also suggested that prior knowledge of learners affects their preferences of the levels of support in the scaffolds. The findings of Lee and Songer (2004) indicated that students with both low and high knowledge benefited from the 
continuous domain-specific support compared to the faded domain-specific support. Because students with high knowledge attempted to find quick answers through simple guessing, continuous support directed their attention and helped them develop more warranted explanations.

The Role of Students' Metacognitive Skills

Studies on the performance of good-poor problem solvers (Dorner et al., 1983), good-poor learners (Thorndyke \& Stasz, 1980), and expert-novices (Simon \& Simon, 1978) showed the importance of metacognition in that it helps solvers to be more systematic and use executive control strategies, including monitoring, checking, evaluation, and analyzing their own cognitive state and solution by planning carefully. However, novice learners often have difficulties with using these skills and they tend to focus on reaching immediate outcomes without interpreting their actions (Brush \& Saye, 2001; Loh, 2003; Quintana et al., 2004; Reiser, 2004). Therefore, novice learners' lack of metacognitive skills causes them to be unaware of their thinking process and not to reflect on their learning (Davis \& Linn, 2000; Loh et al., 2001).

The effectiveness of using different scaffolding strategies to facilitate metacognitive skills of learners is well-documented in the literature (Azevedo \& Cromley, 2004; Ge \& Land, 2003; King, 1991; McNeill et al., 2006; White \& Frederiksen, 1998; 200). However, there is tension between the domain-generality and specificity of metacognitive skills. Some researchers have proposed metacognitive skills are domain-general, suggesting that high metacognitive skills can potentially compensate for overall aptitude and prior knowledge of learners (Swanson, 1990; 
Veenman, Elshout, \& Meijer, 1988; White \& Frederiksen, 1998; 2005). Based on this view, students with poor prior knowledge and metacognitive skills may benefit from domain-general scaffolds. However, a number of studies pointed out the role of the domain-specificity of metacognitive skills (Garner \& Alexander; 1989; Glaser, Schauble, Raghavan, \& Zeitz, 1992; Lucangeli, Coi, \& Bosco, 1997). These studies suggest that although metacognitive skills can compensate for limited knowledge, use of metacognitive strategies often depends on having relevant prior domain-knowledge. Based on this view, students with poor metacognitive skills may also benefit from domain-specific scaffolds. However, none of these studies explicitly examined how learners with different levels of metacognitive skills might benefit from different scaffolding characteristics.

\section{Purpose of the Study}

Although a few studies explored prior knowledge of learners, more research is needed to understand how learners with different characteristics, especially middle school students in ill-structured problem-solving environments, benefit from the different types of scaffolds. Hence, the purpose of this study was to examine whether students with different levels of prior knowledge and metacognitive skills benefited from domain-general and domain-specific scaffolds in different ways. Moreover, this study also aims at examining which levels of support in the scaffolds, continuous or faded, better meets the needs of learners with different prior knowledge and metacognitive skills. The investigation of this study was guided by the following questions: 
1. Does students' prior knowledge predict success in solving problems across four scaffolding conditions?

2. Do students' metacognitive skills predict success in solving problems across four scaffolding conditions?

\section{Method}

\section{Participants}

Participants were drawn from 415 sixth grade students at three middle schools in the Southwestern United States. The participants reflected the ethnic makeup of the schools that were 50\% Hispanic, 35\% African American, 14\% White, and 1\% other. A total of 332 students (181 male, 51 female) returned consent forms and agreed to participate in the study. There were nineteenth classes: two of the teachers had six classes, one of the teachers had five classes, and one of the teachers had two classes.

\section{Materials}

The hypermedia program used in this study was Alien Rescue, a problem-based learning environment designed to engage middle school students in solving complex, illstructured problems (Liu et al., 2002). The primary learning objectives of Alien Rescue focus on our solar system and the tools and procedures that scientists use to study it.

The program begins with a presentation of a complicated problem in which students were asked to participate in problem solving, acting as scientists. The scenario includes a group of six species of aliens, whose planetary system has been destroyed, that have arrived in Earth's orbit. Students were asked to work at a newly operational international space station to rescue the alien species by finding them new homes in our 
solar system that can support their life forms. To accomplish this goal, students learned about the planets and large moons of our solar system.

\section{Scaffolding Treatment Conditions}

\section{Types of Scaffolds}

Based on the previous research on scaffolding problem solving, two types of scaffolds were designed in the study: domain-general and domain-specific. Domaingeneral scaffolds were designed to support the processes of ill-structured problem solving which were defined by Ge and Land (2003) as problem representation (PR), developing solutions (DS), making justifications (MJ), and monitoring and evaluation (ME). Domain-general scaffolds were designed to direct students to each step of the problem-solving process regardless of the content area (McNeill \& Krajcik, 2006). Additionally, domain-specific scaffolds were designed to support students' understanding in the domain. Domain-specific scaffolds were intended to reflect salient features in the content and to help students think what content knowledge to use during problem solving. All treatment materials were reviewed by a middle school science teacher. Examples of domain-general and domain-specific scaffolding treatment materials are provided in Appendix A and Appendix B.

Adapted from Lee and Songer (2004), three kinds of prompts for each scaffolding condition were designed in the form of questions $(\mathrm{Q})$, examples $(\mathrm{E})$, and sentence starters (SS). Examples of the prompts are presented in Table 3.2.

First, prompts were provided in question format to highlight the problem-solving processes in the domain-general condition and the salient content knowledge related to 
the problem in the domain-specific condition. Domain-general question prompts were intended to support students in understanding the problem, developing solutions, providing evidence, and evaluating solutions. On the other hand, domain-specific question prompts provided content and task specific hints to consider during the problem-solving processes, such as facts about the alien species and characteristics of worlds.

Second, prompts were given in the form of examples. In the domain-general condition, an example of the general problem-solving process was provided in order to present how a problem solver might approach and engage in the ill-structured problemsolving processes. In the domain-specific condition, an example of solving the problem of one alien species, the Eolani, was provided.

Third, prompts were provided in the form of sentence starters. These were similar to the question prompts in that they guided students through the problem-solving processes and provided hints specific to the problem. Unlike the question prompts, sentence starters provided less support and were more reflective.

\section{Levels of Support in Scaffolds}

Previous studies faded scaffolds by a systematic gradual reduction of support. For example, in the study of Palincsar and Brown (1984), the teacher initially modeled and demonstrated the effective comprehension activities to support seventh-grade poor readers. Then, students took turn to use these strategies. Students had difficulties at the beginning, but guidance and prompts provided by the teacher helped them become more capable of assuming their role and applying the strategies. In another example, Lee and 
Songer (2004) provided modeled explanations, content prompts, and sentence starters. They withdrawed the modeled explanations first, the direct content prompts second, and sentence starters at last. Having been provided with the example explanations, students became familiar with how to use direct content prompts in their own explanations.

Based on the literature, order of fading three types of prompts has been decided to create continuous and fading support conditions (Lee \& Songer, 2004; Palincsar \& Brown, 1984). As shown in Table 3.3, in the continuous support condition all of the three prompts were provided during all of the four problem-solving activities. However, in the fading support condition prompts were faded gradually over four problem-solving activities: examples were withdrawn after the first activity, both examples and questions were withdrawn after the second activity, and all of the examples, questions and sentence starters were withdrawn after the third problem-solving activity. No scaffolding was provided for the last problem-solving activity.

\section{Procedure}

This study was conducted daily during 45-minute period science classes. Students engaged in the program Alien Rescue for thirteen class periods. They also engaged in introduction and data collection for two class periods.

Before the study, the researcher contacted the teachers and explained the purposes of research, procedure, scaffolding conditions, and the hypermedia-learning environment, Alien Rescue. Two weeks prior to engaging in Alien Rescue students were informed about the study and consent forms were handed out. Ten days prior to assigning to the conditions, students took a multiple-choice pretest and an inventory of 
metacognitive self-regulation. Next, the classes of each teacher were randomly assigned to one of the four scaffolding conditions in such a way that each teacher taught all four conditions: DG-C ( $\mathrm{n}=84)$, DG-F ( $\mathrm{n}=69)$, DS-C $(\mathrm{n}=103)$, and DS-F $(\mathrm{n}=76)$. However, only one teacher, who had two classes, taught the domain-general continuous and the domain-specific continuous conditions. Each class received different worksheets throughout four problem-solving activities, depending on the condition they had been assigned. Participant teachers were instructed to avoid providing different information than what was in the worksheets. The researcher participated as an observer in the classroom in order to check if teachers were using the worksheets properly. Teachers confirmed not to give additional support and observation of the classroom indicated that they used the worksheets appropriately.

On the first day of the study, students watched the opening scenario and became familiar with the learning environment. On the second day, they were informed that they needed to engage in problem-solving activities for each of the four species in order: the Akona, the Jakala-Tay, the Kaylid, and the Wroft. Next, teachers passed out the worksheets for the first problem-solving activity, the Akona. Students spent two days working on the first activity by using the software Alien Rescue and the worksheets. Students were reminded throughout the activity that they should use the worksheets as a guide by reading the example, answering the questions, and completing the sentence starters. At the end of the two-day problem-solving activity, students gave the worksheets to the teacher. On the next day, students were provided with forms to write their recommendations for the problem solution for the first alien, the Akona. Next day, 
students started working on the second problem-solving activity. Teachers followed the same procedure for the rest of the activities as the first one. Overall, students spent two days working on the problem of each species, and one day writing their recommendations for the problem solution.

Data Sources and Measurement

\section{Multiple-Choice Pretest}

A pretest with 20 multiple-choice items served as a measure of students' prior knowledge. The items were chosen from the Holt Science and Technology Assessment Item Listing (1998), released TASS and TAKS items, and the factual knowledge test in the Teacher's Manual of Alien Rescue (Pedersen, 2000). The multiple-choice test items covered three key content learning goals in the hypermedia problem-based learning environment: components of the solar system, characteristics of worlds that define them, and instruments that scientists use. Multiple-choice responses were scored, with a maximum possible score of 20. Reliability analysis showed that Cronbach's alpha was 0.743. The multiple-choice test is included in Appendix C. Inventory of Metacognitive Self-Regulation

Metacognitive skills of students were measured by using the Inventory of Metacognitive Self-Regulation (IMSR) designed by Howard, McGee, Shia, and Hong (2000). The IMSR (See Appendix F), a 32 item self-report inventory, measured four factors related to metacognitive skills in the context of problem solving: 1) Knowledge of cognition: Understanding the extent and utilization of one's cognitive abilities, 2) Regulation of cognition: Subtask monitoring and evaluation, 3) Problem representation: 
Understanding the problem fully before proceeding, and 4) Objectivity: Standing outside oneself and thinking about one's learning as it proceeds. For each of the 32 items in the IMRS, students were instructed to circle the answer that best described "the way they are" when solving problems in math or science class $(1=$ never, $2=$ seldom $/$ rarely, $3=$ sometimes, 4 = often/frequently, 5 = always). Howard et al. (2000) reported reliability alpha as .93. Reliability analysis for the current study showed that the inventory had Cronbach's alpha of 0.89 .

\section{Recommendation Forms}

Students completed four recommendation forms (see Appendix D), one for each species, and these were used to assess their problem-solving outcomes. A rubric system developed by Ge and Land (2003) had been modified and used to score students' recommendation forms. The rubric was based on research of ill-structured problem solving (Chi \& Glaser, 1985; Jonassen, 1997; Kitchener, 1983; Sinnott, 1989; Voss, 1988; Voss \& Post, 1988) and developed rubrics (Blum \& Arter, 1996; Hong, 1998). In the rubric system Ge and Land (2003) identified four constructs as important indicators for measuring ill-structured problem-solving outcomes: (a) problem representation, (b) developing solutions, (c) making justifications for generating and selecting solution, and (d) monitoring and evaluating the solutions. These constructs, which correspond to the dependent variables of this study, could be found in the recommendation forms where students were required to write their solution, provide rationale by explaining benefits and drawbacks for choosing one world over the other worlds. 
By using the rubric, students' recommendation forms for each of the four problem-solving activities were scored. The average of the scores of four problemsolving activities was then computed to give a single problem-solving performance score for each student. The scoring rubric is provided in Appendix E. Table 3.4 presents the rubric and examples of scoring problem-solving performances of students in recommendation forms.

The first construct in the rubric, representing the problem, was intended to measure the identification of relevant information about each alien species. Students were scored one point for each need they stated. The second construct, developing solutions, was evaluated by two attributes, including selecting a solution and providing supporting data. Students received two points if they recommended the best world, one point if they recommended an acceptable world, and zero points for any other choices. Moreover, students received one point for each supporting detail that they stated, to a maximum of five points. The third construct, making justifications, was subdivided into two attributes: constructing an argument and providing evidence. Students received scores based on the quality of their arguments for the proposed solution and the quality of evidence about the selected world. The last construct, monitoring and evaluation, included two attributes, including evaluation of solutions and assessing alternative solutions. Students received scores based on the statements they made about the effectiveness or benefits of the selected world, and the potential pros and cons, and how they supported these claims with relevant evidence. Moreover, students were scored for assessing alternative solutions. 
Recommendation forms were graded by two raters, including the researcher. The raters were blind to student names and the scaffolding conditions associated with each recommendation form. Before grading, the researcher explained each construct in the rubric to the independent rater. Then, the researcher and the rater reached a consensus on the rubric by scoring twenty of the recommendation forms together. Then, both raters scored the remaining recommendation forms independently using the rubric. Next, two raters discussed any discrepancies of the assigned values until they reach a consensus. For the first two constructs, there were not many differences between the scores of the two raters; this was because scoring was simply counting the number of needs of the aliens that were stated, scoring the world that they chose, and counting the supporting details about the world that they chose. Constructing argument was the hardest one to score since it was more subjective than the others.

\section{Data Analysis}

Multiple regression analyses were conducted to examine the extent to which students' problem-solving performances could be predicted from measures of prior knowledge and metacognitive skills across four scaffolding conditions. Two hundred and eight students completed all of the four problem-solving activities and were included in the analysis.

Students' pretest scores and four sub-components of metacognitive skills (knowledge of cognition, regulation of cognition, problem representation, and objectivity) were used as independent variables. Students' overall problem-solving performance score was used as the dependent variable. Simultaneous regression analysis 
was designed to enter all predictor variables simultaneously into the regression equation. Four separate regression analyses were run by regressing the prior knowledge and four sub-components of metacognitive skills on students' problem-solving performances in four scaffolding conditions.

Pearson's correlations among independent variables in each condition are presented in Table 4.1. Results indicated that although correlations between prior knowledge and sub-components of metacognitive skills were not significant, correlations among some of the sub-components of metacognitive skills were significant. Structure coefficients (bivariate correlation of predictors with the criterion) are not affected by collinearity. Thompson and Borrello (1985) and Courville and Thompson (2000) suggested that both beta weight and structure coefficients should be used in interpreting the regression analysis when collinearity is present. Therefore, both regression coefficients were interpreted in the analysis.

\section{Results}

A summary of the multiple regression analysis for variables predicting problemsolving performance across the four conditions is presented in Table 4.2. Moreover, significant predictors of success in problem solving across the four conditions are shown in Table 4.3. 
Table 4.1 Pearson's correlation among independent variables

\begin{tabular}{|c|c|c|c|c|c|}
\hline Variable & 1. Prior knowledge & 2. Knowledge of cognition & 3. Regulation of cognition & 4. Problem representation & 5. Objectivity \\
\hline $\begin{array}{l}\text { DG-C condition } \\
\text { 1. Prior knowledge }\end{array}$ & - & & & & \\
\hline 2. Knowledge of cognition & .089 & - & & & \\
\hline 3. Regulation of cognition & .031 & $.674(* *)$ & - & & \\
\hline 4. Problem representation & -.004 & $.505(* *)$ & $.716(* *)$ & - & \\
\hline 5. Objectivity & .072 & $.435(* *)$ & $.642(* *)$ & $.543(* *)$ & - \\
\hline 2. Knowledge of cognition & .204 & - & & & \\
\hline 3. Regulation of cognition & .152 & $.803(* *)$ & - & & \\
\hline 4. Problem representation & -.018 & .244 & $.374(* *)$ & - & \\
\hline 5. Objectivity & .102 & $.581(* *)$ & $.608(* *)$ & .154 & - \\
\hline $\begin{array}{l}\text { DS-C condition } \\
\text { 1. Prior knowledge }\end{array}$ & - & & & & \\
\hline 2. Knowledge of cognition & .107 & - & & & \\
\hline 3. Regulation of cognition & .137 & .173 & - & & \\
\hline 4. Problem representation & -.227 & $.476(* *)$ & .003 & - & \\
\hline 5. Objectivity & .011 & $.320(*)$ & .251 & .147 & - \\
\hline $\begin{array}{l}\text { DS-F condition } \\
\text { 1. Prior knowledge }\end{array}$ & - & & & & \\
\hline 2. Knowledge of cognition & .302 & - & & & \\
\hline 3. Regulation of cognition & .340 & .324 & - & & \\
\hline 4. Problem representation & -.059 & .078 & -.105 & - & \\
\hline 5. Objectivity & .347 & .231 & $.358(* *)$ & .188 & - \\
\hline
\end{tabular}

Note. DG-C = Domain-general continuous; DG-F = Domain-general faded; DS-C = Domain-specific continuous; DS-F = Domain specific faded.

$* * p<.01 . * * * p<.001$. 
Table 4.2 Summary of multiple-regression analysis

\begin{tabular}{|c|c|c|c|c|c|}
\hline Variables & $B$ & SE B & $\beta$ & $r_{s}$ & $\left(r_{s}\right)^{2}$ \\
\hline \multicolumn{6}{|c|}{$\begin{array}{l}\text { Problem-solving in the DG-C condition } \\
(N=52)\end{array}$} \\
\hline Prior knowledge & 0.24 & 0.14 & 0.23 & 0.52 & 0.27 \\
\hline Knowledge of cognition & -1.06 & 0.72 & -0.28 & -0.45 & 0.21 \\
\hline Regulation of cognition & 0.58 & 0.98 & 0.15 & -0.14 & 0.02 \\
\hline Problem representation & 0.80 & 0.75 & 0.21 & 0.10 & 0.01 \\
\hline Objectivity & -0.88 & 0.61 & -0.27 & -0.44 & 0.19 \\
\hline \multicolumn{6}{|l|}{$R^{2}=.13(p>.25)$} \\
\hline \multicolumn{6}{|c|}{$\begin{array}{l}\text { Problem-solving in the DG-F condition } \\
(N=51)\end{array}$} \\
\hline Prior knowledge & 0.40 & 0.13 & $0.35 * *$ & $0.77 * * *$ & 0.59 \\
\hline Knowledge of cognition & 0.84 & 0.73 & 0.25 & $0.47 * * *$ & 0.22 \\
\hline Regulation of cognition & -1.21 & 0.80 & -0.36 & 0.28 & 0.08 \\
\hline Problem representation & 0.92 & 0.50 & 0.25 & $0.40 * *$ & 0.16 \\
\hline Objectivity & 0.74 & 0.50 & 0.24 & $0.47 * * *$ & 0.22 \\
\hline \multicolumn{6}{|l|}{$R^{2}=.29(p<.01)$} \\
\hline \multicolumn{6}{|c|}{$\begin{array}{l}\text { Problem-solving in the DS-C condition } \\
(N=53)\end{array}$} \\
\hline Prior knowledge & 0.15 & 0.11 & 0.15 & 0.29 & 0.08 \\
\hline Knowledge of cognition & -0.81 & 0.52 & -0.20 & 0.03 & 0.00 \\
\hline Regulation of cognition & 1.85 & 0.43 & $0.47 * * *$ & $0.80 * * *$ & 0.64 \\
\hline Problem representation & -0.09 & 0.50 & -0.02 & -0.13 & 0.02 \\
\hline Objectivity & 1.37 & 0.37 & $0.42 * * *$ & $0.68 * * *$ & 0.46 \\
\hline \multicolumn{6}{|l|}{$R^{2}=.49(p<.00)$} \\
\hline \multicolumn{6}{|c|}{$\begin{array}{l}\text { Problem-solving in the DS-F condition } \\
(N=52)\end{array}$} \\
\hline Prior knowledge & 0.34 & 0.10 & $0.34 * *$ & $0.77 * * *$ & 0.59 \\
\hline Knowledge of cognition & 0.32 & 0.36 & 0.08 & $0.45 * * *$ & 0.20 \\
\hline Regulation of cognition & 1.08 & 0.37 & $0.30 * *$ & $0.72 * * *$ & 0.52 \\
\hline Problem representation & -0.28 & 0.34 & -0.07 & -0.06 & 0.00 \\
\hline Objectivity & 1.32 & 0.35 & 0.38 & $0.78 * * *$ & 0.60 \\
\hline \multicolumn{6}{|l|}{$R^{2}=.65(p<.00)$} \\
\hline
\end{tabular}


Table 4.3 Significant predictors of success of problem solving across four scaffolding conditions

\begin{tabular}{lccccc}
\hline Conditions & $\begin{array}{c}\text { Prior } \\
\text { knowledge }\end{array}$ & $\begin{array}{c}\text { Knowledge of } \\
\text { cognition }\end{array}$ & $\begin{array}{c}\text { Regulation of } \\
\text { cognition }\end{array}$ & $\begin{array}{c}\text { Problem } \\
\text { representation }\end{array}$ & Objectivity \\
\hline DG-C & & $\mathrm{X}$ & $\mathrm{X}$ & $\mathrm{X}$ & $\mathrm{X}$ \\
DG-F & & $\mathrm{X}$ & $\mathrm{X}$ & $\mathrm{X}$ \\
DS-C & $\mathrm{X}$ & $\mathrm{X}$ & $\mathrm{X}$ \\
DS-F & \multicolumn{2}{l}{$\begin{array}{l}\text { Note. DG-C = Domain-general continuous; DG-F = Domain-general faded; DS-C = Domain-specific continuous; DS-F = Domain- } \\
\text { specific faded. }\end{array}$}
\end{tabular}

The results of the analysis failed to reach a significant model for the DG-C condition, $F$ $(5,46)=1.38, \mathrm{p}>.25$. Thus, prior knowledge, knowledge of cognition, regulation of cognition, problem representation, and objectivity were not significantly involved in the problem-solving performance of students in the DG-C condition.

However, the results of the analysis indicated a statistically significant prediction model for the DG-F condition, explaining $29 \%$ of the variance in problem-solving performance, $R^{2}=.29, F(5,45)=3.62, p<.01$. Examination of both beta weight and the squared structure coefficient of the pretest indicated that prior knowledge was the best predictor of problem-solving performance of students in the DG-F condition, explaining 59\% of the total variance. Although beta weights of knowledge of cognition, problem representation, and objectivity were not significant, the squared structure coefficients were significant, accounting for $22 \%, 16 \%$, and $22 \%$ of the total variance, respectively. However, regulation of cognition failed to contribute to the prediction model.

The results of the analysis also yielded a statistically significant prediction model for the DS-C condition explaining $49 \%$ of the variance, $R^{2}=.49, F(5,47)=9.15$, 
$p<.00$. Interpretation of both beta weights and squared structure coefficients of regulation of cognition and objectivity indicated that they were significant predictors of problem-solving performance in the DS-C condition, accounting for $64 \%$ and $46 \%$ the total variance, respectively. However, prior knowledge, knowledge of cognition, and problem representation were not significant predictors.

In addition, the results indicated a statistically significant prediction model for the DS-F condition, accounting $65 \%$ of the variance, $R^{2}=65, F(5,46)=17.46, p<.00$. Examination of both beta weights and squared structure coefficients indicated that prior knowledge, regulation of cognition, and objectivity was the statistically significant predictor of problem-solving performance in the DS-F condition, explaining 59\%, 52\%, and $60 \%$ of the total variance. Although beta weight of knowledge of cognition was not significant, the squared structure coefficient was significant, accounting for $20 \%$ of the total variance. However, problem representation was not a significant predictor.

\section{Comparison of Regression Slopes}

The regression of the problem-solving scores of students on each of the predictor measures was plotted and examined separately. Five regression equations for each scaffolding condition are presented in Table 4.4. 
Table 4.4 Regression equations for the four scaffolding conditions

Regression of problem-solving scores on

\begin{tabular}{|c|c|c|c|c|c|}
\hline & Prior knowledge & $\begin{array}{l}\text { Knowledge of } \\
\text { cognition }\end{array}$ & Regulation of cognition & Problem representation & Objectivity \\
\hline DG-C & $Y_{1}=0.20 X_{1}+10.65$ & $Y_{1}=-0.63 X_{2}+14.25$ & $Y_{1}=-0.19 X_{3}+12.67$ & $\mathrm{Y}_{1}=0.13 \mathrm{X}_{4}+11.41$ & $Y_{1}=-0.53 X_{5}+13.77$ \\
\hline DG-F & $\mathrm{Y}_{1}=0.42 \mathrm{X}_{1}+8.85$ & $\mathrm{Y}_{1}=0.83 \mathrm{X}_{2}+8.46$ & $Y_{1}=0.51 X_{3}+9.60$ & $\mathrm{Y}_{1}=0.77 \mathrm{X}_{4}+8.28$ & $\mathrm{Y}_{1}=0.77 \mathrm{X}_{5}+8.71$ \\
\hline DS-C & $Y_{1}=0.21 X_{1}+10.04$ & $\mathrm{Y}_{1}=0.12 \mathrm{X}_{2}+10.85$ & $\mathrm{Y}_{1}=2.22 \mathrm{X}_{3}+3.00$ & $Y_{1}=-0.38 X_{4}+12.90$ & $Y_{1}=1.56 X_{5}+5.77$ \\
\hline DS-F & $Y_{1}=0.63 X_{1}+5.24$ & $Y_{1}=1.39 X_{2}+4.77$ & $Y_{1}=2.14 X_{3}+1.78$ & $Y_{1}=-0.17 X_{4}+10.42$ & $Y_{1}=2.15 X_{5}+2.23$ \\
\hline
\end{tabular}

Note. $\mathrm{Y} 1$ = Predicted problem-solving scores; X1 = Prior knowledge scores; $\mathrm{X} 2$ = Knowledge of cognition scores; X3 =Regulation of cognition scores; X4 = Problem representation scores; $\mathrm{X} 5=$ Objectivity scores 


\section{Regression on Prior Knowledge}

Regression slopes for each scaffolding condition on prior knowledge are illustrated in Fig. 4.1. The slopes of the regression line for continuous conditions were not steep, which indicates a weak relationship of students' prior knowledge with problem-solving scores. However, the slopes of the regression line for the domaingeneral and specific faded conditions were sharp, which was also reflected in the higher regression coefficients. This confirmed that prior knowledge was a significant predictor for faded groups and that there was a strong relationship of students' prior knowledge with problem-solving scores. Further, the intercepts for the faded conditions were lower than the ones for the continuous conditions. Moreover, at high prior knowledge levels (where $\mathrm{X}$ is around 14) all four conditions showed approximately similar achievement on problem-solving activities.

\section{Regression on Knowledge of Cognition}

Regression slopes for each scaffolding condition on knowledge of cognition are illustrated in Fig. 4.2. The regression coefficients of the slope for the domain-specific continuous condition were small; indicating a weak relationship of students' knowledge of cognition with problem-solving scores. Moreover, the negative coefficient of slope for the domain-general continuous condition indicated that there was a reverse relationship of students' knowledge of cognition with problem-solving scores. On the other hand, the slopes of the regression line for the domain-general and specific faded conditions were sharp. This confirmed that there was a strong relationship of students' knowledge of cognition with the problem-solving scores in faded conditions. Graphical interpretations 


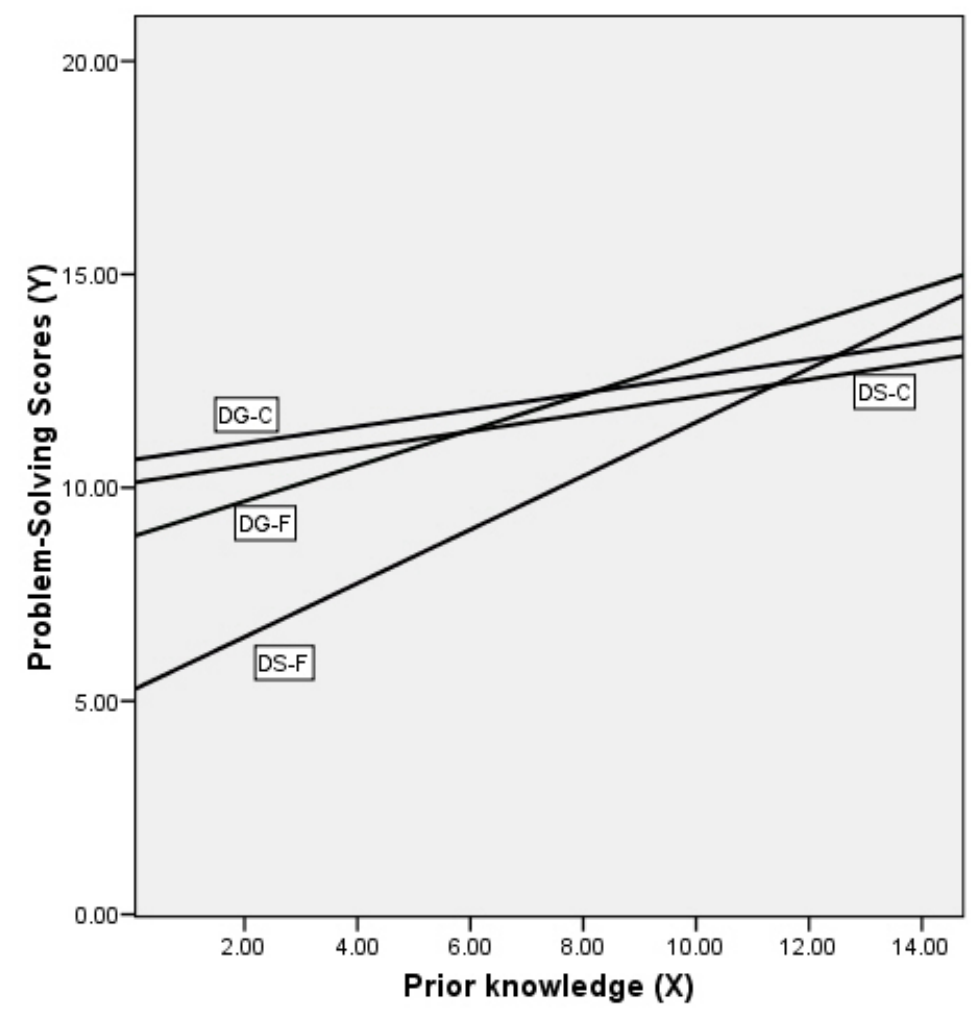

Fig. 4.1 Regression slopes of problem-solving scores on prior knowledge

of the slopes reveal that intercepts for faded conditions are lower than the ones for continuous conditions. Namely, at low knowledge of cognition levels (where $\mathrm{X}$ is near 0) faded conditions showed lower achievement than continuous ones. Further, at high knowledge of cognition levels (where $\mathrm{X}$ is around 5), all four conditions showed more or less similar achievement on problem-solving activities. 


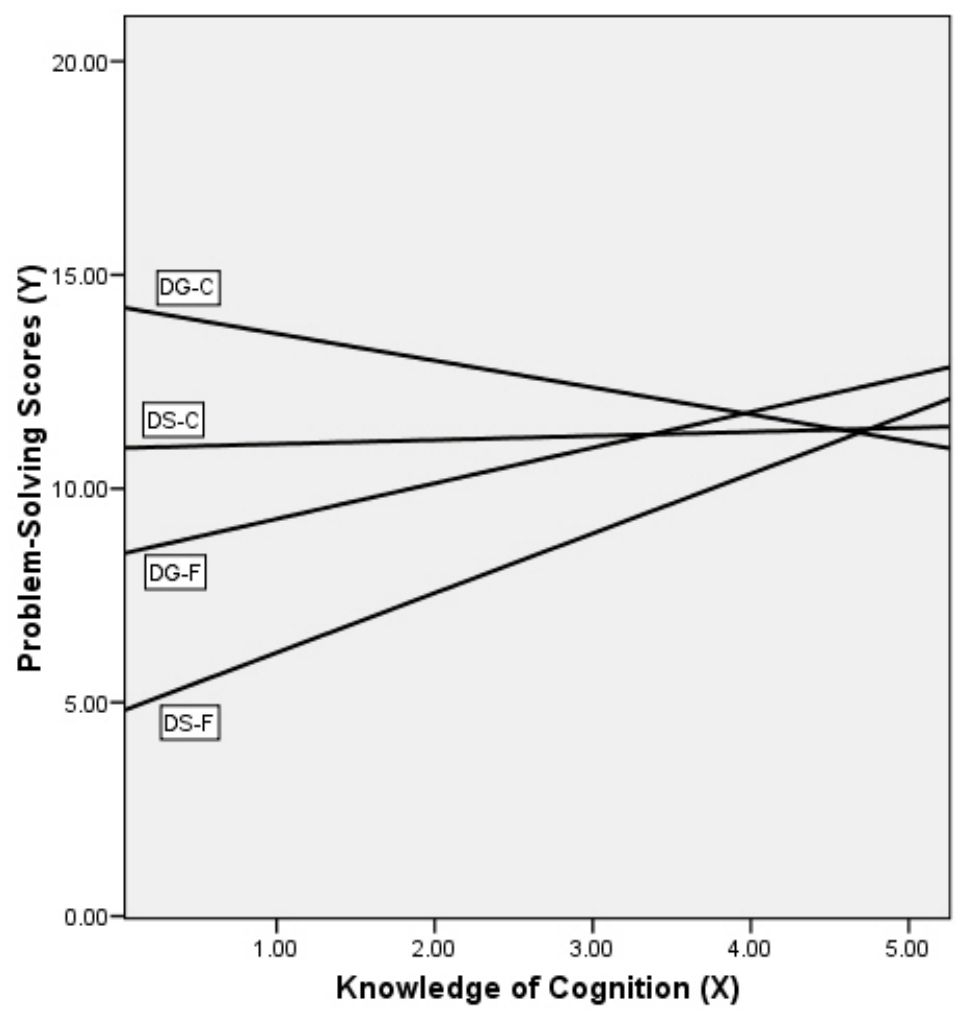

Fig. 4.2 Regression slopes of problem-solving scores on knowledge of cognition

\section{Regression on Regulation of Cognition}

Regression slopes for each scaffolding condition on regulation of cognition are illustrated in Fig. 4.3. The slopes of the regression line for domain-general conditions were not steep, which indicated a weak relationship of students' regulation of cognition with problem-solving scores. However, the slopes of the regression line for domainspecific conditions were sharp, which confirmed that regulation of cognition was a significant predictor and there was a stronger relationship of students' regulation of cognition with the problem-solving scores. Additionally, at low regulation of cognition levels (where $\mathrm{X}$ is near 0), domain-general conditions showed higher achievement than 
the domain-specific conditions. However, at high regulation of cognition levels (where $\mathrm{X}$ is around 5), all four conditions showed approximately similar achievement on problem-solving activities.

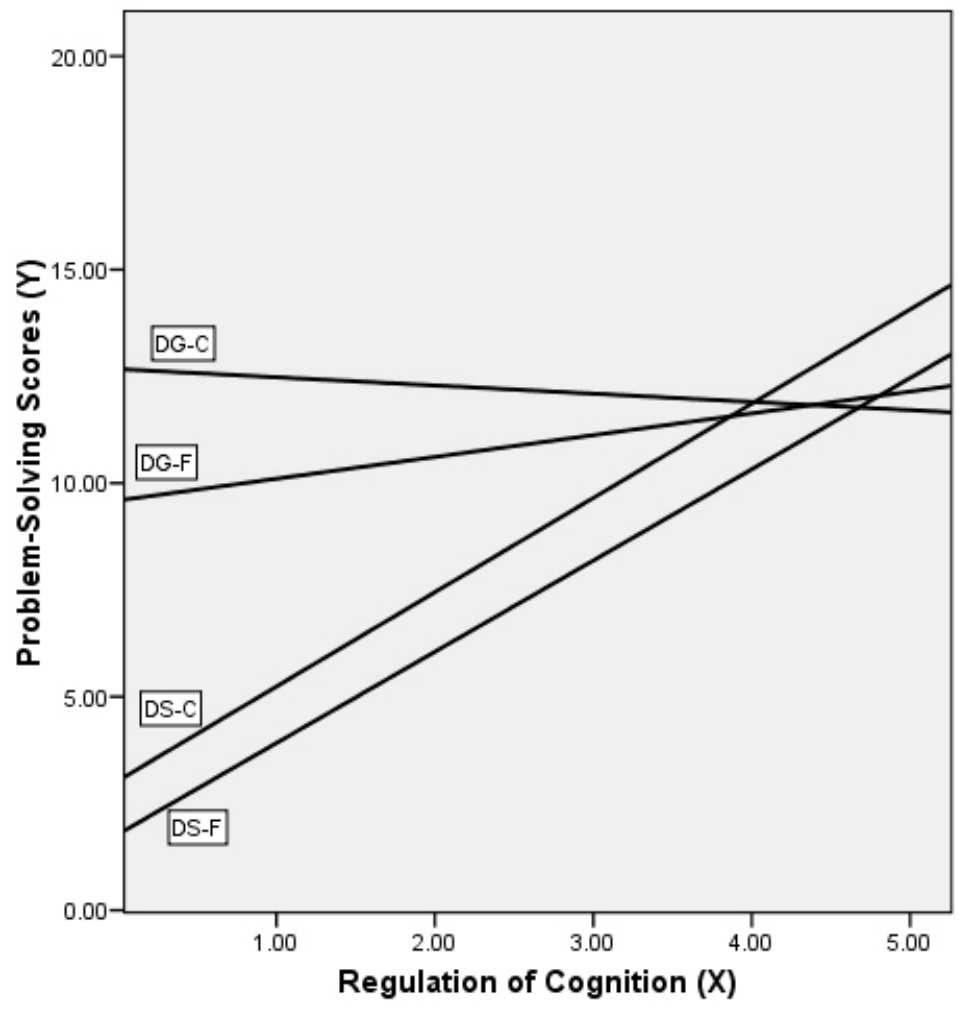

Fig. 4.3 Regression slopes of problem-solving scores on regulation of cognition

\section{Regression on Problem Representation}

Regression slopes for each scaffolding condition on problem representation are illustrated in Fig. 4.4. The slope of the regression line for the domain-general faded condition was sharp compared to the others; meaning that there was a strong relationship between students' problem representation and problem-solving scores. On the other 
hand, the small regression coefficient in the other conditions reports a weak relationship of students' problem representation with the problem-solving scores. Moreover, at low problem representation levels (where $\mathrm{X}$ is near 0 ), the domain-specific continuous condition showed the highest achievement. At high problem representation levels (where $\mathrm{X}$ is around 5), domain-general conditions tend to show higher achievement.

Regression on Objectivity

Regression slopes for each scaffolding condition on objectivity are illustrated in Fig. 4.5. The slope of the regression line for the domain-general continuous condition was a downward slope and less steep than the other conditions. However, the slopes of the regression line for the other three conditions were sharp, which indicates a strong relationship of students' objectivity levels with the problem-solving scores. Graphical interpretation of the slopes also indicated that at low objectivity levels (where $\mathrm{X}$ is near 0), domain-general continuous condition showed the highest achievement. On the other hand, at high objectivity levels (where $\mathrm{X}$ is around 5), domain-general continuous condition tend to show the lowest achievement on problem-solving activities. 


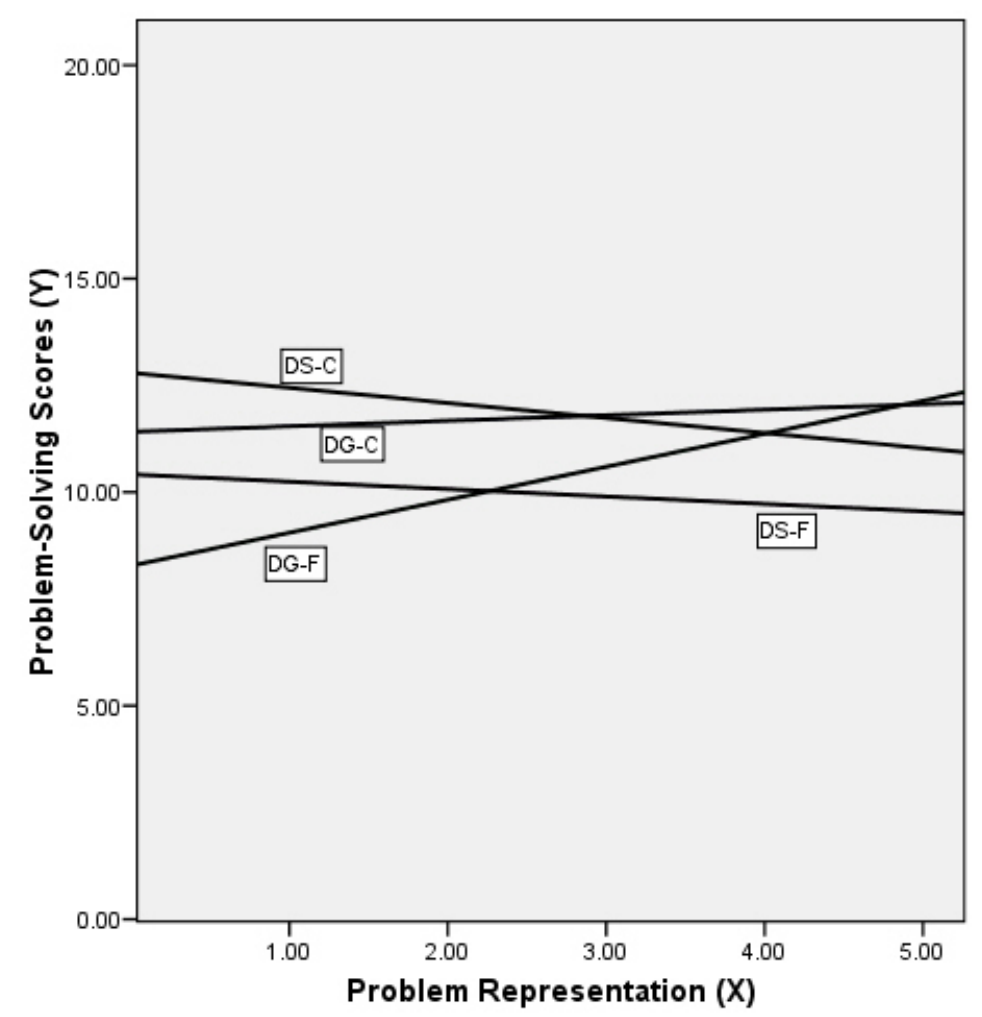

Fig. 4.4 Regression slopes of problem-solving scores on problem representation

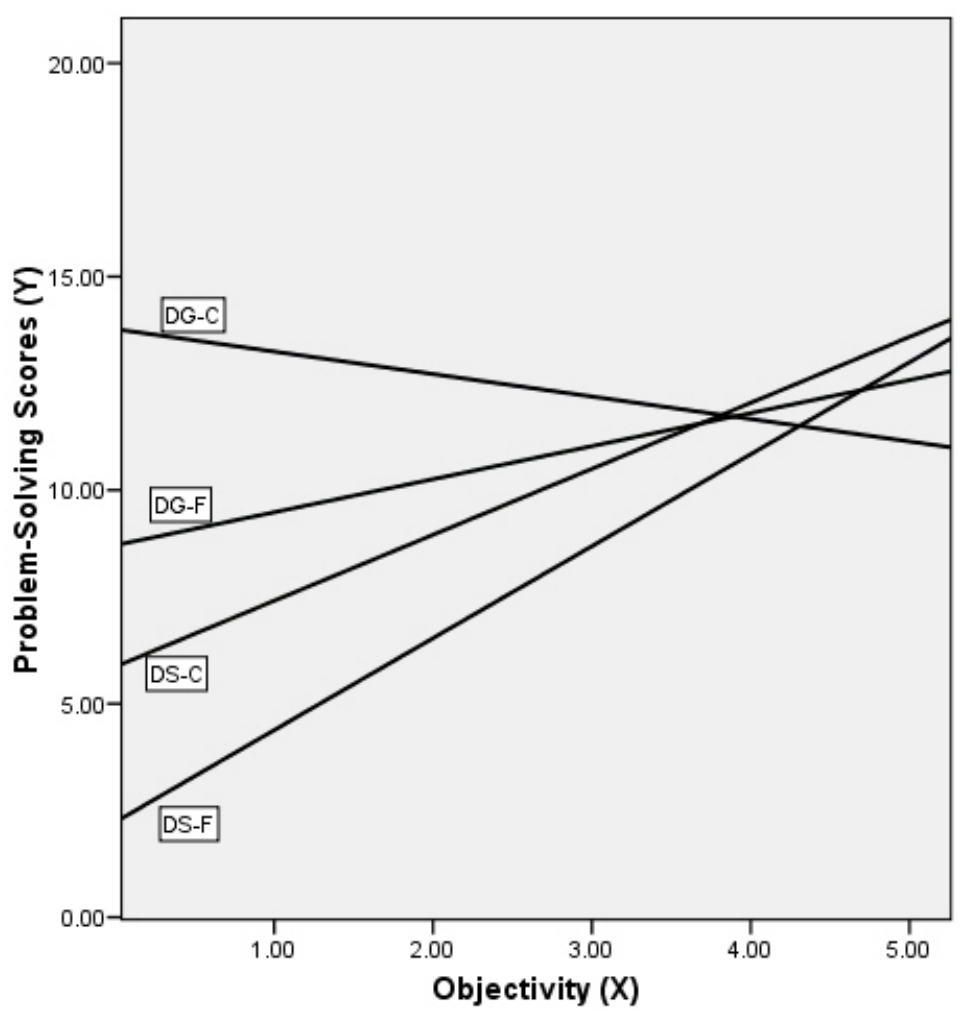

Fig. 4.5 Regression slopes of problem-solving scores on objectivity 


\section{Discussion}

The study findings suggest that the effects of scaffolding conditions on problemsolving performance varied significantly with prior knowledge and metacognitive skills of the students.

\section{Effects of Prior Knowledge}

Results indicated that prior knowledge was a predictor in domain-general and domain-specific faded conditions. This finding suggested that faded conditions were not effective in enabling students with lower prior knowledge to attain the same level of competence in problem solving as the students with higher prior knowledge. On the other hand, results indicated that students' prior knowledge was not a predictor in domain-general and domain-specific continuous conditions. This finding suggested that continuous conditions benefited the students with lower prior knowledge relatively the same as it did the students with higher prior knowledge. It is likely that continuous scaffolds could have benefited the limited prior knowledge students by encouraging them to self-evaluate and become aware of their knowledge limitations. These results were supported by the research of Lee and Songer (2004), which found that students with low prior knowledge benefited more from continuous domain-specific scaffolds than faded ones.

The study results contradicted the findings of a research reported by Land and Zembal-Saul (2003), where they found that students with high prior knowledge benefited more from the domain-general continuous scaffold than those with low prior knowledge. However, in the present study it is likely that students with higher prior 
knowledge did not effectively use the continuous scaffolds as much as the students with lower prior knowledge did. They could have seen the continuous scaffolds as a restricting factor in their process. Moreover, it is likely that those students had developed their own scaffolding strategies even when the scaffolds were faded. These results confirm the notion of "redundant scaffolds," which is defined by Tabak (2004) as multiple forms of support for the same need. In this study, scaffolds may have been redundant for students with higher prior knowledge.

\section{Effects of Metacognitive Skills}

Four components of metacognitive skills, including regulation of cognition, knowledge of cognition, problem representation, and objectivity were examined in the context of solving ill-structured problems.

\section{Knowledge of Cognition}

Results indicated that knowledge of cognition was not a predictor in continuous scaffolding conditions. This finding suggested that students with lower knowledge of cognition benefited from continuous scaffolds in the same way as those students with higher knowledge of cognition. On the other hand, results indicated that knowledge of cognition was a predictor in domain-general and domain-specific faded conditions. This finding suggested that faded conditions were not effective in enabling students with lower knowledge of cognition to attain the same level of competence in problem solving as the students with higher knowledge of cognition. It is likely that domain-general and domain-specific continuous scaffolds could be beneficial for students with lower knowledge of cognition and those scaffolds make them become aware of their learning, 
strengths, and weaknesses. This finding was consistent with the mixed view of domaingenerality and domain-specificity of metacognitive skills (Elshout \& Veenman, 1992; Veenman, 1993). Both general and specific scaffolding strategies supported students' self-awareness regarding their cognitive resources and abilities. The comparison of regression slopes indicated that although lower knowledge of cognition students benefited from continuous scaffolds, higher knowledge of cognition students showed the same achievement in all four conditions. It is likely that continuous scaffolds might have been redundant for higher knowledge of cognition students. Moreover, higher knowledge of cognition students may develop their own scaffolds to evaluate their knowledge even when scaffolds are faded.

\section{Regulation of Cognition}

In this study, the regulation of cognition did not predict problem-solving scores in domain-general continuous and faded conditions. This finding suggested that students with lower regulation of cognition benefited from domain-general scaffolds in the same way those students with higher regulation of cognition. It is likely that domain-general scaffolds could be beneficial for students with lower regulation of cognition in planning, monitoring, and evaluation. On the other hand, results indicated that regulation of cognition was a predictor in domain-specific conditions. Domain-specific conditions were not effective in enabling students with lower regulation of cognition to attain the same level of competence in problem solving as the students with higher regulation of cognition. Unlike general scaffolds, domain-specific scaffolds might not support students' self-control and self-regulatory mechanisms. These results were consistent 
with the domain-generality of metacognitive skills (Swanson, 1990; Veenman et al., 1988; White and Frederiksen, 1998; 2005). Providing domain-general scaffolds might support students with lower regulation of cognition and enable them to attain the same level as the higher regulation of cognition students. The comparison of regression slopes indicated that although students with lower regulation of cognition benefited from domain-general scaffolds, students with higher regulation of cognition showed the same achievement in all four conditions. It is likely that domain-general scaffolds became redundant for higher regulation of cognition students.

\section{Problem Representation}

Results indicated that problem representation did not predict problem-solving scores in domain-specific conditions. This finding suggested that both continuous and faded domain-specific scaffolds enable students with lower problem representation to achieve the same level of achievement of students with higher problem representation. Results also indicated that while problem representation was not a predictor for the domain-general continuous condition, it was a predictor in the domain-general faded condition. This finding suggested that the domain-general faded condition was not effective in enabling students with lower problem representation to attain the same level of competence in problem solving as the students with higher problem representation. A comparison of regression slopes reveal that higher problem representation students showed higher achievement in domain-general rather than domain-specific conditions. If students have higher problem representation skills, domain-specific scaffolds might be redundant for them. 


\section{Objectivity}

Results indicated that objectivity predicted problem-solving scores in domainspecific conditions. This suggests that domain-specific conditions were not effective in enabling students with lower objectivity to attain the same level of competence in problem solving as the students with higher objectivity. On the other hand, results indicated that while objectivity was a predictor for the domain-general faded condition, it was not a predictor in the domain-general continuous condition. This finding suggests that the domain-general continuous condition enables students with lower objectivity to think about their own learning process and therefore gain the same achievement of students with higher objectivity.

\section{Conclusion}

Findings of this study can inform the design of scaffolds based on learners' needs and abilities. Different scaffolding characteristics would enable students with lower prior knowledge and lower metacognitive skills to attain the same level of competence in problem solving as the students with higher prior knowledge and higher metacognitive skills. For example, while continuous domain-general scaffolds would be effective for students with lower prior knowledge and lower metacognitive skills, faded domaingeneral scaffolds would be useful for students with lower regulation of cognition. Moreover, while the domain-specific continuous condition would be beneficial for students with lower prior knowledge, lower knowledge of cognition, and lower problem representation, the domain-specific faded condition would be beneficial for students with lower problem representation. 
Although different scaffolds were found to be particularly beneficial to students with lower prior knowledge and lower metacognitive skills, they did not substantially benefit the students with higher prior knowledge and higher metacognitive skills.

Students with higher prior knowledge and metacognitive skill demonstrated more or less the same level of competence in problem solving across different conditions. One reason for this might be although scaffolds supply students a starting point to make connections to their existing knowledge, they might become redundant and not necessary for those students. Students could even develop their own scaffolds once others are faded. Further studies can be conducted with a control group to examine the benefits of scaffolds for students with higher prior knowledge and metacognitive skills. 


\section{CHAPTER V}

\section{CONCLUSIONS}

The purpose of this study was to investigate the effects of domain-general and domain-specific scaffolds with different levels of support on learning of scientific content and problem-solving process. This study also aimed at examining whether students' prior knowledge and metacognitive skills predict their success in problem solving across different scaffolding conditions.

Overall findings of this study illustrated that students' learning of scientific content did improve over time in all four scaffolding conditions. However, the results from the study showed benefits of providing middle school students with domainspecific scaffolds, especially if it was provided consistently, compared to domaingeneral scaffolds. By reflecting salient features in the content and guiding what content knowledge to use during problem solving, domain-specific scaffolds improved students' learning and knowledge integration.

With regard to problem-solving processes, the results of the study showed the advantages of both domain-general and domain-specific scaffolds in supporting generating solutions and making justifications. The results showed that while domainspecific scaffolds supported students' problem representation, domain-general scaffolds supported students' monitoring and evaluation. Domain-specific scaffolds facilitated the solution and justification processes by supporting students' problem representation skills. In addition, domain-general scaffolds facilitated students' solution and 
justification processes by supporting their self-checking, monitoring, and evaluation skills.

In terms of the change of problem-solving outcomes over time, the results of the study did not illustrate relative advantages of the continuous and faded supports within domain-general scaffolds. Over time, both continuous and faded domain-general conditions affected students' problem representation, developing solutions, making justifications, and monitoring and evaluation in the same way. Therefore, domaingeneral scaffolds seemed to benefit students even when they were faded. From this aspect, students might have transferred their metacognitive skills acquired from domaingeneral scaffolds and become successful problem solvers. On the other hand, the results of the study illustrated that providing the continuous domain-specific scaffolds better supports students' problem-solving outcomes over time compared to the faded domainspecific scaffolds. The linear trend in the faded domain-specific scaffolding condition indicated that students' developing solution and making justification scores decreased over time. Students might have depended on the specific scaffolds and removing them might have made students frustrated. One remaining questions is that how students used scaffolds and at what point they made switch from continuous to faded scaffolds. In the future work, I would like to examine their worksheets to identify the best timing of the fading of scaffolds.

The results of the study also illustrated that different scaffolding characteristics may be particularly beneficial to students with lower prior knowledge and lower metacognitive skills. In this study, students with lower prior knowledge and lower 
knowledge of cognition were positively affected by continuous scaffolds. Continuous scaffolds encourage students to become aware of their knowledge, strengths, and weaknesses. Moreover, students with lower regulation of cognition benefited from domain-general scaffolds. Those scaffolds supported students' self-regulatory mechanisms, including monitoring, planning, evaluating the effectiveness actions, and revising one's strategies for learning. In addition, only the domain-general faded condition did not benefit students with lower problem representation. Finally, the domain-general continuous condition benefits students with lower objectivity by making them reflect on their learning process. On the other hand, different scaffolding strategies did not substantially benefit the students with higher prior knowledge and higher metacognitive skills. Although scaffolds benefited those students at the beginning, they might have become redundant.

In summary, this study illustrated that different scaffolding strategies have the potential to facilitate middle school students' knowledge acquisition and problemsolving outcomes in ill-structured learning environments. However, findings suggested that the effectiveness of scaffolds depends on certain factors, including the types of scaffolds, levels of support in scaffolds, and individual characteristics of learner. Therefore, instructional designers and teachers should be careful when designing and choosing scaffolding strategies in complex problem-solving environments.

Domain-specific scaffolds could be used to facilitate students' learning and knowledge construction. These scaffolds can support students with lower problem representation. Metacognitive support is important in a problem-based learning 
environment and domain-general scaffolds could be used to guide students in planning, monitoring, and evaluating. These scaffolds can support students with lower regulation of cognition. Unlike domain-specific scaffolds, domain-general scaffolds have potential to facilitate students in transferring their self-regulatory skills even when they are faded. Moreover, continuous scaffolds have potential to support students become aware of their learning during the problem-solving process.

This study has some limitations that can recommend possible future studies. First, this study is limited to the nature of the problem-solving task, which was ill structured. Future studies should examine how different types of scaffolds can support different types of problems, well- or ill-structured. Second, this study is limited to the hypermedia program. Future studies are recommended to investigate if scaffolding strategies in the present study would have the same effect when they are embedded into other programs. Finally, the classroom environment is a complex system where different factors can affect students' learning and performance. Therefore, further studies are suggested to examine the role of interaction between teachers and peers. 


\section{REFERENCES}

American Association for the Advancement of Science. (1993). Benchmarks for science literacy. New York: Oxford University Press.

Azevedo, R., Cromley, J. G., Winters, F. I., Moos, D. C., \& Greene, J. A. (2005, April). Adaptive human scaffolding facilitates adolescents' self-regulated learning with hypermedia. Paper presented at the annual meeting of the American Educational Research Association, Montréal, Canada.

Azevedo, R. \& Jacobson, M. J. (2008). Advances in scaffolding learning with hypertext and hypermedia: A summary and critical analysis. Educational Technology Research and Development, 56(1), 93-100.

Baker, L., \& Brown, A. L. (1984). Cognitive monitoring in reading. In J. Flood (Ed.), Understanding reading comprehension (pp. 21-44). Newark, DE: International Reading Association.

Bell, P. (1997). Using argument representations to make thinking visible for individuals and groups. In R. Hall, N. Miyake, \& N. Enyedy (Eds.), Proceedings of CSCL '97: The Second International Conference on Computer Support for Collaborative Learning, (pp. 10-19). Toronto: University of Toronto Press.

Bell, P., \& Davis, E. A. (2000). Designing Mildred: Scaffolding students' reflection and argumentation using a cognitive software guide. In B. Fishman \& S. O'ConnorDivelbiss (Eds.), Fourth International Conference of the Learning Sciences (pp. 142-149). Mahwah, NJ: Erlbaum. 
Blum, R. E., \& Arter, J. A. (1996). Student performance assessment. Alexandria, VG: Associations for Supervision and Curriculum Development.

Brabeck, M. M., \& Wood, P. K. (1990). Cross-sectional and longitudinal evidence for difference between well-structured and ill-structured problem solving abilities. In M. L. Commons, C. Armon, L. Kohlberg, F. A. Richards, T. A. Grotzer, \& J. D. Sinnott (Eds.), Adult development 2: Models and methods in the study of adolescent and adult thought (pp. 133-146) New York: Praeger.

Bransford, J. D., Sherwood, R. D., \& Sturdevant, T. (1987). Teaching thinking and problem solving. In J. B. Baron \& R. J. Sternberg (Eds.), Teaching thinking skills:Theory and practice (pp. 162-181). New York: W. H. Freeman and Company.

Bransford, J. D., \& Stein, B. S. (1993). The IDEAL problem solver: A guide for improving thinking, learning, and creativity ( $2^{\text {nd }}$ ed.). New York: W. H. Freeman and Company.

Bransford, J., Brown, A., \& Cocking, R. (Eds.). (2000). How people learn: Brain, mind, experience and school. Washington D.C.: National Academy Press.

Brown, A. L. (1975). The development of memory: Knowing, knowing about knowing, and knowing how to know. In H. W. Reese (Ed.), Advances in child development and behavior (Vol. 10, pp. 103-152). San Diego, CA: Academic Press.

Brown, A. L. (1978). Knowing when, where and how to remember: A problem of metacognition. In R. Glaser (Ed.), Advances in instructional psychology (Vol. 1, pp. 77-165). Hillsdale, N. J., Erlbaum. 
Brown, A. L. (1987). Metacognition, executive control, self-regulation, and other more mysterious mechanisms. In F. E. Weinert \& R. H. Kluwe (Eds.), Metacognition, motivation, and understanding (pp. 65-115). Hillsdale, NJ: Lawrence Erlbaum Associates.

Brown, A. L., Bransford, J., Ferrara, R., \& Campione, J. (1983). Learning, remembering, and understanding. In P.H. Musen (Ed.), Handbook of child psychology (Vol. 3, pp. 77-166). New York: Wiley.

Brown, A. L., \& Campione, J. C. (1981). Inducing flexible thinking: A problem of access. In M. Friedman, J. P. Das, \& N. O'Connor (Eds.), Intelligence and learning (pp. 515-529). New York: Plenum.

Brown, A. L., \& Palincsar, A. S. (1987). Reciprocal teaching of comprehension strategies: A natural history of one program for enhancing learning. In J. D. Day \& J. G. Borkowski (Eds.), Intelligence and exceptionality: New directions for theory, assessment, and instructional practice (pp. 81-132). Norwood, NJ: Ablex.

Bruner, J. S. (1985). Vygotsky: A historical and conceptual perspective. In J. V. Wertsch (Ed.), Culture, communication, and cognition: Vygotskian perspectives (pp. 2134). Cambridge, England: Cambridge University Press.

Brush, T., \& Saye, J. (2001). The use of embedded scaffolds in a technology-enhanced student centered learning activity. Journal of Educational Multimedia and Hypermedia, 10(4), 333-356. 
Cazden, C. (1979). Peekaboo as an instructional model: Discourse development at home and at school. Stanford Papers and Reports in Child Language Development, 17, $1-19$.

Cerbin, B. (1988). The nature and development of informal reasoning skills in college students. (ERIC Document Reproduction Service No. ED 298 805)

Chi, M. T. H., Feltovich, P. J., \& Glaser, R. (1981). Categorization and representation of physics problems by experts and novices. Cognitive Science, 5, 121-152.

Chi, M. T. H., Glaser, R., \& Rees, E. (1982). Expertise in problem solving. In R. Sternberg (Ed.), Advances in the psychology of human intelligence (Vol. 1, pp. 776). Hillsdale, NJ: Erlbaum.

Chi, M. T. H., \& Glaser, R. (1985). Problem solving ability. In R. Sternberg (Ed.), Human abilities: An information processing approach (pp. 227-257). San Francisco: W. H. Freeman.

Cho, K., \& Jonassen, D. (2002). The effects of argumentation scaffolds on argumentation and problem solving. Educational Technology Research and Development, 50(3), 5-22.

Choi, I. (2002). Effects of peer-challenge support on learning during on-line small group discussion. Dissertation Abstracts International, 63(09), 3161. (UMI No. 3065878)

Choi, I., Land, S. M., \& Turgeon, A. Y. (2005). Scaffolding peer-questioning strategies to facilitate metacognition during online small group discussion. Instructional Science, 33(5\&6), 483-511. 
Courville, T. \& Thompson, B. (2001). Use of structure coefficients in published multiple regression articles: $\beta$ is not enough. Educational and Psychological Measurement, 61(2), 229-248.

Davis, E. A. (2003). Prompting middle school science students for productive reflection: Generic and directed prompts. The Journal of the Learning Sciences, 12, 91-142.

Davis, E. A., \& Linn, M. (2000). Scaffolding students' knowledge integration: Prompts for reflection in KIE. International Journal of Science Education, 22(8), 819837.

Davis, E. A., \& Miyake, N. (2004). Explorations of scaffolding in complex systems. The Journal of the Learning Sciences, 13(3), 265-272.

Dorner, D., Kreuzig, H. W., Reither, F., \& Staudel, T. (1983). Lohhausen: Vom Umgang mit Unbestimmtheit und Komplexitat [Lohhausen: On dealing with uncertainty and complexity]. Bern, Switzerland: Hans Huber.

Dunkle, M. E., Schraw, G., \& Bendixen, L. D. (1995, April). Cognitive processes in well-defined and ill-defined problem solving. Poster presented at the annual meeting of the American Educational Research Association, San Francisco, CA.

Edelson, D. C., Gordin, D. N., \& Pea, R. D. (1999). Addressing the challenges of inquiry-based learning through technology and curriculum design. Journal of the Learning Sciences, 8(3\&4), 391-450.

Elshout, J. J., \& Veenman, M. V. J. (1992). Relation between intellectual ability and working method as predictors of learning. Journal of Educational Research, 85, 134-143. 
Flavell, J. H. (1976). Metacognitive aspects of problem solving. In L. B. Resnick (Ed.), The nature of intelligence (pp. 231-236). Hillsdale, NJ: Erlbaum

Flavell, J. H. (1979). Metacognition and cognitive monitoring: A new area of cognitivedevelopmental inquiry. American Psychologist, 34, 906-911.

Flavell, J. H. (1981). Cognitive monitoring. In W. P. Dickson (Ed.), Children's oral communication skills (pp. 35-60). New York: Academic Press.

Fretz, E. B., Wu, H., Zhang, B., Krajcik, J. S., \& Soloway, E. (2001, April ). An investigation of scaffolding design and use in a dynamic modeling tool. Paper presented at the annual meeting of the NARST, St. Louis, MO.

Fretz, E. B., Wu, H., Zhang, B., Krajcik, J. S., \& Soloway, E. (2002, April). A further investigation of scaffolding design and use in a dynamic modeling tool. Paper presented at the annual meeting of the American Educational Research Association, New Orleans, LA.

Garner, R., \& Alexander, P. A. (1989). Metacognition: Answered and unanswered questions. Educational Psychologist, 24, 143-158.

Ge, X. (2001). Scaffolding students' problem-solving processes on an ill-structured task using question prompts and peer interactions. Dissertation Abstracts International, 62(06), 2026. (UMI No. 3016657)

Ge, X., \& Land, S. M. (2003). Scaffolding students' problem-solving processes in an illstructured task using question prompts and peer interactions. Educational Technology Research and Development, 51(1), 21-38. 
Gick, M. L. (1986). Problem solving strategies. Educational Psychologist, 21(1\&2), 99120.

Glaser, R., Schauble, K., Raghavan, K., \& Zeitz, C. (1992). Scientific reasoning across different domains. In E. de Corte, M. C. Linn, H. Mandl, \& L. Verschaffel (Eds.), Computer-based learning environments and problem solving (NATO ASI Series F, Vol. 84, pp. 345-371). Heidelberg: Springer-Verlag.

Greene, B. A., \& Land, S. M. (2000). A qualitative analysis of scaffolding use in a resource-based learning environment involving the World Wide Web. Journal of Educational Computing Research, 23(2), 151-180.

Greening, T. (1998). Scaffolding for success in PBL. Medical Education Online, 3. Retrieved January 01, 2006, from http://www.med-ed-online.org/volume3.htm Greeno, J. (1978). Nature of problem-solving abilities. In W. Estes (Ed.), Handbook of learning and cognitive processes: Vol. 5. Human information processing (pp. 239-270). Hillsdale, NJ: Lawrence Erlbaum Associates.

Hannafin, M., Land, S., \& Oliver, K. (1999). Open learning environments: Foundations, methods, and models. In C. M. Reigeluth (Ed.), Instructional design theories and models: Vol. 2. A new paradigm of instructional theory (pp. 115-140). Mahwah, NJ: Lawrence Erlbaum Associates.

Holt Science and Technology Assessment Item Listing (1988). New York : Holt, Rinehart and Winston. 
Hong, N. S. (1998). The relationship between well-structured and ill-structured problem solving in multimedia simulation. Dissertation Abstracts International, 59(08), 2850. (UMI No. 9901039)

Hong, N.S., Jonassen, D.H., \& McGee, S. (2003). Predictors of well-structured and illstructured problem solving in an astronomy simulation. Journal of Research in Science Teaching, 40(1), 6-33.

Howard, B. C., McGee, S., Shia, R., \& Hong, N. S. (2000, April). Metacognitive selfregulation and problem-solving: Expanding the theory base through factor analysis. Paper presented at the Annual Meeting of the American Educational Research Association, New Orleans, LA.

Jacobs, J. E., \& Paris, S. G. (1987). Children's metacognition about reading: Issues in definition, measurement, and instruction. Educational Psychologist, 22, 255-278.

Jonassen, D. H. (1997). Instructional design models for well-structured and ill-structured problem-solving learning outcomes. Educational Technology Research and Development, 45(1), 65-94.

Jonassen, D. H. (2000). Toward the design theory of problem solving. Educational Technology Research and Development, 48(4), 63-85.

Jonassen, D. H. (2003). Using cognitive tools to represent problems. Journal of Research on Technology in Education, 35, 362-381.

Jonassen, D. H., Beissner, K., \& Yacci, M. (1993). Structural knowledge. Hillsdale, NJ: Lawrence Erlbaum Associates. 
King, A. (1991). Effects of training in strategic questioning on children's problemsolving performance. Journal of Educational Psychology, 83(3), 307-317.

King, A. (1992). Facilitating elaborative learning through guided student-generated questioning. Educational Psychologist, 27(1), 111-126.

King, A. (1994). Guiding knowledge construction in the classroom: Effects of teaching children how to question and ho to explain. American Educational Research Journal, 31(2), 338-368.

King, A., \& Rosenshine, B. (1993). Effect of guided cooperative questioning on children's knowledge construction. Journal of Experimental Education, 61(2), 127-148.

Kitchener, K. S. (1983). Cognition, metacognition, and epistemic cognition: A threelevel model of cognitive processing. Human Development, 26, 222-232.

Kluwe, R. H., \& Friedrichsen, G. (1985). Mechanism of control and regulation in problem solving. In J. Kuhl \& J. Beckmann (Eds.), Action control: From cognition to behavior (pp. 183-218). New York: Springer-Verlag.

Kolodner, J. L., Camp, P. J., Crismond, D., Fasse, B., Gray, J., Holbrook, J., et al. (2003). Problem-based learning meets case-based reasoning in the middle-school science classroom: Putting learning by design into practice. The Journal of the Learning Sciences, 12(4), 495-547.

Kyza, E. A., \& Edelson, D. C. (2003, April). Reflective inquiry: What it is and how can software scaffolds help. Paper presented at the Annual Meeting of the American Educational Research Association, Chicago, IL. 
Lajoie, S. P. \& Azevedo, R. (2000) Cognitive tools for medical informatics. In S. P. Lajoie (Ed.), Computers as cognitive tools: No more walls (Vol. 2, pp. 247-271). Mahwah, NJ, Lawrence Erlbaum Associates.

Land, S. M. (2000). Cognitive requirements for learning with open-ended learning environments. Educational Technology Research and Development, 48(3), 6178.

Land, S. M., \& Zembal-Saul, C. (2003). Scaffolding reflection and articulation of scientific explanations in a data-rich, project-based learning environment: An investigation of Progress Portfolio. Educational Technology Research and Development, 51(4), 65-84.

Lee, H. S., \& Songer, N. B. (2004) Expanding an understanding of scaffolding theory using an inquiry-fostering science program. Retrieved January 01, 2006, from www.biokids.umich.edu/about/papers/56LeeSongerScaffolding.pdf

Lehrer, R., \& Schauble, L. (Eds.) (2002). Investigating real data in the classroom: Expanding children's understanding of math and science. New York: Teachers College Press.

Lin, X., \& Lehman, J. D. (1999). Supporting learning of variable control in a computerbased biology environment: Effects of prompting college students to reflect on their own thinking. Journal of Research in Science Teaching, 3(7), 837-858.

Lin, X., Hmelo, C., Kinzer, C. K., \& Secules, T. J. (1999). Designing technology to support reflection. Educational Technology Research and Development, 47(3), 43-62. 
Liu, M., Pedersen, S., \& Williams, D., (2002). Alien Rescue: Designing for studentcentered learning. Educational Technology, 42(5), 11-14.

Linn, M. C. (1997). Knowledge integration environment. Retrieved December 10, 2006, from http://kie.berkeley.edu/KIE/info/KIEReport97.pdf

Linn, M. C. \& Slotta, J. D. (2000, October). WISE science. Educational Leadership, 2932.

Linn, M. C., Shear, L., Bell, P., \& Slotta, J. D. (1999). Organizing principles for science education partnerships: Case studies of students' learning about 'Rats in Space' and 'Deformed Frogs'. Educational Technology Research and Development, $47(2), 61-84$.

Loh, B. (2003). Using articulation and inscription as catalysts for reflection: Design principles for reflective inquiry. Dissertation Abstracts International, 65(01), 123. (UMI No. 3118576)

Loh, B., Reiser, B. J., Radinsky, J., Edelson, D. C., Gomez, L. M., \& Marshall, S. (2001). Developing reflective inquiry practices: A case study of software, the teacher, and students. In K. Crowley, C. Schunn, \& T. Okada (Eds.), Designing for science: Implications from everyday, classroom, and professional settings (pp. 279-323). Mahwah, NJ: Erlbaum.

Lucangeli, D., Coi, G., \& Bosco, P. (1997). Metacognitive awareness in good and poor math problem solvers. Learning Disabilities Research and Practice, 12(4), 209212. 
McNeill, K. L. (2006). Supporting students' construction of scientific explanation through curricular scaffolds and teacher instructional practices. Dissertation Abstracts International, 67(10). (UMI No. 3238032)

McNeill, K. L., \& Krajcik, J. (2006, April). Supporting students' construction of scientific explanation through generic versus context-specific written scaffolds. Paper presented at the annual meeting of the American Educational Research Association, San Francisco.

McNeill, K. L., Lizotte, D. J, Krajcik, J., \& Marx, R. W. (2006). Supporting students' construction of scientific explanations by fading scaffolds in instructional materials. The Journal of the Learning Sciences, 15(2), 153-191.

National Commission on Excellence in Education (1983). A nation at risk: The imperative for educational reform. Washington, DC: U.S. Government Printing Office.

National Commission on Mathematics and Science Teaching for the 21st Century (2000). Before it's too late. Washington, DC: U.S. Department of Education.

National Research Council. (1996). National science education standards. Washington, DC: National Academy Press.

Nelson, C., Watson, A., Ching, J., \& Barrow, P. (1996). The effect of teacher scaffolding and student comprehension monitoring on a multimedia/interactive videodisc science lesson for second graders. Journal of Educational Multimedia and Hypermedia, 5(3), 317-348. 
Newell, A., \& Simon, H. (1972). Human problem solving. Englewood Cliffs, NJ:Prentice-Hall.

Palincsar, A. S. (1998). Keeping the metaphor of scaffolding fresh - A response to C. Addison Stone's "The metaphor of scaffolding: Its utility for the field of learning disabilities." Journal of Learning Disabilities, 31(4), 370-373.

Palinscar, A., \& Brown, A. (1984). Reciprocal teaching of comprehension-fostering and comprehension-monitoring activities. Cognition and Instruction, 1(2), 117-175.

Palincsar, A., Brown, A., \& Martin, S. (1987). Peer interaction in reading comprehension instruction. Educational Psychologist, 22, 231-253.

Pea, R. D. (2004). The social and technological dimensions of scaffolding and related theoretical concepts for learning, education and human activity. The Journal of the Learning Sciences, 13(3), 423-451.

Pedersen, S. J. (2000). Cognitive modeling during problem-based learning: The effects of a hypermedia expert tool. Dissertation Abstracts International, 61(08), 3133. (UMI No. 9983316)

Perkins, D. N. \& Salomon, G. (1989). Are cognitive skills context-bound? Educational Researcher, 18(1), 16-25.

Puntambekar, S., \& Hubscher, R. (2005). Tools for scaffolding students in a complex learning environment: What have we gained and what have we missed? Educational Psychologist, 40, (1-12). 
Puntambekar, S., \& Kolodner, J. L. (2005). Toward implementing distributed scaffolding: Helping students learn science from design. Journal of Research in Science Teaching, 42(2), 185-217.

Quintana, C., Reiser, B. J., Davis, E. A., Krajcik, J., Fretz, E., \& Duncan, R. G. et al. (2004). A scaffolding design framework for software to support science inquiry. Journal of the Learning Sciences, 13(3), 337-386.

Reiser, B. J. (2004). Scaffolding complex learning: The mechanisms of structuring and problematizing student work. Journal of the Learning Sciences, 13(3), 273-304.

Reiser, B. J., Tabak, I., Sandoval, W. A., Smith, B., Steinmuller, F., \& Leone, A. (2001). BGuILE: Strategic and conceptual scaffolds for scientific inquiry in biology classrooms. In S.M. Carver \& D. Klahr (Eds.), Cognition and instruction: Twenty-five years of progress (pp. 263-305). Mahwah, NJ: Erlbaum.

Rosenshine, B., \& Meister, C. (1992). The use of scaffolds for teaching higher-level cognitive strategies. Educational Leadership, 4, 26-33.

Salomon, G., Perkins, D. N., \& Globerson, T. (1991). Partners in cognition: Extending human intelligence with intelligent technologies. Educational Researcher, 20(3), 2-9.

Sandoval, W. A. (1998). Explanation Constructor [Computer software]. Evanston, IL: Northwestern University.

Sandoval, W. A. (2003). Conceptual and epistemic aspects of students's scientific explanations. The Journal of the Learning Sciences, 12(1), 5-51. 
Saye, J. W., \& Brush, T. (2002). Scaffolding critical reasoning about history and social issues in multimedia-supported learning environment. Educational Technology Research and Development, 50(3), 77-96.

Scardamalia, M., Bereiter, C. (1985). Fostering the development of self-regulation in children's knowledge processing. In S. F. Chipman, J. W. Segal, \& R. Glaser (Eds.), Thinking and learning skills: Vol.2. Research and open questions (pp. 563-577). Hillsdale, NJ: Lawrence Erlbaum Associates.

Scardamalia, M., Bereiter, C. (1992). An architecture for collaborative knowledge building. In E. de Corte, M. C. Linn, H. Mandl, \& L. Verschaffel (Eds.), Computer-based learning environments and problem solving. Berlin: SpringerVerlag.

Schank, R. C. \& Cleave, J. B. (1995). Natural learning, natural teaching: Changing human memory. In Morowitz, H. J. and Singer, J. L. (Eds.), The mind, the brain, and complex adaptive systems. Reading, MA: Addison-Wesley Publishing Company.

Simon, H. A. (1973). The structured of ill-structured problem. Artificial Intelligence, 4, 1981-201.

Simon, H. A. (1978). Information-processing theory of human problem solving. In W. Estes (Ed.), Handbook of learning and cognitive processes: Vol. 5. Human information processing (pp. 271-295). Hillsdale, NJ: Lawrence Erlbaum Associates. 
Simon, D. P., \& Simon, H. A. (1978). Individual difference in solving physics problems. In R. Siegler (Ed.), Children's thinking: What develops? (pp. 325-348). Hillsdale, NJ: Lawrence Erlbaum.

Sinnott, J. D. (1989). A model for solution of ill-structured problems: Implications for everyday and abstract problem solving. In J. D. Sinott (Ed.), Everyday problem solving: Theory and application (pp. 72-99). New York: Praeger.

Smith, M. U., \& Good, R. (1984). Problem solving and classical genetics: Successful versus unsuccessful performance. Journal of Research in Science Teaching, 21, 895-912.

Smith, B. K. \& Reiser, B. J. (1998). National Geographic unplugged: Classroomcentered design of interactive nature films. In C. Karat, A. Lund, J. Coutaz, \& J. Karat (Eds.), Proceedings of the CHI 98 Conference on Human Factors in Computing Systems (pp. 424-431), Reading, MA: Addison-Wesley.

Stevens, J. P. (2002). Applied multivariate statistics for the social sciences (4th ed.). Mahwah, NJ: Lawrence Erlbaum.

Stone, C. A. (1998). Should we salvage the scaffolding metaphor? Journal of Learning Disabilities, 31(4), 409-413.

Suthers, D. \& Weiner, A. (1995, October). Groupware for developing critical discussion skills. Proceedings of the First International Conference on Computer Support for Cooperative Learning (pp. 341-348), Bloomington, IN. 
Tabak, I. E. (1999). Unraveling the development of scientific literacy: Domain-specific inquiry support in a system of cognitive and social interactions. Dissertation Abstracts International, 60(12), 4323. (UMI No. 9953385)

Tabak, I. (2004). Synergy: A complement to emerging patterns in distributed scaffolding. Journal of the Learning Sciences. 13(3), 305-335.

Thompson, B., \& Borrello, G. M. (1985). The importance of structure coefficients in regression research. Educational and Psychological Measurement, 45, 203-209.

Thorndyke, P. W., \& Stasz, C. (1980). Individual differences in procedures for knowledge acquisition from maps. Cognitive Psychology, 12, 137-175.

Toulmin, S. (1958). The uses of argument. Cambridge, UK: Cambridge University Press.

Tudge, J. (2000). Theory, method, and analysis in research on relations between peer collaboration and cognitive development. Journal of Experimental Education, 69(1), 98-112.

Veenman, M. V. J. (1993). Intellectual ability and metacognitive skill: Determinants of discovery learning in computerized learning environment. Amsterdam: University of Amsterdam.

Veenman, M. V. J., Elshout, J. J., \& Meijer, J. (1988). The generality vs. domainspecificity of metacognitive skills in novice learning across domains. Learning and Instruction, 7(2), 187-209.

Voss, J. F. (1988). Learning and transfer in subject-matter learning: A problem-solving model. International Journal of Educational Research, 11, 607-622. 
Voss, J. F., \& Post, T. A. (1988). On the solving of ill-structured problems. In M. H. Chi, R. Glaser, \& M. J. Farr (Eds.), The nature of expertise (pp. 261-285). Hillsdale, NJ: Lawrence Erlbaum Associates, Inc.

Vygotsky, L. S. (1978). Mind in society: The development of higher psychological processes. London, England: Cambridge University Press.

Webb, N. M. (1989). Peer interaction and learning in small groups. International Journal of Educational Research, 13, 21-39.

Webb, N. M., \& Palincsar, A. S. (1996). Group processes in the classroom. In D. C. Berliner \& R. C. Calfee (Eds.), Handbook of educational psychology (pp. 841873). New York: Simon \& Schuster Macmillan.

Wertsch, J. V. (1985). Vygotsky and the social formation of mind. Cambridge, MA: Harvard University Press.

White, B., \& Frederiksen, J. (1998). Inquiry, modeling, and metacognition: Making science accessible to all students. Cognition and Instruction, 16(1), 3-118.

White, B., \& Frederiksen, J. (2005). Cognitive models and instructional environments that foster young learners'metacognitive development. Educational Psychologist, 40, 211-223.

Windschitl, M. (2002). Framing constructivism in practice as the negotiation of dilemmas: An analysis of the conceptual, pedagogical, cultural, and political challenges facing teachers. Review of Educational Research, 72(2), 131-175.

Wood, D. J., Bruner, J. S., \& Ross, G. (1976). The role of tutoring in problem solving. Journal of Child Psychology and Psychiatry, 17, 89-100. 
Wu, A. S., Farrell, R., \& Singley, M. K. (2002). Scaffolding group learning in a collaborative networked environment. Proceedings of the 2002 Conference on Computer Support for Collaborative Learning (pp. 424-431), Boulder, CO.

Zembal-Saul, C., Munford, D., Crawford, B., Friedrichsen, P. \& Land, S. (2002). Scaffolding preservice science teachers' evidence-based arguments during an investigation of natural selection. Research in Science Education, 32(4), 437465.

Zydney, J. M. (2005). Eighth-grade students defining complex problems: The effectiveness of scaffolding in a multimedia program. Journal of Educational Multimedia and Hypermedia, 14(1), 61-90. 
APPENDIX A

DOMAIN-GENERAL SCAFFOLDING TREATMENT MATERIALS 
Name

\section{The Akona: Understanding the Problem}

Task: As you explore the Alien Rescue environment to solve the problem of the Akona, please read the example and the questions. Show your understanding of the Akona in the space provided.

\section{Questions}

- What information do you need to find in order to solve this problem?

- Which information is not related to the solution of the problem of the Akona?

- How do you plan to solve this problem?

\section{Example problem solving: Air pollution}

In this part of the worksheet, you will learn how to solve problems through step by step processes to become a more effective problem solver. In Alien Rescue, you are trying to solve problems where there is no right answer but there are a couple of good answers. Let's look at how a good problem solver approaches problems like these. Remember your alien species problem solution will be different.

Example problem: "Ashley is asked to propose a solution on what can be done to decrease the air pollution in her community"

Before she can recommend any solutions, she needs to understand the problem. For example,

She investigated and learned this information which is related to the solution of the problem:

\section{Definition of air pollution}

Causes of air pollution

Effects of air pollution on humans and animals

Major pollutants in the air

Sources of air pollutants

She planned to investigate the most important pollutant in her community so she can suggest a solution.

\section{Understanding Alien}

To solve this problem, I need to find ...

My plan is.... 
Name

\section{The Akona: Probe Design}

Task: As you design and launch probes for the Akona and analyze data displayed in the Control room, please read the example and think about the questions below. Show explanations of your probes in the space below.

\begin{tabular}{l|l|l}
\multicolumn{1}{c|}{ Questions } & \multicolumn{1}{c|}{ Example problem solving: Air pollution } & \multicolumn{1}{c}{ Your explanation } \\
\hline $\begin{array}{l}\text { - What is the possible solution } \\
\text { to the problem of the Akona? }\end{array}$ & $\begin{array}{l}\text { After understanding the problem, Ashley needs to } \\
\text { develop solutions. There may be multiple solutions. She } \\
\text { needs to decide and select one of them. For example, } \\
\text { She learned that ozone and smog are the major } \\
\text { pollutant for her community. She already knows that } \\
\text { these pollutants are emitted from the vehicles and } \\
\text { industries by the burning of coal, oil, diesel and other } \\
\text { fuels. } \\
\text { Therefore, possible solution of Ashley is: Using } \\
\text { hydrogen to fuel vehicles as an alternative energy } \\
\text { resource to gasoline and diesel. }\end{array}$ & My response to \\
\hline $\begin{array}{l}\text { - What is your evidence to } \\
\text { support your solution? } \\
\text { - Is your evidence appropriate } \\
\text { for the problem? } \\
\text { - Does your evidence allow you } \\
\text { to figure out your solution? } \\
\text { - Is your evidence enough to } \\
\text { convince someone of your } \\
\text { solution? }\end{array}$ & $\begin{array}{l}\text { Simply listing solutions is not enough. Ashley should } \\
\text { provide relevant evidence to the problem to support her } \\
\text { solution. }\end{array}$ & $\begin{array}{l}\text { For example, evidence provided to support her solution } \\
\text { is: Hydrogen powered vehicles do not have exhaust } \\
\text { fumes. Only emission is water vapor }\end{array}$ \\
\hline
\end{tabular}




\begin{tabular}{|c|c|c|}
\hline Questions & Example problem solving: Air pollution & Your explanation \\
\hline $\begin{array}{l}\text { - How does your evidence } \\
\text { support your solution? }\end{array}$ & $\begin{array}{l}\text { Ashley should also connect her solution and evidence to } \\
\text { show how her data ties into the solution. For example, } \\
\text { Using hydrogen as an alternative source of energy for } \\
\text { vehicles will contribute to the reduction of air pollution. } \\
\text { This is because the only emission of hydrogen powered } \\
\text { vehicles is water vapor. This will reduce both air } \\
\text { pollution and associated health problems. }\end{array}$ & $\begin{array}{l}\text { My proposed solution would work } \\
\text { because.... }\end{array}$ \\
\hline $\begin{array}{l}\text { - What are the benefits and } \\
\text { drawbacks of your solution? } \\
\text { - What other possible solutions } \\
\text { can you suggest? } \\
\text { - How are they compared to } \\
\text { your chosen solution } \\
\text { - Are you using your plan? } \\
\text { - Are you on the right track? }\end{array}$ & $\begin{array}{l}\text { Finally, Ashley should evaluate her solution and make } \\
\text { quality judgments. } \\
\text { Benefits of hydrogen production are: } \\
\text { - It can be generated by variety of sources } \\
\text { - It can be generated at variety of places } \\
\text { Drawbacks of hydrogen: } \\
\text { - It is explosive. Special care will be needed for } \\
\text { transporting, distributing, storing, and pumping. } \\
\text { - huge cost of hydrogen fuel cell vehicles } \\
\text { Other possible solution: Another solution could be to } \\
\text { use compressed natural gas (CNG). CNG vehicles } \\
\text { would reduce air pollution and smog, although not as } \\
\text { much as hydrogen vehicles. CNG, like hydrogen is } \\
\text { readily combustible. Also the cost of changing over } \\
\text { vehicles would be high. } \\
\text { Ashley's final decision is: Based on the benefits and } \\
\text { drawbacks of two solutions, it seems hydrogen would be } \\
\text { better solution to decrease air pollution. }\end{array}$ & $\begin{array}{l}\text { Other possible solutions to the problem } \\
\text { are... }\end{array}$ \\
\hline
\end{tabular}


APPENDIX B

DOMAIN-SPECIFIC SCAFFOLDING TREATMENT MATERIALS 
Name

\section{The Akona: Understanding the Problem}

Task: As you explore the Alien Rescue environment to solve the problem of the Akona, please read the example and the questions. Show your understanding of the Akona in the space provided.

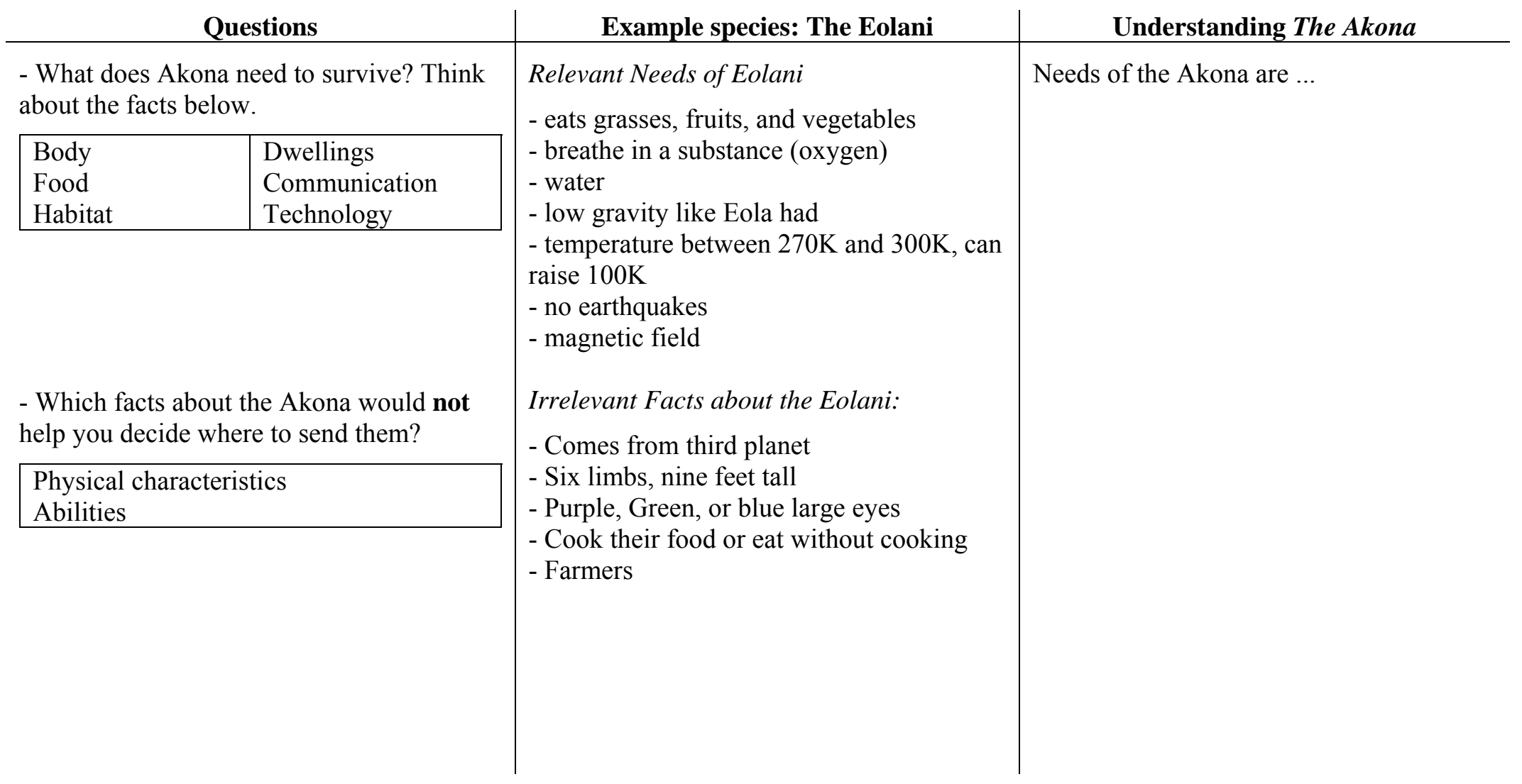




\section{The Akona: Probe Design}

Task: As you design and launch probes for the Akona and analyze data displayed in the Control room, please read the example and think about the questions below. Show explanations of your probes in the space below.

\begin{tabular}{|c|c|c|c|}
\hline \multicolumn{2}{|c|}{ Questions } & Example species: The Eolani & Your explanation: The Akona \\
\hline \multicolumn{2}{|c|}{ - On which world can the Akona survive? } & The Eolani can live on Ganymede. & I think the Akona can live on... \\
\hline \multicolumn{2}{|c|}{$\begin{array}{l}\text { - What are the characteristics of the } \\
\text { selected world that the Akona can live on? } \\
\text { Think about the characteristics below }\end{array}$} & $\begin{array}{l}\text { Information about Ganymede in solar system } \\
\text { database: } \\
\text { - water ice }\end{array}$ & Characteristics of the selected world are.... \\
\hline $\begin{array}{l}\text { * Gravity level } \\
\text { * Seismic activity } \\
\text { * Atmospheric \& } \\
\text { surface features }\end{array}$ & $\begin{array}{l}* \text { Magnetic field } \\
* \text { Temperature } \\
* \text { Chemical } \\
\text { composition }\end{array}$ & $\begin{array}{l}\text { - gravity is } .15 \text { of earth's } \\
\text { - earthquakes in the past } \\
\text { - thick, cold atmosphere } \\
\text { - maybe a magnetic field }\end{array}$ & \\
\hline \multicolumn{2}{|c|}{$\begin{array}{l}\text { - Based on the needs of the Akona, what } \\
\text { else do you need to know about the } \\
\text { selected world? }\end{array}$} & $\begin{array}{l}\text { Mission Statement: This probe will gather } \\
\text { information about Ganymede to answer these } \\
\text { questions: } \\
\text { - Does Ganymede have oxygen in its } \\
\text { atmosphere? } \\
\text { - What is the temperature range on } \\
\text { Ganymede? } \\
\text { - Are there any earthquakes on Ganymede? }\end{array}$ & My mission statement is... \\
\hline
\end{tabular}




\begin{tabular}{|c|c|c|c|}
\hline \multicolumn{2}{|c|}{ Questions } & Example species: The Eolani & Your explanation: The Akona \\
\hline \multicolumn{2}{|c|}{$\begin{array}{l}\text { - How do you measure these } \\
\text { characteristics? Think about the } \\
\text { instruments that scientists use: }\end{array}$} & \multirow{2}{*}{$\begin{array}{l}\text { Instruments that are used in probe design: } \\
\text { - Mass Spectrometer to see is if there is } \\
\text { oxygen in the atmosphere } \\
\text { - Thermometer or infrared camera to learn the } \\
\text { temperature range } \\
\text { - Seismograph to see if there are earthquakes }\end{array}$} & \multirow[t]{2}{*}{$\begin{array}{l}\text { Instruments that I will use in my probe } \\
\text { design... }\end{array}$} \\
\hline \begin{tabular}{|l|} 
Barometer \\
Seismograph \\
Magnetometer \\
Thermometer \\
\end{tabular} & $\begin{array}{l}\text { Mass Spectrometer } \\
\text { Camera } \\
\text { Radar }\end{array}$ & & \\
\hline \multicolumn{2}{|c|}{$\begin{array}{l}\text { - What additional information is gathered } \\
\text { in the control room? }\end{array}$} & $\begin{array}{l}\text { Additional information gathered in the } \\
\text { control room: } \\
\text { - substances: } 4 \% \text { Oxygen, } 52 \% \text { water, } 24 \% \\
\text { carbon dioxide, } 20 \% \text { methane } \\
\text { - seismic activity level is low: Level } 2 \\
\text { - temperature range: } 50 \text { to } 200 \mathrm{~K}\end{array}$ & $\begin{array}{l}\text { Additional information about my selected } \\
\text { world is... }\end{array}$ \\
\hline \multicolumn{2}{|c|}{$\begin{array}{l}\text { - How are the characteristics of the } \\
\text { selected world useful in finding a new } \\
\text { world for the Akona? }\end{array}$} & $\begin{array}{l}\text { - Ganymede has both oxygen and water ice } \\
\text { that Eolani need. } \\
\text { - Since Eolani buildings are too fragile and } \\
\text { would fall in earthquakes, seismic activity } \\
\text { level } 2 \text { (low) on Ganymede will help them to } \\
\text { survive. } \\
\text { - Ganymede has a magnetic field that the } \\
\text { Eolani need. }\end{array}$ & $\begin{array}{l}\text { Characteristics of my selected world will be } \\
\text { useful because... }\end{array}$ \\
\hline
\end{tabular}




\begin{tabular}{|c|c|c|}
\hline Questions & Example species: The Eolani & Your explanation: The Akona \\
\hline $\begin{array}{l}\text { - What are the benefits and drawbacks of } \\
\text { the selected world? } \\
\text { - What are the other worlds that you think } \\
\text { the Akona can survive? } \\
\text { - How are they compared to your selected } \\
\text { world? }\end{array}$ & $\begin{array}{l}\text { Ganymede can be a suitable world for the } \\
\text { Eolani because there is oxygen, a magnetic } \\
\text { field, water, and low seismic activity. } \\
\text { Drawbacks of Ganymede are: } \\
\text { - It is too cold for the Eolani since they like } \\
\text { the temperature between } 270 \mathrm{~K} \text { - } 300 \mathrm{~K} \\
\text { - Its gravity is } 0.15 \text { of Earth's, too low for the } \\
\text { Eolani. } \\
\text { The Eolani can also live on Mars because } \\
\text { there is a moderate level of seismic activity } \\
\text { (level 3), oxygen, and water. Average } \\
\text { temperature on Mars (140K-300K) is higher } \\
\text { than Ganymede which is suitable for the } \\
\text { Eolani. One problem that the Eolani may have } \\
\text { on Mars is the high gravity. } \\
\text { It seems that Mars would be better suited for } \\
\text { the Eolani's needs. }\end{array}$ & $\begin{array}{l}\text { My decision to select the world as potential } \\
\text { home is ... }\end{array}$ \\
\hline
\end{tabular}


APPENDIX C

MULTIPLE-CHOICE PRETEST AND POSTTEST 


\section{Multiple-Choice Test}

Name

Class Period

Circle the letter of the correct answer.

1. What is the difference between a moon and a planet?
A. moons are closer to the sun than planets
B. moons are smaller than planets
C. planets have plant life and moons do not
D. moons orbit planets but planets do not orbit moons

2. Which of the following does an atmosphere do for a world?
A. causes volcanoes to erupt
B. pushes heat out into space so the world does not get too hot
C. protects it from meteors
D. makes plant life develop on the world

3. Which of the following does a magnetic field do for a world?
A. protects it from the solar wind
B. lowers its temperature
C. causes earthquakes
D. gives it seasons

4. A world will have a magnetic field if
A. it has a thick atmosphere
B. it has a core made of liquid metal
C. it has liquid water
D. it is close to the sun

5. Terrestrial planets are than gas giants
A. Larger
B. Less dense
C. Rockier
D. All of the above

6. Which of these worlds is farther from the sun than Saturn?
A. Mars
B. Earth's moon
C. Mercury
D. Charon 
7. Venus
A. is a gas giant
B. has two moons
C. has an atmosphere denser than Earth's
D. is very cold because of a greenhouse effect

8. Io
A. is the closest planet to the sun
B. has active volcanoes
C. has a solid core
D. is as cold as Pluto

9. Which of these worlds has the lowest surface gravity?
A. Earth
B. Triton
C. Jupiter
D. Mars

10. The lunar module weighted more on Earth than it did on the moon because Earth has a greater ....
A. gravitational force
B. atmosphere
C. electromagnetic field
D. density

11. What is the most obvious feature of Mercury's landscape?
A. Oceans
B. Dense cloud
C. Volcanoes
D. Craters

12. Liquid water cannot exist on the surface of Mars because...
A. The temperature is too high
B. Liquid water once existed there
C. The gravity of Mars is too weak
D. The atmosphere pressure is too low

13. What is remarkable about the magnetic field of Uranus?
A. It is stronger than that of any other planet
B. It is tipped at a large angle with respect to the axis of rotation
C. There are two north magnetic poles
D. It vanishes and reappears every few minutes 
14. What is unusual about the obits of Neptune and Pluto?

A. Pluto is sometimes nearer the sun than is Neptune

B. They occasionally have near collisions

C. Their years have the same length

D. They are always on opposite sides of the sun from each other

15. Titan
A. has magnetic field
B. is a gas giant
C. has thick atmosphere
D. has low seismic activity

16. Which of these instruments can be used to learn about temperature on a world?
A. seismograph
B. RADAR
C. infrared camera
D. mass spectrometer

17. Imagine that you need to determine whether or not a moon's surface has carbon. What instrument would you use?
A. wide-angle camera
B. mass spectrometer
C. seismograph
D. barometer

18. Scientists want to measure the pressure of Mars' atmosphere. What instrument would they use?
A. barometer
B. thermometer
C. magnetometer
D. infrared camera

19. You need to design a probe to go to Titan to find out if it has a magnetic field or earthquakes. Which of the following would you choose to include on your probe?
A. a battery and a solar panel
B. an infrared camera and a magnetometer
C. a barometer and a seismograph
D. a magnetometer and a seismograph

20. Which of these could be considered a "signature" for an element?
A. a seismograph
B. barometric pressure
C. an infrared picture
D. a spectrogram 
APPENDIX D

RECOMMENDATION FORM FOR ALIEN SPECIES 
Name

Class Period

\section{Recommendation form: The Akona}

Write the world that you have chosen as a home for the Akona. Please explain the reasons, benefits and drawbacks for choosing this world over the other worlds.

\section{Chosen World:}

Explanation of my solution: 


\section{APPENDIX E \\ SCORING RUBRIC FOR MEASURING PROBLEM-SOLVING OUTCOMES IN STUDENTS' RECOMMENDATION FORMS}




\section{Scoring Rubric for Measuring Problem-Solving Outcomes in Students' Recommendation Forms}

1. Representing the problem (Subtotal Points: 7)

1.1. Identify relevant information and known facts

\begin{tabular}{|cll|}
\hline$\underline{\text { Score }}$ & \multicolumn{1}{c|}{ Description } & \multicolumn{1}{c|}{ Criteria } \\
7 & 7 needs of alien are identified. & Needs of each alien species are \\
6 & 6 needs of alien are identified. & provided in problem solution. \\
5 & 5 needs of alien are identified. & \\
4 & 4 needs of alien are identified. & \\
3 & 3 needs of alien are identified. & \\
2 & 2 needs of alien are identified. & \\
1 & 1 need of alien are identified. & \\
0 & No need is provided or irrelevant & \\
\hline
\end{tabular}


2. Developing solutions (Subtotal Points: 7)

2.1. Selecting solution

$\underline{\text { Score }}$

2

1

0

Poor $\underline{\text { Description }}$

Excellent

Good

\section{Criteria}

Best world for the species is recommended.

Acceptable world for the species is recommended.

No world is selected or world other than best and acceptable ones is recommended.

2.2.Providing supporting data for the solution in the recommendation form Students can still receive credit for correct supporting detail provided for the selected world even if the solution is wrong.
$\underline{\text { Score }}$
$\underline{\text { Description }}$
55 or more pieces of relevant supporting data about the world are provided.
44 pieces of relevant supporting data about the world are provided.
33 pieces of relevant supporting data about the world are provided.
22 pieces of relevant supporting data about the world are provided.
11 piece of relevant supporting data about the world are provided.
$0 \quad$ No supporting data is provided or irrelevant data is provided.

$\underline{\text { Criteria }}$
Number of relevant supporting data about the world provided for the acceptable and unacceptable worlds based on the elimination chart


3. Making justifications for the proposed solutions (Subtotal points: 7)

3.1.Constructing argument - Students can still receive credit for strong argument for the selected world even if the solution is wrong.

$\underline{\text { Score }}$

$4 \quad$ Argument is well constructed.

2 Argument is poorly constructed.

$0 \quad$ No argument is constructed.

\section{Criteria}

Coherent and persuasive premises are provided to support the recommended world, and needs of the species are discussed.

Irrelevant or incoherent premises are provided to support the recommended world, and needs of the species are partially discussed.

Premises are missing, and no factors (needs of the species) are discussed.

\subsection{Providing evidence - Students can still receive credit for correct evidence} provided for the selected world even if the solution is wrong.

$\underline{\text { Score }}$

3 Evidence to support
strong and relevant.

2 Evidence to support the argument is relevant.

1 Evidence to support the argument is weak or irrelevant.

\section{$\underline{\text { Criteria }}$}

Specific and relevant evidences about the selected world is provided.

Relevant evidences about the selected world is provided.

Vague or irrelevant evidences about the selected world is provided.

$0 \quad$ No any evidence is provided. 
4. Monitoring and evaluating problem space and solutions (Subtotal points: 7)

4.1. Evaluating solution(s) - Students can still receive credit for evaluating solutions for the selected world even if the solution is wrong.

$\underline{\text { Score }}$

3

The recommended world is evaluated, and drawbacks are discussed, supported with reasoning.

\section{Criteria}

A statement is made about the effectiveness or benefits of the world, and the potential drawbacks of the world are discussed in relation to pros and cons and supported with relevant evidence.

A statement is made about the effectiveness or benefits of the world, and the potential drawbacks of the world are mentioned but not discussed in relation to pros and cons nor supported with relevant evidence.

evaluated, and drawbacks are mentioned, but no reasons are provided.

1 Evaluation of the world is stated, but no reasoning is provided, and no potential drawbacks are mentioned.

$0 \quad$ The world is not evaluated.

A statement is made about the effectiveness or benefits of the world, but the potential drawbacks of the world are not mentioned.

No statement is made about the effectiveness or benefits of the world. 
4.2. Assessing alternative solutions - Students can still receive credit for assessing alternative solutions even if the solution is wrong.

\section{$\underline{\text { Score }}$}

Description

4

Alternative world(s) are stated and discussed, supported with reasoning.

2

Alternative world(s) are stated but no reasons are provided.

\section{Criteria}

At least one world is discussed. Reasons are given on why a world is selected over the other(s), with drawbacks discussed.

At least one world is described, but no reasons are given on why it is selected.

Alternative world(s) are not mentioned at all.

Source: Ge, X. (2001). Scaffolding students' problem-solving processes on an illstructured task using question prompts and peer interactions. Dissertation Abstracts International, 62(6), 2026. (UMI No. 3016657) 
APPENDIX F THE INVENTORY OF METACOGNITIVE SELF-REGULATION 


\section{How do You Solve Problems?}

Please read the following sentences and circle the answer that best describes the way you are when you are trying to solve a problem. Think about a problem that you might see in a science or math class.

- Think about when you have to solve a hard problem. What do you do before you start?

- What do you do while you work the problem?

- What do you do after you finish working the problem?

There are no right answers--please describe yourself as you are, not how you want to be or think you ought to be. Your teacher will not grade this.

\begin{tabular}{|ccccc|}
\hline Never & Seldom/ Rarely & Sometimes & Often/ Frequently & Always \\
A & B & C & D & E \\
\hline
\end{tabular}

1. I try to understand what the problem is asking me.

A B C D E

2. I think of several ways to solve a problem and then choose the best

A B C D E one.

3. I look back at the problem to see if my answer makes sense.

A B C D E

4. I use different ways to memorize things.

A B C D E

5. I think to myself, do I understand what the problem is asking me?

A B C D E

6. I read the problem more than once.

A B C D E

7. I think about what information I need to solve this problem.

A B C D E

8. I use different learning strategies depending on the problem.

A B C D E

9. I look back to see if I did the correct procedures.

A B C D E

10. I think about how well I am learning when I work a difficult

A B C D E problem.

11. I use different ways of learning depending on the problem.

A B C D E

12. I go back and check my work.

A B C D E

13. I read the problem over and over until I understand it.

A B C D E

14. For this question, please circle letter B.

A B C D E 


\begin{tabular}{|ccccc|}
\hline Never & Seldom/ Rarely & Sometimes & Often/ Frequently & Always \\
A & B & C & D & E \\
\hline
\end{tabular}

15. I check to see if my calculations are correct.

A B C D E

16. When it comes to learning, I can make myself learn when I need to.

A B C D E

17. I ask myself how well I am doing while I am learning something

A B C D E new.

18. I check my work all the way through the problem.

A B C D E

19. I identify all the important parts of the problem.

A B C D E

20. I try to understand the problem so I know what to do.

A B C D E

21. I think about all the steps as I work the problem.

A B C D E

22. I can make myself memorize something.

A B C D E

23. When it comes to learning, I know my strengths and weaknesses.

A B C D E

24. I pick out the steps I need to do this problem.

A B C D E

25. When I am done with my schoolwork, I ask myself if I learned

A B C D E

what I wanted to learn.

26. I double-check to make sure I did it right.

A B C D E

27. For this question, please circle letter A.

A B C D E

28. I try to break down the problem to just the necessary information.

A B C D E

29. I use learning strategies without thinking.

A B C D E

30. When it comes to learning, I know how I learn best.

A B C D E

31. I ask myself if there are certain goals I want to accomplish.

A B C D E

32. I try more than one way to learn something.

A B C D E

Source: Howard, B. C., McGee, S., Shia, R., \& Hong, N. S. (2000, April). Metacognitive self-regulation and problem-solving: Expanding the theory base through factor analysis. Paper presented at the Annual Meeting of the American Educational Research Association, New Orleans, LA. 


\section{VITA}

Saniye Tugba Bulu, the daughter of Asim and Gunay Tokel, was born in Ankara, Turkey. She received a B.A. and M.S. degree in Computer Education and Instructional Technology from the Middle East Technical University. She began her doctoral studies at the Texas A\&M University in January 2003. Her research interests include scaffolding strategies, problem solving, technology supported learning, open-ended and virtual learning environments, and metacognition.

Name: $\quad$ Saniye Tugba Bulu

Address: $\quad$ Konutkent 2 Blok A-3 No: 160653 Cayyolu Ankara/TURKEY

Email Address: $\quad$ tokel@metu.edu.tr

Education: $\quad$ B.A., Computer Education and Instructional Technology, Middle East Technical University, 2001

M.S., Computer Education and Instructional Technology, Middle East Technical University, 2003

Ph.D., Educational Psychology, Texas A\&M University, 2008 